\title{
IMPLEMENTING THE AHAFO BENEFIT AGREEMENTS: SEEKING MEANINGFUL COMMUNITY PARTICIPATION AT NEWMONT'S AHAFO GOLD MINE IN GHANA
}

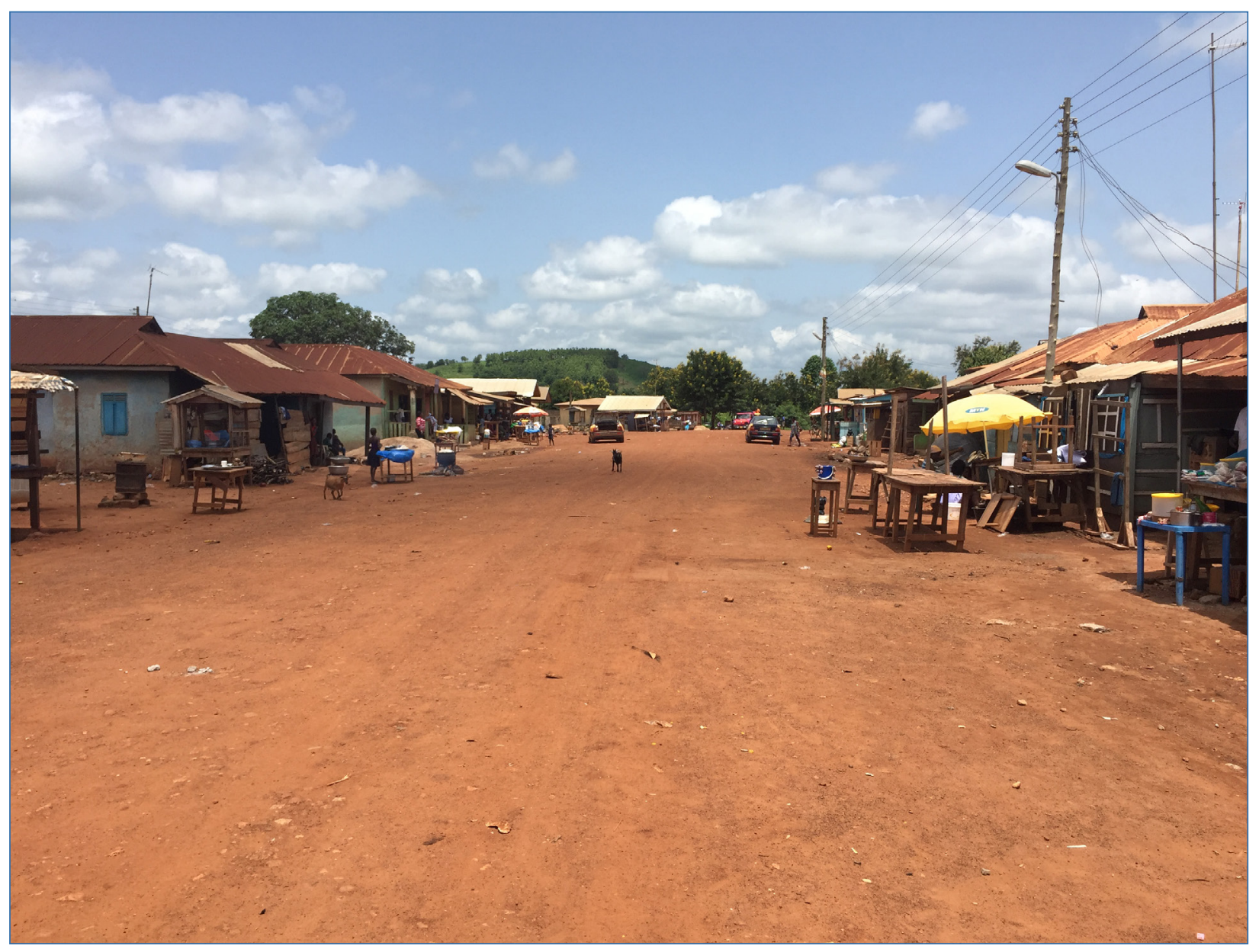


(C) 2018 by the University of British Columbia and Canadian International Resources and Development Institute (CIRDI).

The material in this publication is copyrighted. Quoting, copying, and/or reproducing portions or all of this work is permitted provided the following citation is used:

Boakye, B., Cascadden, M., Kuschminder, J., Szoke-Burke, S., Werker, E. (2018). Implementing the Ahafo Benefit Agreements: Seeking Meaningful Community Participation at Newmont's Ahafo Gold Mine in Ghana. Canadian International Resources and Development Institute (CIRDI) Report 2018-003

\section{Canadà̀}

Program undertaken with the financial support of the Government of Canada provided through Global Affairs Canada.

Programme réalisé avec l'appui financier du gouvernement du Canada agissant par l'entremise d'Affairs mondiales Canada.

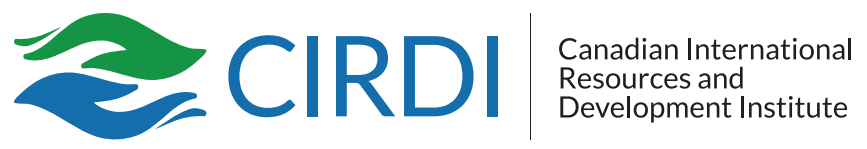

Canadian International Resources and Development Institute Vancouver, British Columbia, Canada

www.cirdi.ca

info@cirdi.ca

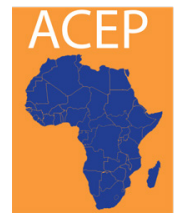

Africa

Centre for Energy Policy
$\Perp$

INDEPENDENT

SOCIAL PERFORMANCE

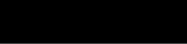

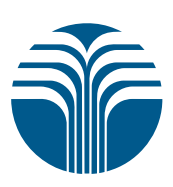

Columbia Center on Sustainable Investment A JOINT CENTER OF COLUMBIA LAW SCHOOL AND THE EARTH INSTITUTE, COLUMBIA UNIVERSITY

Cover photo: Eric Werker 
June 2018

This report was written by Benjamin Boakye (Africa Centre for Energy Policy (ACEP)), Maggie Cascadden (Simon Fraser University (SFU)), Jordon Kuschminder (Independent Social Performance (ISP)), Sam Szoke-Burke (Columbia Center on Sustainable Investment (CCSI)), and Eric Werker (Canadian International Resources and Development Institute (CIRDI) and Simon Fraser University (SFU)). Funding for the fieldwork was provided by CIRDI, and included in-kind contributions from ACEP, CCSI, ISP, and SFU. Fieldwork for the report was conducted in May 2017. We deeply thank the many people who spent time to discuss the implementation of the Ahafo benefit agreements with us. In the interests of ensuring factual accuracy, excerpts of all factual findings included in a draft of the report were sent to traditional authority representatives from each of the ten community towns and to Newmont representatives for feedback. We are grateful for the peer reviews of eight subject matter experts: Delgermaa Boldbaatar, Dalaibuyan Byambajav, Deval Desai, Kristi Disney, Tom Gunton, Andy Hira, Sean Markey, and Perrine Toledano. All remaining errors, and the discussion and considerations that follow from the research findings, are our own. 


\section{TABLE OF CONTENTS}

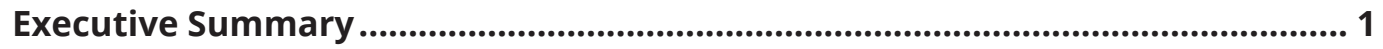

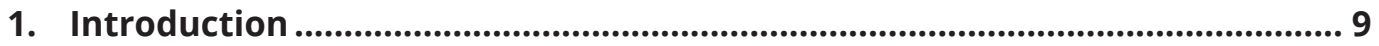

$1.1 \quad$ What are Benefit Agreements?........................................................................ 10

1.2 Implementation of Benefit Agreements ......................................................... 11

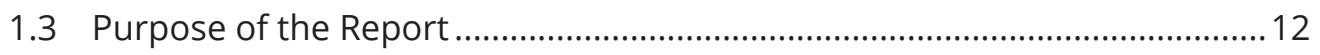

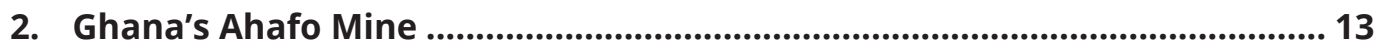

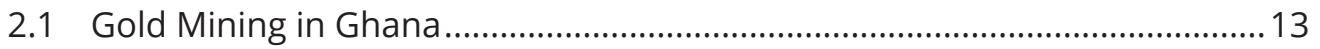

2.2 The Brong-Ahafo Region and the Ahafo Communities ................................ 13

2.3 Newmont and the Ahafo Concession........................................................... 15

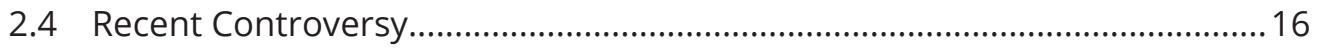

3. What is in the Agreements ................................................................................... 17

3.1 The 2008 Ahafo Benefit Agreements............................................................. 17

3.1.1 Social Responsibility Agreement ............................................................. 17

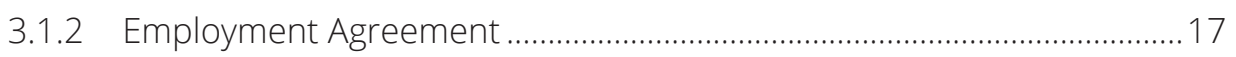

3.1.3 Development Foundation Agreement ........................................................18

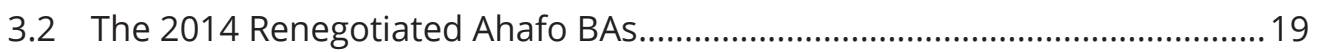

3.2.1 Relationship Agreement........................................................................ 19

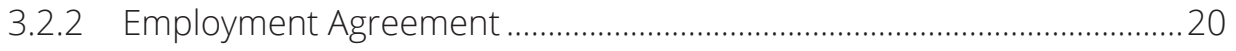

3.2.3 Development Foundation Agreement ………...........................................20

3.3 Development Funding from the BAs ................................................................2

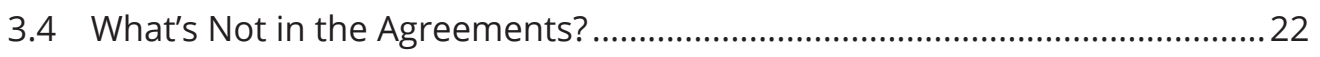

4. Earlier Findings on the AHAFO BAs ............................................................... 24

4.1 Newmont or Newmont-Funded Observations...............................................24

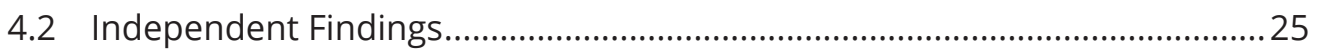

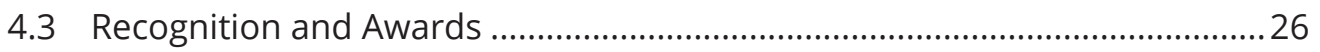

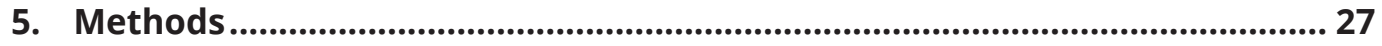

6. Ahafo Perspectives.............................................................................................. 30

6.1 Negotiation and Renegotiation of the Ahafo Benefit Agreements ............... 30

6.1.1 Objectives of the Ahafo BAs ................................................................... 30

6.1.2 Challenges to a Fair Deal During the Negotiations .................................. 31

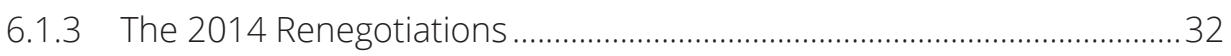


6.1.4 Support Available to Communities .............................................................33

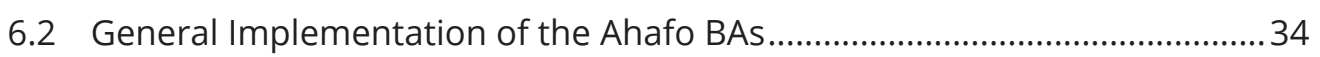

6.2.1 Varying Experiences of Communities ……………………………..........34

6.2.2 Varying Experiences Within Communities..................................................... 34

6.2.3 Community Awareness of the Ahafo BAs ..................................................35

6.2.4 Information Sharing and Communication ...............................................35

6.2.5 Barriers to Articulating Grievances .........................................................36

6.2.6 Barriers to Meaningful Community Participation ...................................... 36

6.3 Implementation of the Relationship Agreement ............................................38

6.3.1 The Forum as a Multi-Stakeholder Body ..................................................38

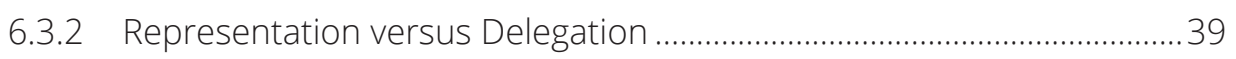

6.3.3 Environmental and Social Monitoring ....................................................40

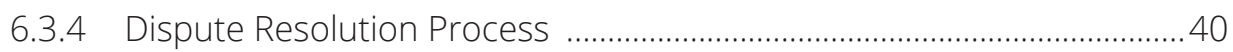

6.4 Implementation of the Employment Agreement .........................................4 41

6.4.1 Meeting the Target ..................................................................................... 41

6.4.2 Dissatisfaction with Community Citizen Validation...................................42

6.4.3 Unskilled Locals and Training for Jobs .................................................... 43

6.5 Implementation of the Development Foundation Agreement ......................43

6.5.1 Project Selection......................................................................................... 43

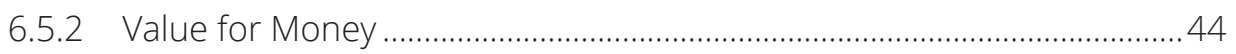

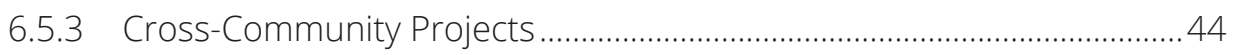

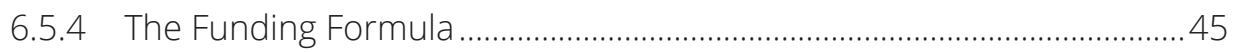

6.6 Performance Outside of the Agreements ....................................................... 45

6.6.1 Developing Local Suppliers ................................................................ 45

6.6.2 Compensation and Resettlement .......................................................... 46

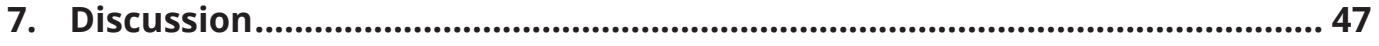

7.1 Design and Implementation of the Ahafo BAs ..............................................4 47

7.2 Towards Better Corporate Performance ......................................................... 49

7.3 Considerations for the 2019 Review of the Ahafo BAs...................................51

7.4 Improving Future Renegotiation Processes for the Ahafo BAs ......................51

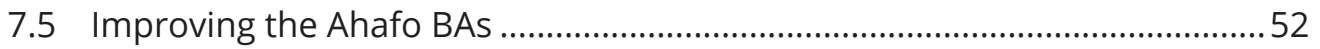

7.5.1 Improving the Implementation of the Ahafo BAs .....................................54

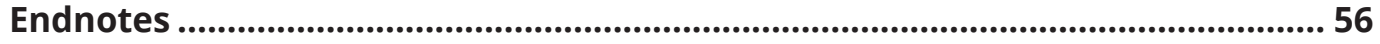




\section{LIST OF FIGURES AND TABLES}

Figure 2-1 Map of Brong Ahafo Region Featuring Asutifi and Tano North Districts ...... 14

Figure 2-2 Map of Ahafo North and South Mines and Communities ...............................15

Table 3-1 Categories of Sustainable Development for NADeF Spending.......................19

Table 3-2 Predicted Contribution to NADeF .....................................................................21

Figure 3-1 Predicted and Actual Contributions to NADeF .................................................21

Table 3-3 Development Outcomes from NADeF .................................................................22

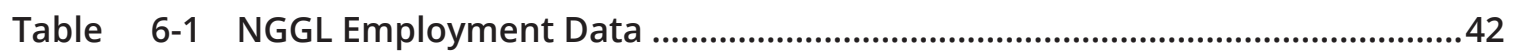

Table 7-1 Spheres of Company-Community Interactions in the Ahafo Mine .................50 


\section{LIST OF ACRONYMS AND ABBREVIATIONS}

AILAP: Agricultural Improvement and Land Access Program

ALP: Ahafo Linkages Program

ALAC: Asociacion Los Andes de Cajamarca

BA: Benefit Agreement

CCC: Community Consultative Committee

CEA: Community Empowerment Associates

CIL: Carbon-in-Leach

CIRDI: Canadian International Resources and Development Institute

CSR: Corporate Social Responsibility

DFA: Development Foundation Agreement

EA: Employment Agreement

ICMM: International Council on Mining and Metals

IFC: International Financial Corporation

M\&E: Monitoring and Evaluation

NADeF: Newmont Ahafo Development Foundation

NGGL: Newmont Ghana Gold Ltd

RA: Relationship Agreement

RNC: Resettlement Negotiation Committee

SDC: Sustainable Development Committee

SRA: Social Responsibility Agreement

UNGA: United Nations General Assembly

WCC: Women's Consultative Committee 


\section{EXECUTIVE SUMMARY}

\section{Introduction}

In 2008, ten communities in the Brong Ahafo region of Ghana entered into agreements with Newmont Ghana Gold Ltd (Newmont Ghana), who had already begun mining in the area. The agreements included promises by the company to create local jobs and fund local development projects, and agreed-upon rules for how the communities and the company would interact and make decisions. Ten years later, this report looks at the communities' experience of those agreements and suggests how they might be improved. The agreements were renegotiated in 2014, and likely will be renegotiated again in 2018 or 2019.

Around the world, mining companies and project-affected communities are increasingly entering into agreements. In some countries, benefit-sharing agreements are required by law before a mining company can begin operations. In other countries, companies will enter into agreements voluntarily, so that local communities welcome the company, and to avoid the risk of any local conflict. Communities can use agreements to reaffirm their rights, obtain protections from the project's negative impacts, and share in the project's economic benefits. Ghana's laws do not require community-company agreements.

We were contacted by members of the communities who requested that we advise on the how the agreements had been operating. Before agreeing to undertake the work, we visited the mining communities and Accra. We found a broad range of support with every stakeholder we spoke to, including the Government of Ghana's Minerals Commission, local officials, unaffiliated community members, local NGOs, members of the governance structures set up by the agreements, and traditional leaders.

We came back to the mine area and Accra in May 2017, where we interviewed more than 100 people, including traditional leaders, local government officials, community representatives, members of civil society and NGOs, farmers, youth, and members of the governance structures set up by the agreements. We also spoke to various Newmont representatives. We are not able to say whether the agreements have left the communities better off because there are not enough data to be able to compare the Ahafo communities with a similar group that has also been affected by a mine but did not enter into an agreement. However, we do make observations and suggestions that could help the agreements work better in the future, and better serve the interests of community members and, through that, the national government and Newmont.

\section{The Ahafo Mine}

The mining industry is important to Ghana's economy. Large-scale gold mines provide jobs for around 7,000 Ghanaians and support a further 66,000 jobs indirectly. Small-scale and artisanal gold mining, or "galamsey," provides many more jobs but also creates unique environmental and social challenges.

The Ahafo mine produced 349,000 ounces of gold in 2016. All of this was from surface mining in the southern half of the concession, which contains the host communities of Ntotroso, Kenyasi No. 1, Kenyasi No. 2, Gyedu, and Wamahinso. Newmont Ghana has also begun an underground expansion in the south, and has conducted a definitive feasibility study for mining to begin in the northern half of the concession, which includes the communities of Susuanso, Terchire, Yamfo, Afrisipakrom, and Adrobaa. Two thirds of the workforce in the area was engaged in agriculture before the mine began operations in 2006. 
In August 2017, youth from the concession area demonstrated against the mine, complaining of high youth unemployment, pollution, and unfulfilled development promises. In January 2018, the regional government urged Newmont Ghana to review the agreements to reflect the impact of underground mining and to undertake more community engagement.

\section{What is in the Agreements?}

The communities and Newmont Ghana entered into three separate agreements: a Relationship Agreement setting up a multi-stakeholder governance structure (originally called a Social Responsibility Agreement); an Employment Agreement establishing targets for local jobs; and a Development Foundation Agreement arranging for income from the mine to be spent on local development projects.

The Relationship Agreement (RA) aims to encourage "harmonious" company-community relations, to enable the communities to make decisions with the company. It establishes:

- The Forum, a 58-person body including representatives from traditional authorities and government, Newmont Ghana, groups within the communities including women and youth, and moderators. Its purpose is to oversee the implementation of the agreements.

- A 16-member Standing Committee within the Forum, which has extra powers.

- The Newmont Ahafo Development Foundation (known as "NADeF") to implement development projects in the communities.

- A Complaints Resolutions Committee to resolve complaints relating to the implementation of the RA.

- Other processes for community-company conflict resolution and communication, including tasking the Nananom, or chiefs, with mediating conflict between the communities and the company, preventing informal mining on the concession, and providing land for resettlement.

The Community Consultative Committee (CCC), set up by Newmont Ghana in each district, is noted to be the preferred communication channel between the communities, company, and Forum. The RA also mentions land management, access, and compensation, with community participation in environmental, social, and reclamation management. In addition, the RA says that it "does not create any legally enforceable rights."

The Employment Agreement (EA) sets out targets for local employment. The original (2008) EA required Newmont Ghana to have 35\% of the Ahafo Mine workforce, including contractors, be "citizens" of the ten communities, and to increase this share of employment to $50 \%$ within ten years of gold production. In 2014, this number was renegotiated down to a $24 \%$ target, which must reach $35 \%$ after ten years of gold production. The agreement requires that at least $90 \%$ of unskilled labour employed in any year must be local citizens. The EA also promises Newmont Ghana-funded training for jobs at the Ahafo Mine. Like the RA, the EA says that it does not create legally enforceable rights.

The Development Foundation Agreement (DFA) is an agreement between Newmont Ghana and NADeF. It establishes that NADeF's revenue for spending on development projects is to come from Newmont Ghana, which pays $\$ 1$ for every ounce of gold it sells, and $1 \%$ of its pre-tax income, net of some transactions. A percentage of NADeF's total income is invested in an endowment fund; this percentage escalates over time, from $10 \%$ during the first five-year period, to $15 \%$ for the next five years, and so on. NADeF is controlled by a Board of Trustees comprised of community and company representatives as well as a chairman appointed by the Forum. The Board manages NADeF's funds and approves development project proposals from Sustainable Development Committees (SDCs) in each of the 
ten communities. Each SDC is made up of seven community representatives, including at least one youth, one woman, traditional authorities, and an assemblyperson. The District Assembly, a local government entity, coordinates with NADeF on project budgeting and contracting. The DFA specifies a formula for how projects should be allocated to the different towns, and across different categories of spending-from scholarships to infrastructure and cultural activities. Unlike the other Ahafo agreements, the DFA is binding.

As of December 2016, NADeF had received approximately US $\$ 23$ million in contributions from Newmont Ghana. Its budget is around the same size as the local government in each of the two districts covered by the Ahafo lease. Thousands of scholarships and numerous construction projects have been financed by NADeF.

\section{How have the agreements been operating?}

We started by asking about how the agreements were negotiated in 2008 and renegotiated in 2014. Newmont Ghana representatives explained that discussions between the communities and the company started in 2005. In 2006, the mine began, and an early version of the Forum was established. The moderator of the Forum led the negotiations.

\section{Negotiation and renegotiation of the agreements}

The agreements list objectives of fostering sustainable development, allowing the communities to benefit from the mining, and meeting concerns about unemployment. Community members interviewed emphasized that employment creation was a key concern of community members who knew about the negotiations. The communities' narrative was, in effect, "land for jobs." On the other hand, Newmont's CEO is said to have suggested the \$1/ ounce royalty and $1 \%$ of net profit transfer to the communities.

Interviewees suggested several challenges to ensuring the communities' equal, meaningful participation during negotiations. These challenges are linked to problems in the Forum and the agreements more generally. For example:

- Many community members described the Forum's Standing Committee as taking a dominant role in negotiations, and some Forum members who were not in the Standing Committee felt excluded.

- The Forum's moderator allegedly did not always allow opportunities for different community representatives to participate in the negotiations.

- Some community members thought Newmont Ghana focused on chiefs and community power brokers, but ignored other community perspectives. One Forum member described this by saying, "when you cut the head off a snake, all that is left is the rope." Relatedly, chiefs participating in the negotiations tended to dominate and silence other community representatives.

- Some community members suspected that chiefs may not have been adequately informed and skilled to properly represent the communities during negotiations.

- Many community members felt that their representatives did not properly consult or represent them during negotiations. This led to community members being "shocked" by outcomes, such as the reduction from 35 to $24 \%$ of the local employment target during the 2014 renegotiations.

Most people we spoke to said that the communities had a lawyer (or perhaps two) during the signing of the agreements. No other experts were made available to the communities. The lawyer apparently explained to the community negotiators what the draft agreement said but did not provide advice or advance their concerns. Such an arrangement likely left the community negotiators without enough support, information and preparation. 
The agreements, and the mine more generally, affect a range of different communities with different priorities and experiences. Community members located within the active Ahafo South mine area shared experiences of environmental and social impacts, but also of opportunities, including employment and NADeF projects. Members of a satellite community described disruptions to their access to water, food, education, and other essential services; they also struggled to benefit from the agreements because they were located far from the community towns. Members of northern communities focused on future mining activities in the north. Many were impatient for the mine activities to reach them, in part because they thought the mine would bring more opportunities for jobs and economic stimulation, which so far were mainly enjoyed by communities in the south.

Other relevant communities, such as those located just outside of the mining area, are not included in the agreements. These communities miss out on many chances to benefit, but are still negatively affected by the mine. One example is Hwidiem, located near Kenyasi No. 2. One resident said that community members from Hwidiem bore the mine's negative impacts, including hosting an influx of job-seekers and environmental pollution, but were not able to take advantage of any positive opportunities under the agreements.

Different individuals and groups within communities experienced the agreements differently. Individuals who benefitted from the agreements tended to be satisfied. These individuals included chiefs and opinion leaders, local contractors of the mine, and individuals who financially benefitted from Newmont Ghana's initiatives. On the other hand, those who felt ignored were less satisfied. A representative of people with disabilities felt that their perspective was excluded from the Forum and other deliberative spaces. Community members who had been resettled, others whose wishes to be resettled were ignored, and those located in satellite communities or outside of the mine area tended to be dissatisfied with the agreements. Representatives from the District Assembly also had concerns about a lack of coordination between SDCs and the District Assembly, which is needed to align NADeF projects with local development plans.

\begin{abstract}
Many community members were dissatisfied with information sharing and communication between Newmont and the communities. Community members alleged that representatives often do not share information about Forum discussions, and that community queries to Newmont Ghana about issues like local employment numbers are sometimes handled in an unhelpful way. Representatives from Newmont Ghana also noted that it is difficult to reach the grassroots of each community, but highlighted the Community Consultative Committee's work in connecting the company with community perspectives. They also confirmed that Newmont Ghana does not monitor whether Forum representatives are meaningfully consulting within their community.
\end{abstract}

Some community members also there were no safe ways of complaining about the agreements. One Forum member warned that complaining could be risky, asking "why would [anyone] open their mouth? If they did it would be shut up." Another community member felt he was not properly compensated for the loss of his land, but stopped pursing this complaint because "I don't want to destroy my children's future."

Despite efforts to design new ways to encourage community participation, community members still feel excluded and face barriers. The agreements create various entities and processes to encourage community participation in decision-making regarding the allocation of benefits. But these entities and processes are undermined by differing levels of experience, education, and other sources of power imbalances. (Challenges in the operation of the Forum, the SDC, and EA community citizen validation process are discussed below.) The unfortunate result is that Newmont appears to be acting responsibly by encouraging community participation, but community members themselves are often unable to meaningfully participate in key decisions. Local powerbrokers exploit this gap. 
The RA established the Forum to increase community participation in company decisions and improve openness and information sharing, but it failed to achieve these goals in practice. Some community members expressed frustration that the presence of chiefs at the Forum introduced challenges: on the one hand, chiefs were regarded as so powerful that other participating community members were reluctant to contradict them and felt silenced; on the other, some chiefs lack the language skills or confidence to organize collectively and resist undesirable company proposals. Community members and Newmont Ghana also suspected that Forum members did not always report what happens at Forum meetings back to community members. In addition, some community groups were underrepresented: there was no representative for people with a disability, less than one third of Forum representatives were women, and some youth representatives were older than the age group they represented.

The representative nature of the Forum is undermined by an influential Standing Committee and moderator. Interviewees said the Standing Committee would decide on the agenda for Forum meetings and proposals, and would often just tell Forum members what it had already agreed should be decided. The moderator also played a commanding role in meetings of the Forum and the Standing Committee. He was regarded as very knowledgeable, but several people interviewed saw him as too dominant and often dismissive. This allegedly intimidated community representatives discouraged them from participating in discussions. Various interviewees regarded the moderator as being too closely affiliated with Newmont and thus not acting impartially.

The participatory monitoring process in the RA has not yet occurred. The RA's requirement for training about the monitoring process to be provided to participating community representatives also has not sufficiently reached community members. Community interviewees generally said that they had not heard of any participatory monitoring program but thought it would be a good opportunity. The company now appears to be preparing to finally implement this initiative; nonetheless, community members highlighted the need to sensitize community members as to why it would be important to participate, and about the environmental dangers of living near a mine more generally. Concerns were also raised that participating community members would be viewed as unfavourable candidates for mine-related jobs.

It is unclear if the RA's dispute resolution process is functioning effectively; if not, it could be because of its design and power imbalances. Despite the various grievances that community members shared with us, no interviewees shared experiences about engaging with the Complaints Resolution Committee. This may be because complaints from individuals aren't provided for. Instead, community complaints must come from community towns (not individuals), and be communicated to the Committee by the chief or Omanhene. Given the challenges that even members of the Forum face in raising concerns, other community members may be reluctant to raise grievances if they have to liaise through chiefs-others may not even know that the process exists.

\title{
Implementation of the Employment Agreement (EA)
}

\begin{abstract}
Although the mine created jobs for local community members, Newmont Ghana did not deliver on its original headline promise, which was to ensure that at least $35 \%$ of jobs went to community members. The data show that as of 2017 this target had been met but the original target of $50 \%$ was still a long way off. Regarding measurement, interviewees were critical that part-time and temporary positions were being counted towards the total number of jobs created. Some community members believed that employers were more interested in hiring their "own people" than employing locals.
\end{abstract}

Many community interviewees thought the process of certifying who counted as a 
community citizen was unreliable. The process requires the chief, Assembly member, and youth leader to jointly validate whether or not a person is from the community.

Yet sometimes leaders were accused of demanding and accepting bribes to validate as "community citizens" people from outside the communities. The 2014 review of the agreements made the validation process more transparent but still faces challenges.

Community members and Newmont disagree on the relationship between the skill level of community members, and the training programs available to them. Some community members noted the transformative potential of the training, observing that community members who go through such trainings "come back as different people," now able to earn a livelihood, for example, by driving bulldozers. Others lamented that while many locals had obtained university degrees with the assistance of NADeF scholarships, including in relevant disciplines, they found that there were no jobs available upon completion of their studies. Essentially, the community skill level has been rising, but community members still find it frustratingly difficult to get desired work with the company.

Implementation of the Development Foundation Agreement (DFA)

NADeF, the development foundation whose financing and mandate are set up in the DFA, was generally well regarded in the communities. It was seen as professionally run and successfully spending money on community projects and scholarships.

Community members and other stakeholders identified potential areas for improvement, including project selection, value for money, inter-community projects, and NADeF's funding formula. Not all projects were seen as delivering equal community value; sometimes this was due to SDCs needing to consult more effectively with the communities, and in other cases it was because of the restrictions around spending categories, which led to NADeF continuing to fund the renovation of chiefs' palaces, for example, while scholarships were cut. One complication is that SDCs prioritize projects before knowing what they are going to cost, with the cost ultimately determined in the tender process. Another is that no cross-community projects, which might generate some benefits of greater scale, have been undertaken. Finally, there was dissatisfaction with the amount of money provided through the funding formula, which was not seen to keep up with population growth, the mine's negative impacts, or the price of gold.

\section{Performance outside of the agreements}

Two significant areas of company-community interactions-local supplier development, and compensation and resettlement-were generally not governed by the agreements and received mixed reviews by interviewees. Newmont Ghana undertook strong efforts to develop local suppliers, through the IFC-supported Ahafo Linkages Program, early on in the mine's life even though it was not mentioned in the agreements. We spoke with suppliers who had benefited from this program and the company's general openness to local businesses participating in the value chain of the mine's activities. On the other hand, the company's compensation and resettlement practices, which were included in the agreements only to the extent that they recognized that Newmont's commitment was to that of Ghanaian law, continued to be a source of community grievances. Communities on the edge of the mine that were being resettled faced a greatly diminished quality of life and reported inadequate compensation being offered.

\section{Insights for the Design and Implementation of Benefit Agreements}

This report seeks to provide some insights on the implementation of the agreements, since they are now a decade old and are regarded as an example of best practice by the World Bank. As we observed, negotiating agreements is just one step of a very complex process. What happens after agreements are signed may require even more attention. 
The Forum attempts to bring a variety of stakeholders together. Yet we observed that achieving true multi-stakeholder participation and collaboration is hard. Not all representatives have equal voice, and different representatives represent and consult with their constituents to varying degrees. The agreements' focus on bringing different stakeholders into decision-making needs to go beyond having people in the room to actually targeting and facilitating meaningful and representative participation.

We also noted that it is hard to create new entities, such as the Forum, the SDCs, and the tender board, that work as intended. These new entities suffered from weak consultation, replicated existing power imbalances, were not always used, and sometimes created conflicts of interest that were not easy to resolve. More successful entities need to be designed to anticipate how people might act within them, perhaps by relying on an "honest broker" like the government or an international organization.

We also observed that even for a national government like Ghana that has no policy or legal requirement for agreements, they are effectively a party to the agreement whether they like it or not. They therefore would be advised to develop a clear policy toward benefit agreements between communities and companies.

\section{Insights for Better Corporate Performance}

Companies with existing benefit agreements or who are considering new ones can learn from the Ahafo experience. We found a mismatch in the narratives of each of the company and community. The company focused on its $\$ 1 / \mathrm{oz}$. and $1 \%$ of profit contribution; but community members believed they gave up land in exchange for the promise of jobs. Paying attention to the community narrative is important.

The implementation of the agreements themselves goes beyond spending the money and meeting employment targets. Both the company and the communities will need to be committed to continuous improvement, including taking baseline data and using a transparent monitoring system, to have a successful agreement in the future.

Finally, we observed that many community-company interactions occur outside of the agreements. In Ahafo, many important aspects of the relationship, including compensation, resettlement, and support to local businesses in the supply chain, had little or nothing to do with the agreements. In some cases, Newmont Ghana went above the call of duty but in others it did not aspire to international standards. A more comprehensive set of legally enforceable agreements might have prevented some of the flashpoints that have occurred at Ahafo.

\section{Recommendations for Consideration in the Renegotiation of the Agreements}

In the body of the report, we offer 25 considerations for the renegotiation process, the agreements themselves, and their implementation. Here we summarize a selection of those, sometimes joining two or three together.

During the renegotiation of the agreements:

1. Provide community representatives at the Forum with independent, experienced legal counsel and technical assistance, and capacity building on negotiation skills, mining, and community agreements.

2. Publicize the renegotiations beforehand and consult widely within the communities.

3. Make the agreements available in plain-language, Twi versions.

4. Include more representatives of the communities as signatories to the agreement to encourage the participation of less dominant community representatives. 
Consider the following changes to the agreements:

1. A more representative Standing Committee and more trusted moderator, perhaps through election by Forum members.

2. An independent grievance mechanism in which grievances can be lodged privately by individual community members without fear of retribution or discrimination.

3. More ambitious compensation and resettlement standards, such as Newmont's own standards, or those of the IFC.

4. Local procurement development targets to encourage an escalating share of contracting work to the mine to be done by local companies.

5. More ambitious and escalating employment targets that take into account the rising level of capacity of local community members.

6. For Newmont Ghana's contribution to NADeF, a profit term that is easier to monitor and verify than the current "net pre-tax income after consideration of all inter-company transactions."

7. Permitting and encouraging NADeF projects that would be shared by multiple communities.

8. Auditing and adjusting the agreements for gender awareness and inclusion of under-represented groups.

9. Making the agreements legally enforceable.

During the implementation of the agreements (including before, during, and after the renegotiations):

1. Hold transparent meetings (of the Forum, the Standing Committee, and other committees), with agendas, minutes, and accessible presentations available in Newmont's information offices and on the Internet.

2. Collect local employment data, disaggregated by community, gender, full-time/ part-time, skilled/unskilled, etc., and report this to communities in a transparent and accessible manner.

3. Publish, at the parent-company level, the contributions to NADeF and the BAsis for those contributions.

4. Improve consultation between community representatives in the Sustainable Development Committees and Forum and their constituents through capacity building on consultation and participation, increased time for consultation before decisions, and monitoring of consultation practices.

5. Establish participatory environmental and social monitoring processes, accompanied by appropriate training and sensitization of community members. 


\section{INTRODUCTION}

Extractive-sector companies and project-affected communities are increasingly entering into formal agreements in order to acknowledge the provision of community consent to a project. Companies use such agreements to acquire a "social license to operate" ${ }^{1}$ in the area in which they work, thereby minimizing the risk of conflict risk for projects. ${ }^{2}$ From the perspective of project-affected communities, agreements with companies can act as a formal vehicle to reaffirm community rights, ensure the mitigation of the project's adverse impacts, and provide a mechanism for sharing in the economic benefits that the project may bring. Communities may also seek to negotiate agreements that create legally enforceable protections of their rights, and with which they can hold corporate actors to account. ${ }^{3}$ These agreements go by many names, depending on the jurisdiction or project proponents, including impact and benefit agreements, community development agreements, benefit sharing agreements, negotiated agreements, and partnership agreements. ${ }^{4}$ In this report, we refer to them generically as benefit agreements (BAs).

While some thirty-two countries mandate specific community benefits in their mining laws, only a handful of those countries, including Mongolia, Nigeria, Papua New Guinea, Sierra Leone, and South Africa, require formal agreements that govern benefit allocation. ${ }^{5}$ In other countries, like most of Canada, ${ }^{6}$ BAs are considered de facto, unwritten, regulatory requirements. ${ }^{7}$ Ghana is among the large group of countries that have no BA requirements, whether enshrined in law or in practice. ${ }^{8}$

The Ahafo mine is an open-pit gold mine, with a planned underground expansion, in the densely populated and rural Brong-Ahafo region in central Ghana. The mine is owned entirely by Newmont Ghana Gold Ltd (NGGL), 'a subsidiary of the Colorado-BAsed company Newmont Mining. Newmont bought the leases and licenses to mine and extract gold at Ahafo from Normandy Mining in 2002 and began commercial production in 2006. At the time of construction, the project was expected to directly affect ten communities and displace approximately 20,000 people.

NGGL signed three agreements in 2008 to govern company-community relations: a relationship agreement setting up a multi-stakeholder governance structure (originally called a social responsibility agreement), an employment agreement establishing targets for local hiring, and a development foundation agreement setting up a funding formula to contribute income from the mine to the local communities as well as establishing the institution to spend it. We refer to these agreements collectively as the Ahafo BAs in this report. The Ahafo BAs are noteworthy for a number of reasons: they were initiated voluntary by the company, they set up a complex institutional arrangement to govern negotiations and implementation, and-having been signed in 2008-these agreements are relatively mature for BAs signed in a low- or middle-income country. They were all renegotiated in 2014, and are likely to be renegotiated again in 2018 or 2019.

We were contacted by members of the affected communities who requested that we might advise (pro-bono) on the implementation of the Ahafo BAs. Before agreeing to undertake the work, two of the authors conducted a scoping visit to determine the level of interest. We found a broad range of support with every stakeholder we spoke to, from the Government of Ghana's Minerals Commission and local officials to unaffiliated community members, local NGOs, members of the BA governance structure, and chiefs. As we describe below, little published research exists on BA implementation; instead, almost all of the scholarly literature and practitioner guidebooks on BAs are about negotiations. Thus, the interest from the community and Ghanaian government to improve on a nearly decade-old set of BAs align with our own interest, as part of a Canadian International Resources and Development Institute (CIRDI) project on "Making Benefit Agreements Work," to develop knowledge to inform the successful implementation of BAs both in specific communities and more broadly.

We try to use the term "Newmont" for the parent company and "NGGL" for the Ghanaian subsidiary for clarity; when ambiguous, referring to both (e.g. Newmont and NGGL employees) or referring to a corporate practice even if undertaken in Ghana alone, we use just "Newmont" for brevity. 
All the direct costs for this work were funded by CIRDI, an institute founded by the University of British Columbia, Simon Fraser University, and Polytechnique Montreal, with additional in-kind contributions by the Africa Centre for Energy Policy, Columbia Centre on Sustainable Investment, Independent Social Performance, and Simon Fraser University.

The purpose of this report, as we state in more detail below, is to study the implementation experience of the Ahafo BAs' and to suggest how they might be improved.

\subsection{WHAT ARE BENEFIT AGREEMENTS?}

BAs formally lay out how communities will be compensated for environmental and social costs and how they will partake in the economic benefits of projects, ${ }^{10}$ often in exchange for social license for the project. ${ }^{11}$ In addition to compensation and benefit-sharing, BAs can describe how adverse impacts can be mitigated, reaffirm and protect community rights, and define the relationship between the company and the community, including how information is shared and issues addressed. BAs, if they are employed correctly, have the potential to contribute to poverty alleviation through financial and economic opportunity, ${ }^{12}$ as well as build a positive relationship between the project proponents and the local communities and ensure that the environmental assessment and management process is upheld. ${ }^{13}$

BAs have been commonly used in Canada ${ }^{14}$ and Australia, and today their use is international ${ }^{15}$. BAs are often used in the resource extraction sector, but may also be negotiated for agriculture and forestry, ${ }^{16}$ urban, ${ }^{17}$ and infrastructure projects. In this report we restrict our focus to BAs in the mining sector.

Besides enshrining commitments to mitigate the social, cultural, and environmental costs of resource extraction, BAs are used to specify how the project proponent will bring additional benefits to the signatory communities. Three of the most common forms of economic benefits included in BAs are financial payments, jobs, and business linkages. Financial payments come in a variety of commitments, from annual payments to equity sharing, and can be delivered in a variety of ways, whether directly or through a trust fund. ${ }^{18} \mathrm{Job}$ benefits involve specific efforts and/or targets to employ locals in both the mining company and its contractors' work. ${ }^{19}$ Linkage benefits in BAs serve to increase the participation of local firms in the business opportunities spurred by a resource development project, especially supplying business services to the project proponent..$^{20}$ As with jobs clauses, linkage clauses in BAs may be "pull" factors like specific targets for local employment or procurement, or "push" mechanisms like training programs and preferential hiring or contracting language. Some clauses in BAs create mandatory obligations on a party, while others are more open, for example, requiring "best efforts."

BAs are not the only way to capture benefits from mining projects; legislation, voluntary corporate initiatives, and international standards are other ways in which community benefits can be achieved. In this report we do not take a stance regarding the optimality of BAs vis-à-vis these other instruments.

Legislated resource development requirements can clarify company responsibilities, create clear rules, and stabilize the investment climate. ${ }^{21}$ Moreover, like a BA, legislation can capture resource development benefits for affected communities. In Ghana, for example, the 1991 Mineral Development Fund, a central government-funded but locally-managed resource fund, was mandated to receive $10 \%$ of mineral royalties from development. ${ }^{22}$ This money was then paid back to local and traditional government to use for development projects. ${ }^{23}$ In 2016 a new act was passed, raising the royalty contribution to $20 \% .{ }^{24}$

Voluntary corporate initiatives to ensure community consent may be achieved through corporate social responsibility (CSR) initiatives, which can include BAs (assuming they are not required in the jurisdiction). While historically CSR has been reactionary, there has been a movement towards more proactive CSR initiatives. ${ }^{25}$ In one case study of the Aloca of Australia and Greening Australia relation- 
ships, researchers found that employing a collaborative and proactive CSR strategy reduced conflict and had positive benefits for both parties. ${ }^{26}$

Finally, guidelines and standards, including from corporate initiatives, such as the International Council of Mining and Minerals, ${ }^{27}$ or international financial institutions, such as the International Finance Corporation, ${ }^{28}$ can influence community participation in project planning, improve management of the local environment, and generate benefits for the community. ${ }^{29}$ While voluntary guidelines may not be enforceable, performance standards that are imposed as a condition to the provision of finance for the project may create strong incentives for compliance.

In spite of the range of alternatives to BAs to achieve community development from mining projects and improve company-community relations, there has been an "explosion" of new BAs ${ }^{30}$ as well as a number of "best practice" guides and model agreements. ${ }^{31}$ Yet as we will describe below, very little research has been done on what leads to successful implementation of BAs.

\subsection{IMPLEMENTATION OF BENEFIT AGREEMENTS}

As described in scholarly literature and practitioner guidebooks, leading practice in BAs includes early planning for implementation and monitoring. Loutit, Mandelbaum, and Szoke-Burke researched publicly accessible BAs and noted with approval that some of the agreements reviewed included an implementation plan, a dispute resolution framework, and a monitoring program. ${ }^{32}$ Monitoring, including community-BAsed monitoring, is often recommended by guides as a practice that can lead to better implementation. ${ }^{33}$ Monitoring increases transparency and accountability, as long as the monitoring metrics are sound,,$^{34}$ and especially when there is a mechanism to address monitoring results or review the agreement. ${ }^{35} \mathrm{~A}$ dispute resolution framework can support successful BA implementation by being a way to address unanticipated results and implementation failures. ${ }^{36}$

In spite of these strong recommendations, academic literature on BA implementation is one of the gaps generated by the fast-paced employment of BAs; resultantly, case examples of implementation is commonly identified as a topic in need of further research. ${ }^{37}$ Moreover, existing literature on BA implementation has focused on cases in Australia and Canada, with little information available from cases in low- or middle-income countries. It may also be the case that the fact most BAs are confidential has limited the ability of researchers to learn what drives effective implementation. However, there are a few exceptions, as we note below.

O'Faircheallaigh compared the implementation of two uranium mining BAs in Australia and identified a long list of potential reasons for failure; these included omission of critical issues, rivalry between government agencies, lack of clarity and precision in the BA and relevant legislation, absence of specific penalties for non-compliance, absence of appropriate institutional arrangements, inadequate resources, staff turnover, lack of information on the BA and relevant policies and legislation, inadequate BA implementation planning due to time constraints, lack of commitment to the agreement from all parties, inadequate consultation and preparation, complex and culturally inappropriate institutional arrangements, and inadequate implementer skills and capacities. ${ }^{38}$ Subsequently, O'Faircheallaigh reviewed BAs negotiated in Australia and Canada and found seven necessities for implementation: adequate financial and human resources, empirical connection between policy initiatives and desired outcomes, clear and measurable goals, delineated implementation responsibilities, implementation to be at the forefront of policy design, adequate political support, and regular monitoring of progress towards relevant goals. ${ }^{39}$

Prno, Bradshaw, and Lapierre assessed the implementation of BAs pertaining to three diamond mines in the Northwest Territories in Canada, and found that these BAs were, on the whole, meeting their objectives and delivering benefits, but not evenly: communities that had experience with prior negotiations, some authority over their land, and more political influence in the area benefitted the most from their BAs. ${ }^{40}$ Siebenmorgan and Bradshaw interviewed fourteen key informants involved 
in a handful of confidential BAs in northern Ontario in Canada, and found that the BAs were failing to meet a number of the expectations of communities, in both the content of the BAs and their implementation. ${ }^{41}$

O'Faircheallaigh, in a review of Australian BAs, found that implementation performance was relatively weak for almost all BAs, especially those that did not perform well on the author's other measures of BA success (including cultural heritage protection, strong financial provisions, and employment provisions). ${ }^{42}$

\subsection{PURPOSE OF THE REPORT}

This report studies the implementation of the Ahafo BAs. The Ahafo BAs are often described as a best practice example in the literature ${ }^{43}$ but, as one of the Ghanaian government officials we spoke to said, "anything can be improved." This report therefore seeks to identify those aspects of the Ahafo BAs' implementation that have room for improvement, and to make concrete suggestions to the various audiences of the paper that they might consider, particularly if the BAs are renegotiated in 2018 or 2019. The three core questions we sought to answer, as we describe in further detail in the methodology section, are: (1) How do community members and other stakeholders regard the Ahafo BAs' performance and implementation? (2) What are the challenges and barriers that have been experienced with regards to the Ahafo BAs' implementation and performance? (3) How are company-community relations outside the specific jurisdiction of the BAs?

Our primary audience is the stakeholders involved in the Ahafo BAs, from government officials to Newmont managers, but especially the community members and their leaders. We use the term "community" in this report in reference to each of: (a) the level of the settlement, or community town, as are identified as being affected communities in the Ahafo BAs (the Ghana Census reports also label these settlements as communities); (b) the collective group of people living in those settlements whose common interest is defined vis-à-vis the mine and opportunities/challenges with its presence; and (c) as an attributive adjective that references those settlements or group of people with a collective interest, such as the term "community members" in the previous sentence. We wish for the results of this study to be informative, helpful, and actionable. Our secondary audience is policymakers and BA negotiators and practitioners in Accra and around the world who can learn from the Ahafo mine case. Of course, each mine, set of communities, and agreement(s) is different. Finally, as this project is part of an initiative to fill the knowledge gap around BA implementation in low- and middle-income countries, our third audience is scholars and researchers of community development in natural resource-rich areas, so that they can use this detailed review of the Ahafo BAs to inform a wider comparative analysis.

The methodology of the research, as we explain later in the paper, is a single case study, in which we sought a comprehensive perspective from all sources available, including interviews conducted at the site and all other material we could find. This study qualitatively weighted the perspective of the affected communities over other stakeholders.

The rest of the report is structured as follows. Section 2 describes the Ahafo mine and its local context, including a brief summary of the history of mining and governance in Ghana as well as information on Newmont and the local communities. Section 3 includes more detailed information on the Ahafo BAs' content and the development foundation that they establish. Section 4 reviews previous research findings on the Ahafo BAs. Section 5 explains the report's methodology. Section 6 discusses the results of the research, including multiple perspectives on the Ahafo BAs' negotiation and renegotiation, performance of the each of the Ahafo BAs, and information about how the project is performing outside of matters that are detailed in the BAs. Section 7 discusses the implications for designing and implementing BAs in light of the collective findings from the report. Finally, Section 8 lists topics for consideration for the 2019 Ahafo mine BAs' review and any BAs pertaining to new sites in Ghana or elsewhere. 


\section{GHANA'S AHAFO MINE}

\subsection{GOLD MINING IN GHANA}

The Republic of Ghana is a lowland, tropical country located on the West African coast bordered by Côte d'Ivoire to the west, Burkina Faso to the north, Togo to the east, and the Atlantic Ocean to the south. Ghana gained independence from British colonial rule in 1957 and became a republic in the British Commonwealth of Nations in 1960. While Ghana's leading export commodities have traditionally been cocoa, gold, and timber, the economy has more recently diversified to export non-traditional commodities like pineapples, bananas, yams, and cashews. ${ }^{44}$

The mining industry is important to Ghana's economy. In 2014, mining comprised over 35\% of the country's merchandise exports with large-scale gold mining operations accounting for approximately $65 \%$ of the production. ${ }^{45}$ Ghana is Africa's second largest gold producer after South Africa ${ }^{46}$ and gold accounts for over $95 \%$ of Ghana's total mineral revenues. ${ }^{47}$ As of 2011, Ghana's gold mining sub-sector accounted for $95 \%$ of all foreign direct investment into the mining sector. ${ }^{48}$

While large-scale gold mines provide a source of employment for an estimated 7,000 Ghanaians and support a further 66,000 jobs indirectly, ${ }^{49}$ their contribution to the country's labour demand is significantly smaller than that from artisanal and small-scale gold mining. This includes "galamsey" miners (a term used in Ghana amalgamating the English phrase "gather them and sell," which refers to informal mining without a license) that are estimated to directly support over one million Ghanaians and additionally provide employment opportunities for as many as five million more people in downstream industries and markets. ${ }^{50}$ However, there is currently a massive national crackdown on the "galamsey menace" for its environmental, political, and social impacts, which is accompanied by a media campaign. ${ }^{51}$

The Minerals Commission of Ghana was established in 1992 as both the main promotional and regulatory body for the country's minerals sector. It is responsible for the coordination and implementation of policies related to mining, including monitoring for compliance with Ghana's mining laws and regulations.52 The Minerals and Mining Act 2006 (Act 703) remains the current mining law in Ghana. The Act stipulates compensation principles for holders of surface rights, including compensation for crops and structures on the land, and references the goal of "localization," or replacing expatriate workers with Ghanaians, but does not require any community-level agreements.

\subsection{THE BRONG-AHAFO REGION AND THE AHAFO COMMUNI- TIES}

The Ahafo mine is located in the Brong-Ahafo region, the second largest of Ghana's ten regions. The majority of the region lies in the forest zone and is a cocoa- and timber-producing area, with the northern part of the region being part of the savannah zone and a grain and tuber-producing area. Local government and traditional government each provide leadership and services in the region. The legislative wing of the region is the District Assembly. One third of its membership is appointed by the national government in consultation with local leaders, while the remaining members are elected on non-party lines. The Brong-Ahafo Region has nineteen administrative districts. Local government's executive functions are run by District Chief Executives..$^{53}$ 


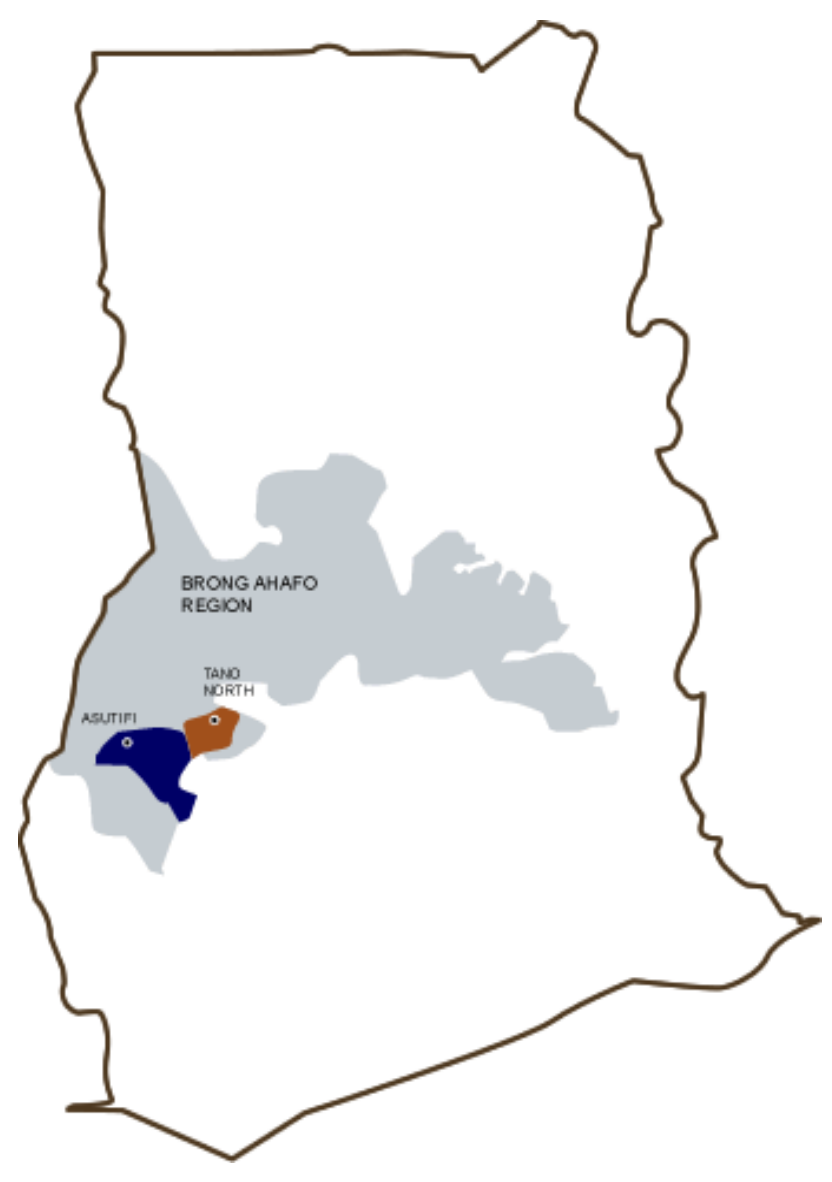

Figure 2-1 Map of Brong Ahafo Region Featuring Asutifi and Tano North Districts ${ }^{54}$

The ten identified "host communities," identified by NGGL because they overlap with the mining lease, are located in two districts inside the region: Asutifi North and Tano North (see Figure 2-1). The Ahafo South concession, within the Asutifi North district, contains the host communities of Ntotroso, Kenyasi No. 1, Kenyasi No. 2, Gyedu, and Wamahinso (see Figure 2-2). The host communities of Susuanso, Terchire, Yamfo, Afrisipakrom, and Adrobaa, are located in the Tano North district, within the Ahafo North concession (see Figure 2-2). ${ }^{55}$ To date, NGGL has only carried out mining within the southern concession area; the northern communities have only experienced exploration activities. While there is no formally disclosed date for when the development of the Afaho North mine will occur, in its first quarter 2018 results, Newmont noted that Ahafo North has advanced to a definitive feasibility study. ${ }^{56}$

Traditional authorities possess considerable institutional relevance and influence in rural Ghanaian communities. The Ahafo mine falls within the Ashanti kingdom, the seat of which is in Kumasi. The Ashanti king recognizes a number of Omanhene, or paramount chiefs, each of whom administers a "stool," or traditional jurisdiction, through an oath of allegiance which includes managing traditional land. Within the Ahafo mine communities, Kenyasi No. 1, Kenyasi No. 2, and Ntotroso are host to paramount chiefs, while Gyedu and Wamahinso are represented by divisional (or autonomous) chiefs. The paramount chiefs exert political control over the various sub-chiefs that represent major communities within their respective stools, as well as over the village chiefs that represent smaller communities. Disputes are typically resolved at the village level by sub-chiefs and village chiefs in consultation with elders. Chiefs at all levels play a role in stool land allocation. 


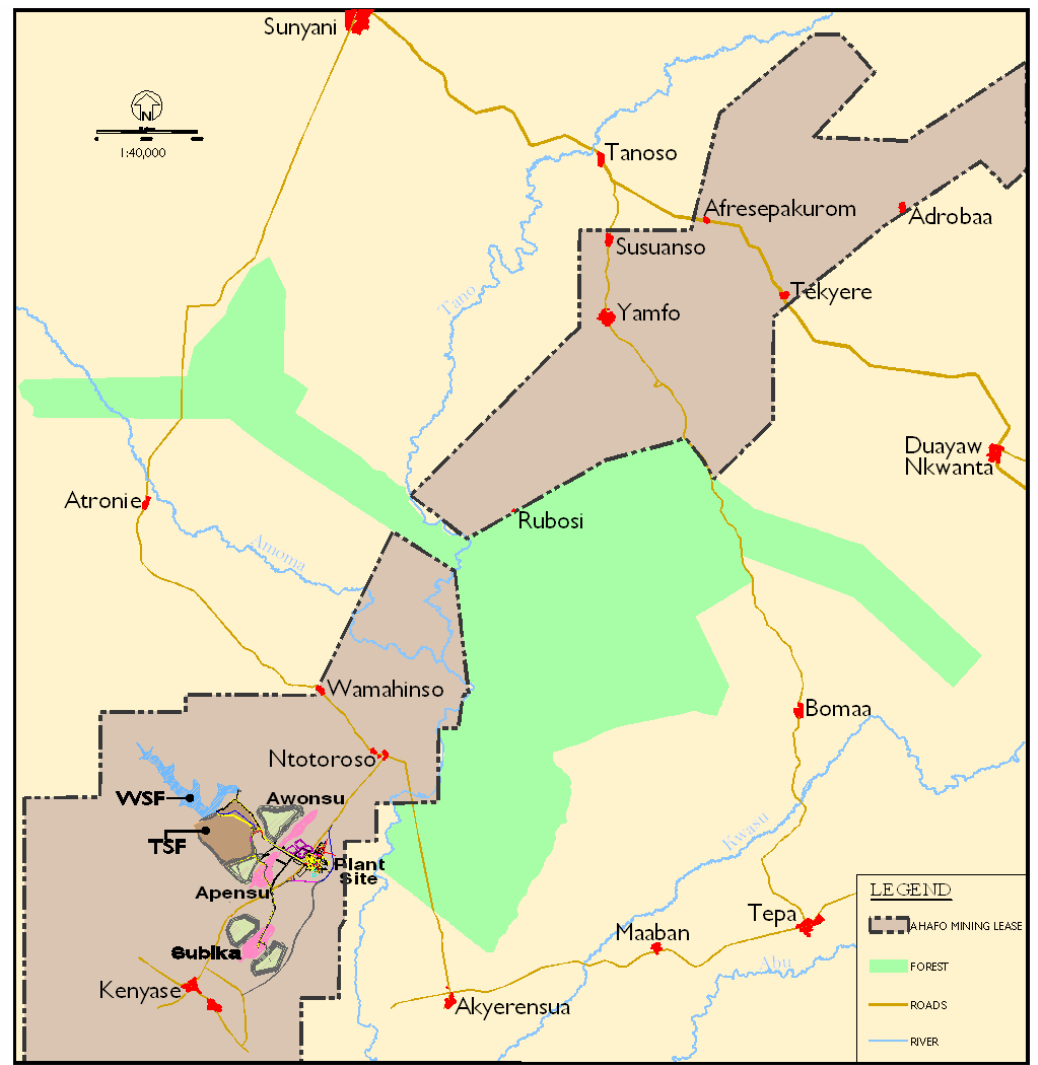

Figure 2-2 Map of Ahafo North and South Mines and Communities ${ }^{57}$

In 2010, according to the 2010 census, ${ }^{58}$ the five host communities in Ahafo South were also the five largest communities in the district, with a population ranging from over 11,000 in Kenyasi No. 2 to just over 1,600 in Wamahinso. Two thirds of economically active people in the district were engaged in agriculture; four fifths of the workforce were employed through informal markets including subsistence farming. The total fertility rate in the district was 4.3 children per woman, and less than half of houses had electricity. In Ahafo North, the five host communities were all among the largest eight communities in that district, with a population similarly ranging from over 11,000 in Yamfo to under 1,600 in Afrisipakrom. ${ }^{59}$

\subsection{NEWMONT AND THE AHAFO CONCESSION}

Newmont, an American company registered on the New York Stock Exchange, was founded in 1916 and is one of the world's largest gold companies. Newmont presently operates in seven countries with approximately 23,000 employees and contractors worldwide. ${ }^{60}$ The Ahafo mine became part of Newmont's portfolio in 2002 with its acquisition of the Australian company Normandy Mining. Newmont's initial intent with Ahafo was to sell it immediately after acquisition, but after a geological re-evaluation in 2003, Newmont decided to initiate what would become an aggressive three-year drilling program that ultimately resulted in a reassessment of Ahafo's ore reserves from 3.3 million to 12.6 million ounces of gold in $2006 . .^{61}$

The Ahafo BA approach originated from lessons learned by Newmont from its Yanacocha gold mine in Peru. In the Peruvian case, a development foundation called ALAC (Asociacion Los Andes de Cajamarca) exists. ${ }^{62}$ Newmont's experiences in Peru fostered the creation of the Ahafo Social Responsibility Forum, which later signed the BA establishing the Newmont Ahafo Development 
Foundation (NADeF). ${ }^{63}$ NADeF's first intentions of focusing upon entrepreneurial development, institutional capacity building, and human capital development are parallel to ALAC's goals.

The Ahafo South mine project sits on a lease concession of approximately 137,000 acres. The operation currently includes three open pits moving through about 95,000 tonnes of ore per day, facilitated by three excavation shovels, thirty-eight 141 -tonne trucks for moving material, and a processing plant. The processing plant includes a rock crushing plant, an ore grinding circuit, several CIL (carbon-in-leach) plants, elution and counter current decantation circuits, and a tailings waste disposal facility. ${ }^{64}$ This led to a production of 349,000 ounces of gold during 2016 . The costs applicable to sales for the Ahafo project were on average $\$ 655 /$ oz for the first 6 months of 2016 and $\$ 743 /$ oz for the same period in 2017 . The average all-in sustaining costs for the same two six-month periods were $\$ 888 /$ oz and $\$ 934 /$ oz respectively. ${ }^{65}$

In 2017, NGGL announced in 2017 that it would build a new underground mine, known as Subika, and expand Ahafo Mill, the processing plan, capacity by $50 \%$ by adding a grinding mill, a crusher, and a leeching tank. ${ }^{66}$ The Subika underground mine received environmental approval and permits in March 2017 and is expected to produce 1.8 million ounces of gold over an approximate 10-year mine life. Subika supports gold production at Ahafo through at least 2029 without needing to access Ahafo North. The mill expansion is currently under construction. On April 7, 2018, a mill expansion tunnel collapsed, killing six contractor employees. ${ }^{67}$ Work was suspended to conduct a risk assessment and was reportedly resumed as of April 10, 2018. ${ }^{68} \mathrm{NGGL}$ expects first gold production at the mill expansion in the first half of 2019 and commercial production starting in the second half of 2019. ${ }^{69}$

\subsection{RECENT CONTROVERSY}

On August 1, 2017, youth from the concession area demonstrated against the Ahafo Mine. ${ }^{70}$ News reports state that the demonstration was fomented by concerns about high youth unemployment, pollution concerns, and unfulfilled community development promises. ${ }^{71}$ Youth leaders accused Newmont of not sharing detailed statistics on non-local employment, failing to award contracts to companies owned by community members, and deceiving locals by posting ads yet hiring outsiders. The protestors rejected Newmont's claims that locals lack the qualifications and experience to be hired, and accused Newmont of hiring outsiders in more lucrative, permanent, secure, and strategic positions. Moreover, the demonstrators expressed concern regarding the lack of an agreement that addresses the Subika underground mining project, as well as the opaque nature of most company activities..$^{72}$ A Newmont press release reiterated the company's commitment to "transparent and respectful stakeholder engagement" as well as its impact on the local workforce and economy. ${ }^{73}$

It appears that this was not a spontaneous demonstration: the youth had informed Newmont on December 13, 2016, disrupting an Environmental Protection Agency public hearing about the underground mining, that continuing project development without addressing youth unemployment would result in a demonstration. ${ }^{74}$ Following the demonstration, Regional Minister Kwaku AsomahCheremeh and Newmont management agreed that they would meet with stakeholders, including the youth leaders, about how to resolve the matter. Youth leaders agreed to wait for the minister to make the next move. ${ }^{75}$ Months later, on Tuesday, September 12, 2017 youth leader Kennedy gave a one-week ultimatum to the Regional Minister to start employing the youth of the area or face another demonstration. ${ }^{76}$

In response, the regional government established a seven-member committee to look into the claims and concerns of the youth in the five communities affected by the current operations of NGGL. The committee's findings and conclusions were captured in a white paper issued by the Regional Coordinating Council under the signature of the Regional Minister on January 26th, 2018. Among other things, the white paper urged Newmont to "review the Social Responsibility Agreement to reflect the impact of underground mining," put up a district hospital by December 2018, and initiate steps to undertake more engagement than established in the BA. The white paper also identified responsibilities for the District Assembly and the leadership of the concerned youth to foster coexistence with the mine. ${ }^{77}$ 


\section{WHAT IS IN THE AGREEMENTS}

In this section we summarize the contents of the Ahafo BAs signed in 2008 as well as changes to the BAs following renegotiations in 2014. (In section 6.1 we describe the community experience with the negotiation and renegotiation.) In addition, we describe the subsequent spend through the Newmont Ahafo Development Foundation (NADeF) and NGGL corporate social responsibility initiatives that were not part of the BAs. We BAse our analysis of the 2008 agreements on the publicly available copies of those agreements. One peculiarity of those copies is that the signature pages for the SRA and EA appear to have been switched out for the signature page of the DFA, and thus feature the signatures of representatives from NGGL and NADeF, rather than the signatures of representatives of the communities listed as parties to the agreements.

\subsection{THE 2008 AHAFO BENEFIT AGREEMENTS}

\subsubsection{Social Responsibility Agreement}

The Social Responsibility Agreement (SRA) between the Ahafo local communities and NGGL aims to ensure that company-community relations are harmonious, ${ }^{78}$ that the community participates and works with the company, and that the ten affected communities experience sustainable economic and social development. ${ }^{79}$

One of the SRA's main focuses is the Forum. Under the SRA, the Forum originally comprised fifty-six different members, including traditional authorities and government, NGGL, community representatives, and moderators. ${ }^{80}$ Its purpose is to oversee the Ahafo BAs' implementation. ${ }^{81}$ The SRA also established the sixteen-member Standing Committee, which takes on the role of the Forum during an emergency or in between Forum meetings. ${ }^{82}$

The SRA also established NADeF, whose purpose is "to fund sustainable development projects in the Community." ${ }^{183}$ Further details about NADeF are contained in the Development Foundation Agreement, which is discussed below.

While the agreement says that it "does not create any legally enforceable rights," ${ }^{84}$ it established a Complaints Resolutions Committee to resolve complaints relating to the implementation of the SRA. ${ }^{85}$ This committee is made up of the Forum moderator and co-moderator, company representatives, and community delegates. ${ }^{86}$

Finally, the SRA delineated various systems for community-company conflict resolution and communication. The Nananom, or chiefs, are tasked with mediating conflict between the community and the company, preventing informal mining on the concession, and providing land for resettlement. ${ }^{87}$ The Community Consultative Committee (CCC), set up by NGGL in each district, is cited as the preferred communication channel between the community, company, and Forum. ${ }^{8}$ Land management, access, and compensation are also outlined in the agreement, with community participation in environmental, social, and reclamation management. ${ }^{89}$

\subsubsection{Employment Agreement}

The Ahafo Social Responsibility Agreement: Local Employment Agreement (EA) endeavoured to address employment of affected communities' members at the Ahafo mine. ${ }^{90}$ Like the SRA, the EA contained a provision aimed at rendering the agreement not legally enforceable; specifically, the parties renounced their rights to litigate any disputes arising out of the EA. ${ }^{91}$ 
This agreement required NGGL to adopt a policy to have 35\% of the Ahafo Mine workforce, including contractors, be "citizens" of the ten affected communities, and to increase this share of employment to $50 \%$ within ten years. ${ }^{92} \mathrm{~A}$ person is considered a citizen if they, their parents, or their spouse is from the town, or if they live in the town and have immovable property in or near the town; the youth leader, Assembly member, and chief may also name someone a citizen. ${ }^{93} \mathrm{~A}$ formula is specified on how unskilled jobs should be allocated across the ten communities; factors that increase a town's entitlement to jobs include population, land area, and "commitment to this Agreement."94 Local employment rates are reported yearly and, if goals are not met, NGGL must provide an explanation. ${ }^{95}$ The EA also promises Newmont-funded training for jobs at the Ahafo Mine. ${ }^{96}$

\subsubsection{Development Foundation Agreement}

The Development Foundation Agreement (DFA) is an agreement between NGGL and NADeF, which concerns NADeF's funding and governance. Unlike the other Ahafo BAs, the DFA is binding, ${ }^{97}$ perhaps because the community is not a party to the agreement (except via community representatives on the NADeF boards). DFA-related disputes are arbitrated under the Arbitration Act of Ghana. ${ }^{98}$

NADeF's revenue comes from a combination of a volume-BAsed royalty and a profit share of the mine's output: $\$ 1$ for every ounce of gold sold, and 1\% of "net pre-tax income after consideration of all inter-company transactions" plus an adjustment for the disposition of assets. ${ }^{99}$ In other words, if the mine produces 500,000 oz of gold and makes $\$ 250$ million (after NGGL has paid Newmont for some goods and services but before taxes), then $\$ 0.5$ million ( $\$ 1 / \mathrm{oz}$ ) plus $\$ 2.5$ million (1\% of profits), or a total of $\$ 3$ million, will be paid to NADeF to be spent on development projects. A percentage of NADeF's total income must be invested in an endowment fund; this percentage escalates over time, from $10 \%$ during the first 5 -year period, to $15 \%$ during the second 5 -year period, and so on. ${ }^{100}$

The DFA sets out a governance structure for NADeF. NADeF is controlled by a Board of Trustees equally comprised of community and company representatives as well as a Forum-appointed chairman. ${ }^{101}$ The Board manages NADeF's funds and approves development project proposalsii from community towns. ${ }^{102}$ In addition, NADeF has a nine-member Tender Board made up of chiefs, youth, local government, and NGGL representatives, which evaluates and recommends development project applications to the Board of Trustees. ${ }^{103}$

A stated goal of the DFA is sustainable development. The DFA defines sustainable development as development that: lasts from generation to generation; is BAsed on actual needs of the community; serves and is owned by the majority of the people; can be maintained with available income; is planned and can be monitored and evaluated; has long term benefits; and is committed to the idea that NADeF business is conducted in the best interests of NADeF and the community. ${ }^{104}$ Each community has a Sustainable Development Committee (SDC), which is made up of seven community representatives, including at least one youth, one woman, traditional authorities, and an assembly person; each SDC selects projects BAsed on the needs of its community town, in consultation with the local government's District Assembly, and submits project proposals to NADeF. ${ }^{105}$ The agreement specifies rules for how much should be invested in each category of sustainable development (see Table 3-1). The resulting infrastructure is jointly owned between the community and the District Assembly. ${ }^{106}$ As with the EA, funding for projects in community towns is BAsed on a formula including population, area, and commitment to the agreement. ${ }^{107}$

ii DFA, s. 6.1(iii) uses the term "applications" rather than "proposals", but the rest of the agreement speaks about community towns submitting proposals through SDCs, so it is assumed that applications and proposal are used interchangeably in the agreement. 
Table 3-1 Categories of Sustainable Development for NADeF Spending ${ }^{108}$

\begin{tabular}{|c|c|c|}
\hline Category & Example of Acceptable Project & $\%$ Allocated \\
\hline $\begin{array}{l}\text { (i) human resource } \\
\text { development }\end{array}$ & Scholarships or pre-job training (s. 13.2) & $24 \%$ \\
\hline $\begin{array}{l}\text { (ii) provision of } \\
\text { infrastructure; }\end{array}$ & $\begin{array}{l}\text { Water, Electricity, Roads, Clinics/Health Centres, Schools, } \\
\text { Toilet facilities, Incinerators (s. 13.3) }\end{array}$ & $23 \%$ \\
\hline $\begin{array}{l}\text { (iii) provision of } \\
\text { social amenities; }\end{array}$ & $\begin{array}{l}\text { Community Centres, Police Posts, Community Libraries } \\
\text { (s. 13.4) }\end{array}$ & $18 \%$ \\
\hline $\begin{array}{l}\text { (iv) economic } \\
\text { empowerment; }\end{array}$ & $\begin{array}{l}\text { Employment - skilled \& unskilled; Establishment of } \\
\text { factories / cottage industries; Credit facilities; Market } \\
\text { Stalls (s. 13.5) }\end{array}$ & $17 \%$ \\
\hline $\begin{array}{l}\text { (v) protection of } \\
\text { natural resources; and }\end{array}$ & & $12 \%$ \\
\hline $\begin{array}{l}\text { (vi) support for cultural } \\
\text { heritage and sports }\end{array}$ & $\begin{array}{l}\text { Festivals, Palaces, Cross cultural activities and protocols, } \\
\text { Sports (s. 13.6) }\end{array}$ & $6 \%$ \\
\hline
\end{tabular}

\subsection{THE 2014 RENEGOTIATED AHAFO BAS}

Unlike many investor agreements between a national government and mining company, the SRA expressly allowed for a review of, or amendments to, the agreement at any annual meeting. ${ }^{109}$ This occurred in 2014 for all three agreements. The main changes are summarized below.

\subsubsection{Relationship Agreement}

The main substantive changes of the Social Responsibility Agreement, retitled the Relationship Agreement (RA) following its 2014 renegotiation, center around the Forum. First, the Forum now has fifty-eight members, and now includes four queen mothers (who are the traditional female authority figure alongside the male chief), as well as each district's Community Consultative Committee moderator; the chief farmers' seats have been removed, and the number of members of parliament have been reduced to two. ${ }^{110}$ Second, the Forum's moderator's remittance is now determined and paid for by the company; ${ }^{111}$ it had previously been determined by the Forum and paid for out of NADeF funds. ${ }^{112}$ Third, the Forum now meets at least once every quarter instead of twice a year. ${ }^{113}$ Fourth, NGGL must now annually publish a flyer or bulletin to disseminate the Forum's decisions and matters of interest relating to the Ahafo BAs within the ten affected communities, ${ }^{114}$ which was only done biannually under the 2008 SRA.

A 2013 "Agreement Review Report," which seems to describe different stakeholders' recommendations for the renegotiations, and which was provided to us by Newmont just before publication of this report, also shows that the CCC for Ahafo South requested that the RA be amended to remove: (i) that "the parties hereby renounce their rights to enter into any form of litigation or arbitration on any disputes or grievances arising out of this Agreement;" and (ii) that the agreement "does not create any legally enforceable rights." The Standing Committee's "comments for Forum consideration" state "Agreed - Cannot trample on Individual rights. Delete the last Sentence."115 Yet, while the 2014 no longer features the prohibition on litigation, it does still contain the assertion that the agreement does not create legally enforceable rights. 


\subsubsection{Employment Agreement}

Under the 2014 EA, there are smaller local employment goals, new hiring procedures, and a new committee to manage employment issues. The Ahafo Mine local employment goal, previously $35 \%$ with an aspiration to $50 \%$, was reduced in 2014 to $24 \%$ with an aspiration to reach $35 \%$ within ten years. ${ }^{116}$ However, at least $90 \%$ of unskilled labour employed in any year must now be local citizens. ${ }^{117}$ Recruitment policy changes affect unskilled labour: when an unskilled employment opportunity arises at the Ahafo Mine, NGGL selects and notifies one or more of the ten affected communities. An employee is then selected from among the interested citizens of the town(s), ${ }^{118}$ and chiefs may now nominate every fifth person to be employed from their town through a separate process where an employee is chosen randomly from a group of shortlisted candidates. ${ }^{119}$ Moreover, community members no longer have to validate their citizenship until they are shortlisted for employment. ${ }^{120}$ Finally, the 2014 EA establishes an Employment Committee made up of NGGL human resources representatives and delegates from each District. This committee's purpose is to monitor local employment trends at the Ahafo Mine and the citizen validation process, as well as any other employment related tasks as assigned. ${ }^{121}$

\subsubsection{Development Foundation Agreement}

Changes to the Development Foundation Agreement (DFA) in 2014 concern NADeF's governance boards and the fund allocations. The 2014 DFA alters the composition of NADeF's Board of Trustees to have a higher share of community representatives (including at least one woman and at least two non-Forum members) but this change is balanced by the fact that the chairman is now appointed by NGGL rather than the board. ${ }^{122}$ Additionally, the 2014 DFA articulates a board turnover protocol ${ }^{123}$ and enlarges the Tender Board to include the executive secretary of the NADeF board and the Chairman of the Projects Committee of NADeF. ${ }^{124}$ Compared to the NADeF fund allocations under the 2008 DFA, the 2014 renegotiations support cultural heritage and sports projects ( $+10 \%$ of allocation) at the expense of natural resource $(-8 \%)$ and social amenity related initiatives $(-2 \%) .{ }^{125}$ In addition, some NADeF funds are now earmarked for NADeF administration and incidental expenses. ${ }^{126} \mathrm{How}$ project funds are doled out to communities also changed: the amount of a community land located within the mining lease now carries more weight than population, and funding is clearly allocated to each community instead of being earmarked BAsed on each community's commitment to the Ahafo BAs. ${ }^{127}$

\subsection{DEVELOPMENT FUNDING FROM THE BAS}

In this sub-section we compare the value contributed to NADeF with the production volume (sold) and costs reported in Newmont's annual reports to the U.S. Securities and Exchange Commission.

The Newmont Ahafo Development Foundation, or NADeF, was established by the 2008 DFA to encourage greater responsibility and self-reliance of the host communities near the Ahafo mine. ${ }^{128}$ NADeF's vision is that "our communities achieve prosperity and self-reliance," and the foundation's mission is "to empower communities through grants, knowledge sharing, partnership, and capacity building to achieve sustainable development."'129 As of December 2016, NADeF had received a total of approximately US $\$ 23$ million through commitments made by NGGL in the DFA. ${ }^{130}$ NADeF's current assets-comprising its endowment fund, which contains the savings for the future, and its community project fund, which pays for the community projects-were worth US\$11.9 million, nearly three quarters of which was in the endowment fund. ${ }^{131}$

Table 3-2 below generates a "predicted" contribution to NADeF by: (1) taking the gold price, ${ }^{132}$ (2) subtracting out Newmont's self-reported costs per oziii to identify the profit margin, (3) multiplying that by Newmont's self-reported volume of gold sold to identify the profits from the mine,

iii Costs applicable to sales plus depreciation and amortization, from the annual reports. 
(4) multiplying that by $1 \%$ following the formula in the DFA, and then (5) adding the volume of gold sold multiplied by $\$ 1 / \mathrm{oz}$. Obviously, this math is too simple, as the DFA also allows for any "inter-company transactions" to be subtracted out. These transactions might include a loan from Newmont to NGGL, for example, or a marketing fee paid to sales agents in a Newmont affiliate in a third country. On top of that, we have no way of unpacking the cost numbers (which vary wildly by year) or matching them to the actual amount of ounces of gold produced versus the amount sold. The predicted contribution, on the penultimate line, can be compared to the actual contribution on the last line, as reported in NADeF annual reports (which was converted to USD at the then-exchange rate by the authors).

\section{Table 3-2 Predicted Contribution to NADeF}

\begin{tabular}{|c|c|c|c|c|c|c|c|c|c|}
\hline Year & 2008 & 2009 & 2010 & 2011 & 2012 & 2013 & 2014 & 2015 & 2016 \\
\hline Avg yer gold price (/troy oz) & $\$ 872$ & $\$ 972$ & $\$ 1,225$ & $\$ 1,572$ & $\$ 1,669$ & $\$ 1,411$ & $\$ 1,266$ & $\$ 1,160$ & $\$ 1,251$ \\
\hline Combined costs ( $\$ / p z)$ & $\$ 534$ & $\$ 569$ & $\$ 600$ & $\$ 611$ & $\$ 738$ & $\$ 679$ & $\$ 698$ & $\$ 780$ & $\$ 1,163$ \\
\hline Volume gold sold (oz) & 520,800 & 546,400 & 545,000 & 566,000 & 561,000 & 570,000 & 571,878 & 332,000 & 349,000 \\
\hline $\begin{array}{l}\text { Predicted contribution } \\
(\$ 1+1 \%)\end{array}$ & $\$ 2,280,896$ & $\$ 2,750,304$ & $\$ 3,948,689$ & $\$ 6,002,543$ & $\$ 5,783,798$ & $\$ 4,743,711$ & $\$ 3,822,433$ & $\$ 1,593,799$ & $\$ 655,213$ \\
\hline NADeF contribution & $\$ 843,314$ & $\$ 1,409,255$ & $\$ 1,852,871$ & $\$ 2,8820,812$ & $\$ 4,610,977$ & $\$ 3,950,489$ & $\$ 4,360,458$ & $\$ 2,067,129$ & $\$ 944,331$ \\
\hline
\end{tabular}

As can be seen from the table and represented in Figure 3-1 below, our estimates predicted much higher transfers to NADeF during the earlier years, but lower transfers to NADeF during later years, and summed over all nine years the predicted and actual transfers are within an error of $40 \%$. This error level indicates that the amount of funds paid to NADeF corresponds to the same order of magnitude as one might reasonably predict using publicly-available figures; however, it still corresponds to a gap of $\$ 8.7$ million. That said, NADeF's endowment appears to have appreciated more than one might have predicted at the outset. We have not modeled the endowment returns but at first glance they are significant.

\section{Figure 3-1 Predicted and Actual Contributions to NADeF}

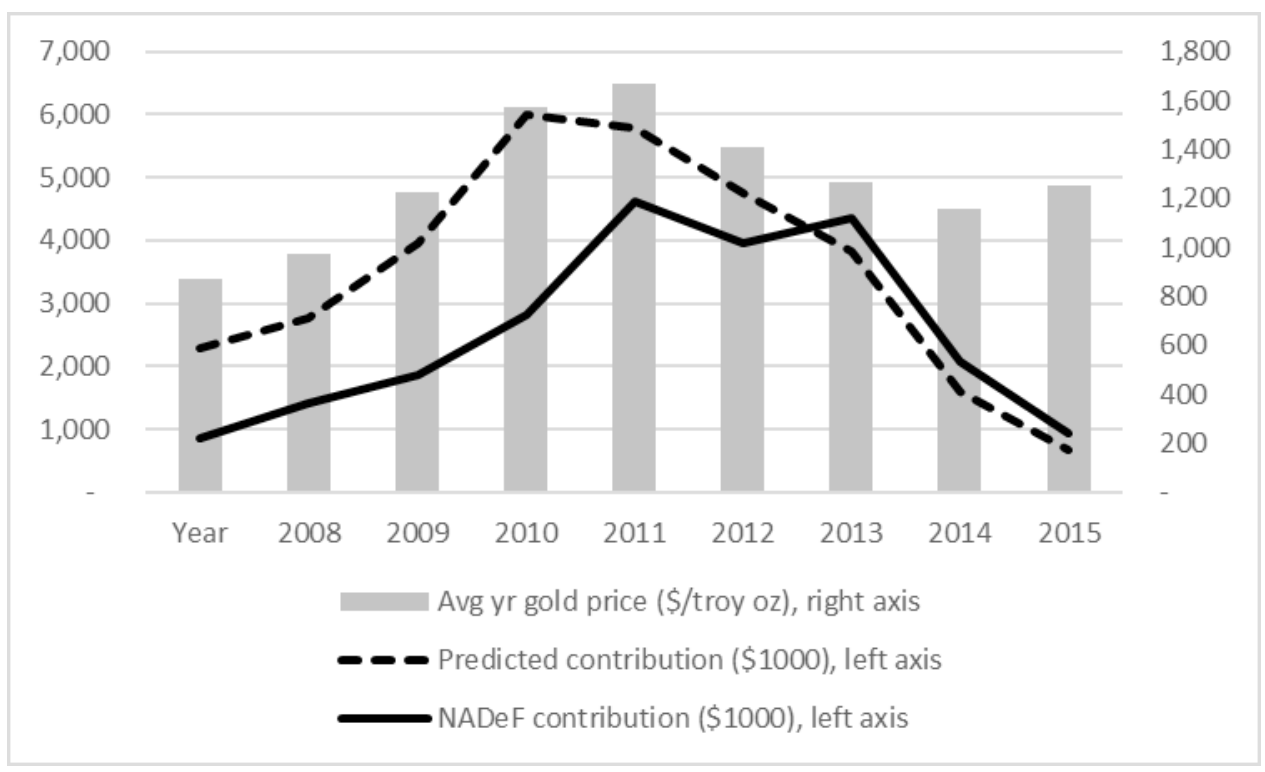


To get a sense of the relative magnitude of NADeF versus other local government expenditure, we compare NADeF's project budget with the entire budget of the district assemblies for each of the two districts within the mine area (Asutifi and Tano North). In 2016, NADeF spent GHS 7,861,494 on projects, invested GHS 11,605,856, and purchased GHS 9,750 worth of non-current assets, for a total expenditure of GHS 19,477,100. ${ }^{133}$ Comparatively, the two District Assemblies were projected to spend, respectively, GHS 9,091,057 and GHS 6,603,421.45 in 2016.134 Of NADeF's budget, just 4.17\% covered its own expenses, probably a far lower share than the District Assemblies whose salary obligations alone would have been much higher. Thus, NADeF's contribution on local public good projects is substantial.

Finally, in Table 3-3, we describe NADeF's deliverables. This table delineates NADeF's development outcomes as identified in a Newmont-contracted report to evaluate the foundation's track record.

\section{Table 3-3 Development Outcomes from NADeF ${ }^{135}$}

\begin{tabular}{|l|l|}
\hline Area of Development & Outcomes \\
\hline Human Resources & $\begin{array}{l}\text { 6177 students had received scholarships } \\
\text { Funding for writing, reading, and listening skill program } \\
\text { Grants to civil society organizations that work in youth empowerment, } \\
\text { entrepreneurship, and girl's education } \\
\text { Exam preparation programs } \\
\text { Quality Improvements in BAsic Schools five-year program started in } \\
2015\end{array}$ \\
\hline Economic Empowerment & 900 microfinance and start-up capital fund clients reached \\
\hline $\begin{array}{l}\text { Infrastructure and Social } \\
\text { Amenities }\end{array}$ & $\begin{array}{l}\text { 75 infrastructure projects completed and handed over to the District } \\
\text { Assemblies }\end{array}$ \\
\hline $\begin{array}{l}\text { Natural Resource Protec- } \\
\text { tion }\end{array}$ & $\begin{array}{l}\text { 4\% of NADeF's annual spending goes to natural resource conservation } \\
\text { Cultural Protection }\end{array}$ \\
\hline $\begin{array}{l}\text { Support programs for building and maintaining culturally significant } \\
\text { buildings } \\
\text { Support for maintaining and protecting cultural artefacts } \\
\text { Funding program encourages inclusive, respective, and participatory } \\
\text { cultural heritage }\end{array}$ \\
\hline Sports & $\begin{array}{l}\text { Programs aimed at enhancing participation and appreciation of } \\
\text { sports }\end{array}$ \\
\hline
\end{tabular}

\subsection{WHAT'S NOT IN THE AGREEMENTS?}

Though the Ahafo BAs and NADeF play crucial roles in development of the area around the Ahafo Mine, they are not the only institutions initiated by NGGL that support local communities and people. As we describe in later sections of the report, the Ahafo BAs only cover some fraction of company-community interactions. Understanding the Ahafo BAs requires understanding their role in that wider context.

On the governance side, two types of relevant committees that exist but were not established by the Ahafo BAs are the Women's Consultative Committee (WCC) and Resettlement Negotiation Committees (RNCS). The WCC, according to Newmont, endeavours to augment women's participation in decision making and empowers women to be economically self-sufficient through the provision of small loans. There are ninety-five members, including queen mothers and elected representatives. ${ }^{136}$ An RNC is formed for each community that will be resettled to advocate for community interests during resettlement entitlement negotiations. ${ }^{137}$ Each RNC is made up of affected residents, traditional leaders, government agencies, and non-profit organizations. ${ }^{138}$ 
On the programmatic side, two economic development initiatives outside of the Ahafo BAs are the Agricultural Improvement and Land Access Program (AILAP) and the Ahafo Linkages Program (ALP). AILAP assists affected farmers by providing farming inputs and technical assistance and promoting land access agreements: AILAP encourages farmers to restart farming after resettlement, according to Newmont-hired consultants. ${ }^{139}$ ALP, on the other hand, funds small and medium enterprises in the local area ${ }^{140}$ with the aim to increase the participation of local businesses in the mining project and bring additional benefits to the surrounding communities. According to university researchers Lawson and Bentil, ALP has supported forty-two businesses and improved the capacity of forty-nine local, non-mining related businesses as of 2013. ${ }^{141}$

Finally, there are a few noteworthy absences in the Ahafo BAs. In terms of compensation for livelihood termination (via acquiring farmland for mining) and resettlement (when dwelling territory is used for mining), the RA merely indicates that NGGL should negotiate "with the person or group of persons to whom the compensation must be paid in line with the established negotiation process and in line with Ghana Legal Processes,"142 and that NGGL and the community "agree to observe the laws of Ghana regarding access to land and compensation." 143 Thus rather than establishing a mutually satisfactory way to manage the complex and critical issues concerning displacement and resettlement of community members, the BAs fall back on Ghanaian law. As discussed in the next section, these omissions led to a number of flashpoints that fall mostly outside the scope of the BAs themselves; as such, while underlining the importance of managing the question of displacement and resettlement in ways that are acceptable to community members and which respect their legitimate rights to the lands and resources, this report does not feature detailed findings or recommedations on this issue. 


\section{EARLIER FINDINGS ON THE AHAFO BAS}

In this section we summarise the existing body of findings and research concerning the Ahafo mine, and the Ahafo BAs in particular. This includes research prepared, funded, or otherwise closely affiliated with Newmont, and independent research conducted by academic and other researchers. We also discuss awards that Newmont has received.

\subsection{NEWMONT OR NEWMONT-FUNDED OBSERVATIONS}

In 2009, Newmont published a global review of its community-facing practices following a 2007 shareholder request. ${ }^{144}$ Ahafo was one of the sites chosen for an in-depth examination, and researchers for the study visited it in October 2007. Overall, they were impressed with Newmont's "proactive approach" 145 and investment in community development projects. They remarked that the Forum and other formal structures served to channel "community concerns and frustrations" in such a way that would decrease conflict. ${ }^{146}$ However, they highlighted some significant risks and concerns, including Newmont's inability to meet the locals' high demand for jobs, resettlement and compensation, and the perceived "close working relationship" between the chiefs and mine officers. ${ }^{147}$ They also noted the potential for community concerns to be amplified through national or international attention, or for resistance around mining in general to lead to local protest.

In 2010, the World Bank published a study that helped to bring international attention to the Ahafo BAs. This seems to be largely BAsed on observations and insights that were shared with the researchers by the Newmont representatives. It describes a number of "lessons learnt,",148 including the following: (1) to work in partnership with, and not replace, local governance systems and government, such as consultation and decision-making through the Forum; (2) though participatory allocation of development funding was good, it neglected social development projects and focused on infrastructure spending; (3) stakeholder capacity building was crucial for free, prior, and informed consent but awareness and capacity could have been raised further; (4) the role of the moderator is important in getting through unsustainable or impractical outcomes; (5) protests that could have delayed construction were handled by the grievance management system. It cited Newmont representatives who argued for the use of voluntary standards as opposed to mandatory community development agreement standards, which could "create a 'lowest common denominator' system where the mining sector performed only to the bare minimum required." ${ }^{149}$

At least two reviews of NADeF have been undertaken, one by a Ghanaian consultancy, Community Empowerment Associates (CEA), and another by a group of Newmont employees. ${ }^{150}$ CEA found a number of positive findings, including NADeF's participatory governance and management structure, the reliability of funds transfer as specified in the agreement, the fair and verifiable disbursement to communities, the relevance of the investments, and the handing over of the capital projects to the local District Assembly. ${ }^{151}$ However, it also found a number of areas for improvement, including stakeholders who were unfamiliar with the governance structures of NADeF and in general need of further human resource development, limited cooperation in projects across communities, delayed project submission and approval, and poor government support to NADeF initiatives. The authors found it hard to evaluate the overall impact since baseline data had not been collected along the six focus areas. ${ }^{152}$

Newmont employees Danso et al. noted, citing an earlier unpublished study by one of the authors, that the community had high levels of acceptance of the mining project in 2010 , with $93 \%$ of people welcoming development. ${ }^{153}$ However, they found that the community may have had unrealistic expectations such as universal employment for local workers, that unskilled people would be trained, and that local businesses and labour would be preferentially contracted and hired. Residents justified these high expectations reasoning that the community bears the costs of mining, that 
corporations owe it to society to have a CSR strategyß, and that they perceived that the community has some ownership over mineral resources. The researchers suggest that the community saw Newmont as a surrogate or de facto government. The accomplishments of NADeF described in the study were around the successful delivery of development projects. In terms of challenges, beyond the conclusions of CEA, the authors found discord between the NADeF Board of Trustees and the Forum, capacity constraints by the local District Assemblies, and the non-performance of SDCs. ${ }^{154}$

\subsection{INDEPENDENT FINDINGS}

The Ahafo BAs have also been examined, usually peripherally, as part of a handful of independent studies looking into different aspects of company-community relations.

NGGL has faced a number of challenges since the Ahafo mine's inception. First, the mining project likely involves the displacement of an estimated 20,000 community members-mostly subsistence farmers with uncertain and incomplete land replacement and/or livelihood assistance. ${ }^{155}$ The completed southern phase of the mine has already required resettlement of 1,700 households, totalling 9,575 people, ${ }^{156}$ and an additional 10,000 people are expected to be displaced by the planned Ahafo North phase, ${ }^{157}$ if constructed. Second, concerns over land expropriation, water rights, and environmental contamination have resulted in many community protests opposing the mine. ${ }^{158}$ Third, there are insufficient property rights protections in Ghana. ${ }^{159}$ In terms of net impact, Ghanaian researchers Lawson and Bentil surveyed two communities affected by the Ahafo mine (and BAs) and found that self-reported satisfaction with public service as well as income and appraisal of the economic situation had, if anything, gotten worse since the mine's inception in 2006. 160

While the BAs are largely silent on the issues of resettlement and compensation, these have been critical issues affecting company-community relations. According to Mares, it was debateable whether expropriation of land during Newmont's initial period was conducted in accordance with Ghana's State Lands Act of 1962, and the "constitutional principle of prompt, fair, and adequate compensation was questionably applied in this context." ${ }^{\prime 61}$ For much of the land transferred to the mining company, community members only received compensation for crops and buildings, rather than receiving compensation for the value of all land held, including fallow land. ${ }^{162}$ When construction of the first phase of the mine began, Newmont was criticized for inadequately compensating displaced people; Newmont, instead, followed national law, which was regarded as insufficient, as well as precedents set by other companies. ${ }^{163}$ This practice was below Newmont's own CSR standards. ${ }^{164}$ In the end, the World Bank's International Financial Corporation (IFC)'s \$125 million loan to Newmont in 2006 led to an improved compensation scheme, ${ }^{165}$ and the devastation caused by the inadequate level of mandated compensation may have prompted NGGL to negotiate BAs with the Ahafo communities. ${ }^{166}$

Henisz described the relationship between Newmont and local communities as not positive during the development of the Ahafo South concession. Community members felt that police were using unwarranted force and arrest; there were environmental impacts from an accidental waste discharge in 2006; and there were several allegations, including that the mine had resulted in increasing malaria and that NGGL was misallocating jobs and favouring chiefs and their allies for work contracts and benefits. ${ }^{167}$

The challenges of the Ahafo context have had further effects beyond the issue of compensation. The Ahafo communities considered Newmont as a surrogate government, according to Lawson and Bentil. ${ }^{168}$ Arce and Miller note that while some groups do protest the Ahafo mine because of its environmental impacts-including the cyanide spill of October 2009169-those Ahafo community members who are benefiting from the mine are not opposed to the mine or protesting for closure but are rather raising grievances concerning the need for better use of finances, respect for rights, and distribution of services. ${ }^{170}$ This is in contrast to many Latin American contexts, where protests have galvanized into strong anti-mining movements. 
Also peripheral to the Ahafo BAs is implementation issues surrounding Ghana's Mineral Development Fund, which is the percentageof royalties earmarked for community development. Dupuy found that corruption, lack of accountability and transparency, and a lack of monitoring and evaluation have resulted in those royalties having a sub-optimal impact. ${ }^{171}$ Chiefs, who are allocated $25 \%$ of the funds, are viewed with much deference in Ghana, and so they are often not challenged regarding decisions concerning the use of funds. ${ }^{172}$ This issue of the potential for local elites to benefit disproportionately would come up in many of our conversations.

\subsection{RECOGNITION AND AWARDS}

Despite the range of community grievances noted by researchers, the Ahafo project has led to Newmont and NGGL winning recognition and numerous awards relating to environmental and corporate social responsibility.

In 2014, NADeF was awarded the best social impact investment vehicle in Africa by the European Union's African Chamber of Commerce in 2014. ${ }^{173}$ In 2015, the Ahafo mine was recognized as the mining company of the year by the Ghana Chamber of Commerce. ${ }^{174}$ Most recently, in 2017, the National Philanthropy Forum recognized NADeF as the Corporate Foundation Philanthropist of the Year at Ghana's 2017 National Philanthropy Excellence Awards. The purpose of the award was to recognize "the long-standing contribution of NADeF toward improving lives and supporting sustainable socio-economic development in the communities neighbouring the Ahafo mine."175

In the 2017 Corporate Responsibility magazine, Newmont was the highest-ranked natural resource extraction company, at 43rd (down from 16th place in 2010). In 2007, the firm had been the first gold company to join the Dow Jones Sustainability World Index, ${ }^{176}$ which covers the top $10 \%$ of the 2500 largest companies in the Dow Jones total stock market index in terms of "economic, environmental, and social factors." ${ }^{177}$ 
The methods used in this research reflect the primary purpose of this report: to study the implementation of the Ahafo BAs with a focus on what aspects can be improved to enhance outcomes for community members.

Our method of inquiry is a single case study, which allows us to get a "holistic" view of the different aspects at work in the Ahafo BAs. ${ }^{178}$ Thus we sought a comprehensive perspective from all sources available, including previous research, news articles, company reports, data analysis, and individual and group interviews conducted in the field with community members, representatives from traditional authorities, the company, and local and national government. This study qualitatively weighted the perspective of the affected communities over other stakeholders. This means that, though the authors spoke to stakeholders with a wide range of perspectives, the primary viewpoints of interest are those of the community. Stakeholders other than community members were interviewed not only to get their unique perspectives but also to triangulate the primary issues raised by the community members. Other weightings might have favoured different constituencies, and therefore would have embedded the research in a different objective function. For example, if we were to over-weigh the views of the mining company, the implicit objective function of the BAs would be "How can I minimize disruption to the mining activity at the lowest cost?" and if we were to over-weigh the views of the national government, the objective function might have been "How can I maximize an equitable contribution to national GDP from a disruptive but promising local economic activity?" We think both of these framings are extremely valuable, and indeed it is a strength of the BA approach in itself to balance these different perspectives, but it is beyond the scope of this report to tackle all three perspectives.

For those readers of this report who are not members of the affected communities themselves, but rather who are seeking to learn from the Ahafo experience, we note that the Ahafo BAs may constitute a "critical case" for studying implementation of community benefit agreements. The Ahafo BAs have a number of advantages for serving as a critical case, which would allow some deductions or generalizability to be inferred from the findings. ${ }^{179}$ First, as noted earlier, it is considered "best practice" for international BAs in low- and middle-income countries, with Newmont having earned substantial accolades for its work with communities including in Ghana, and so to the extent that we find challenges here they are likely to be found elsewhere. Thus, we will learn from, and scrutinize, an environment that is regarded as being on the forefront of leading practices, which will give us a greater chance of learning new insights. Second, there is a relative abundance of material already written about Ahafo, so the existing study can be put into that broader set of findings, and our observations-conducted during a brief window of time during the Ahafo BAs' implementation-can draw from that history of study and data collection.

Our methodology will not allow us to determine causality between the Ahafo BAs and sustainable development outcomes in the affected area. As CEA noted, since there are no BAseline data for the BAs, let alone for a "control" set of households (not affected by the BAs and therefore able to serve as an indication on the "counterfactual" outcomes in a world without the BAs), it is challenging to measure the success of the BAs themselves. ${ }^{180}$ Thus we are limited to being able to identify candidate areas or processes for improvement. This may leave the impression that the paper is inherently critical of the implementation of the BAs, which we try to balance, but that is because we are constrained in our methodology given the lack of any BAseline data that can allow for any meaningful overall evaluation. A related CIRDI project is investigating monitoring and evaluation in BAs with the goal of giving communities and companies guidance on how to collect data both to manage the implementation of, and evaluate, BAs.

Before conducting interviews, two members of the study team completed a scoping visit to the Ahafo region to determine interest in a wider study. During this visit, we found broad-BAsed support 
from the community to the national level. Following the scoping visit, we developed a semi-structured interview protocol and reviewed all of the information on the Ahafo BAs that we could find.

The field research itself occurred in the second half of May 2017. There were two field teams, one of which had a female team member. Each team had a community research manager (community members not employed by the mine) to assist with translation for those researchers who did not speak Twi. A total of 109 people were interviewed, with interviews being conducted in both English and Twi. Of those interviewed, 72 interviewees were men and 37 were women; this gender imbalance, while unfortunate, is reflective of gender ratios among those holding leadership positions in the Ahafo context. As recommended by other researchers with experience working in this jurisdiction, interviews were documented using hand-written notes, and without making any audio or video recordings.

Interviews were conducted in the Asutifi North District, the Tano North District, and in Accra. The interviews were done in every officially affected community, as well as the neighbouring communities of Hwidiem, which is affected by the Ahafo Mine but does not have status in the BAs, and Sunyani. People interviewed include chiefs, sub-chiefs, elders, queen mothers, members of communities covered by the Ahafo Mine BAs, members of communities not covered by the Ahafo BAs, government representatives, District Assemblymen, NGGL and Newmont employees, members of civil society and NGOs, development agencies involved with Ahafo BA implementation, Resettlement Negotiation Committee members, Sustainable Development Committee members, male and female farmers, youth representatives, community members with disabilities, district planning officers, NADeF members, and Forum members. In addition, group interviews were conducted in the officially affected communities of Terchire, Afrisipakrom, Adrobaa, and Ntotroso.

Finally, interview results were verified with community stakeholders, then analyzed. After all interview data had been collected, a qualitative interpretive analysis was done. The researchers, in tandem with the community-BAsed research managers, identified fourteen insights, which are organized to answer three general questions, the first two of which we formulated before the field research was undertaken, found below. The results were interpreted as answers to these questions and, using this interpretation, the researchers identified topics for discussion for the 2018 review of the Ahafo BAs, as well as topics for new BAs in Ghana and elsewhere.

One, how do community members (and the government, the company, and other actors) regard the Ahafo BAs' performance and implementation, with respect to, among other topics, performance on the terms of the agreement, representation and participation, process and administration including grievance mechanisms, effective use of funds, adaptability to unforeseen issues, and communication? This was analyzed in two ways. First, the researchers looked at the general performance of the BAs as a whole. Second, the researchers looked at the performance of each of the three agreements individually.

Two, what are the challenges and barriers that have been experienced with regards to the Ahafo BAs' implementation and performance, and how did these arise? We sought to put the challenges into a richer context so as to be able to better understand the root causes and thus suggest potentially more helpful solutions.

In addition to these two main questions, we sought to explore how company-community relations were doing outside of the scope of the BAs. Early on in the fieldwork, we recognized that the BAs constituted just a formalized subset of company-community relations in the Ahafo context, and we did not want to be restricted to just this window in interpreting how the BAs were working. The analysis for this question includes exploring CSR activity, such as the Ahafo Linkages program, and mitigation strategies, that are not included in the BAs.

Regarding ethics and sensitive information, all research conducted for this report was done in accordance with Simon Fraser University's Ethical Conduct for Research Involving Humans, the TCPS2. As mentioned above, interviews were carefully selected to include differing perspectives on the Ahafo BAs. To assure uninhibited responses and accurate information, interviewees were assured 
of confidentiality. As a result, there is no attribution of information to individuals and the interview list is confidential. Excerpts of the report's factual findings were shared with community leaders and Newmont for feedback before publication. In addition, a draft of the report was shared with subject matter experts around the world. That said, none of those groups retained any editorial control over the final version. 
In this section we describe the findings from the field visit to Ahafo, which are derived from individual and group interviews as well as subsequent feedback and material provided from Newmont and community leaders. We split the findings into five sub-sections. First, we explore the perspectives around the negotiation and renegotiation of the Ahafo BAs. Second, in the process of coding the entire set of interview data, we identified a number of insights that do not apply to any particular agreement, but instead to all of them or their collective implementation. In the second subsection we collect those insights. Finally, in the third through fifth subsections we describe findings related to the relationship, employment, and development foundation agreements respectively. We refrain from making recommendations until section 8.

\subsection{NEGOTIATION AND RENEGOTIATION OF THE AHAFO BENE- FIT AGREEMENTS}

Understanding the negotiation process for the original agreements from 2008 and the revised agreements of 2014 can inform the study of their implementation. Negotiations involve the mediation of different parties' points of view and priorities, and often result in unexpected compromises and concessions. For instance, lowering the local employment target in the 2014 EA was a source of grievance for most community members interviewed; this makes understanding the renegotiations especially important. Since we did not find any documented community perspectives on the negotiation of the Ahafo BAs, we interviewed various stakeholders about the negotiations during our visit. Moreover, our recommendations concerning the BAs should be considered taking into account how they might be renegotiated in practice. According to NGGL, negotiations for the next version of the BAs are scheduled for 2019.

As explained by representatives of NGGL, discussions between Newmont and various chiefs of the mining communities began in 2005, before mining operations began in 2006. The Social Responsibility Forum was also established in 2006, two years before it was formally established by the SRA. Various NGGL representatives say that the BAs were the result of demands by the chiefs for the company to do more for the communities than what was required by domestic law.

The moderator of the Forum led the negotiation of the BAs between 2006 and 2008. These negotiations were conducted in Twi.

\subsubsection{Objectives of the Ahafo BAs}

The 2008 agreements set out objectives that include contributing to the communities' social and economic development, ${ }^{181}$ ensuring that the local communities benefit from the mining operations, ${ }^{182}$ and meeting community concerns regarding the lack of employment in the local community. ${ }^{183}$

Multiple community interviewees recalled that employment creation was a key concern of those community members who were aware of, or participating in, the negotiations. One community representative and former Forum member noted that community members and representatives who were involved in the negotiations of the Ahafo BAs had a strong focus on this objective and, as a result, ignored or paid comparably less attention to other critical issues including the potential for indirect employment creation and business opportunities, and the need to protect against the mine's potential adverse impacts on the environment. The community's narrative was, in effect, "land for jobs." On the other hand, according to both NGGL representatives and one community member interviewed, the CEO of Newmont is said to have initiated the notion of the $\$ 1 /$ oz royalty and $1 \%$ of net profit transfer to the community. 


\subsubsection{Challenges to a Fair Deal During the Negotiations}

Some community members were happy with the negotiation process, noting that the deals signed were the result of a "shared process" and that particular constituencies, such as the youth, were represented. Yet interviewees suggested several broad challenges to ensuring the equal, meaningful participation of community representatives during the negotiations of the 2008 and 2014 agreements. Although they were brought up separately during the discussion of the negotiation and renegotiation, these challenges are BAsically deficiencies relating to the functioning of the Forum and the Ahafo BAs more broadly, and they reappear in that context later in the report.

First, the Forum's Standing Committee was described as taking a dominant role in negotiations. Forum members were present for the negotiations, although one member of the Forum remembered that the Standing Committee would drive negotiations in the absence of other Forum members, and then present proposals for agreement at Forum meetings. Most of these proposals were accepted by the Forum. According to one former Forum member, little opportunity was allowed for other members of the Forum to contribute to the negotiations.

Second, the Forum's moderator allegedly did not always allow opportunities for different community representatives to contribute to the negotiations. One member of the Forum at the time of negotiations recalled that the moderator acted as an authoritative figure during negotiations and during Forum meetings more generally. The moderator was regarded as having relevant technical skills and knowledge. However, according to two former members of the Forum, the moderator did not always make this expertise available to participating community members, often ignored the views of "ordinary" community members (i.e. community members other than chiefs) participating at the Forum and was at times perceived to be on the side of Newmont.

Third, there was some intra- and inter-community tension that prevented full participation. One Forum member saw NGGL's engagement as being focused on chiefs and other community power brokers, effectively ignoring grassroots perspectives. The member described this using a local proverb: "when you cut the head off a snake, all that is left is the rope." This was explained to mean that the interviewee viewed Newmont's engagement with community leaders as a strategy to silence the majority and greatly reduce the number of community interests needing to be satisfied before an agreement could be concluded. As discussed below, one member of the Forum at the time of negotiations recalled that the lawyers provided by NGGL only assisted the chiefs, leaving other community representatives to their own devices. Existing power relationships could exacerbate this challenge at the negotiations. The same former member of the Forum recalled that chiefs participating in the negotiations tended to dominate the other community representatives. For example, when community representatives pushed for compensation for more than just houses and crops, they were told by the chiefs that the land belonged to the chiefs, not the community members. Members of one community also noted that negotiating one agreement between ten different communities made it hard for individual communities with differing priorities to be heard, as they would have nine other communities to argue with. This created pressure to agree with the majority.

Fourth, community members and even community representatives themselves often expressed the assumption that those representing community interests during the negotiations may not have been adequately educated or sufficiently knowledgeable about mining and agreements to adequately represent community interests and understand what was being negotiated. On the other hand, one group of community leaders noted that there was two months of training before the agreement was signed. Another group of leaders was confident that those who signed the agreement understood what they were signing, and a third group stated they knew at least when the negotiations were going on.

Finally, there could have been better consultation from community representatives to their own constituents. Many community members who were not members of the Forum stated that they were not consulted by Forum members about negotiations with Newmont in the lead-up to the 2008 and 2014 agreements. Community members not involved in the Forum or other deliberative 
processes tended to only hear about the Ahafo BAs after they had been signed. This led to community members being "shocked" by what was contained in the renegotiated agreements in 2014. Some community members were not sure if their representatives actually represented their interests during negotiations or not.

\subsubsection{The 2014 Renegotiations}

As with the 2008 negotiations, several community members thought that the 2014 agreement negotiations largely took place through the Standing Committee, rather than the Forum itself. The interviewees also noted that the agenda for renegotiation was set by the Standing Committee the day before Forum meetings; in practice this meant that Forum members not part of the Standing Committee were often not able to raise issues, and were instead merely informed as to what the Standing Committee had already "decided." According to the minutes of the February 2014 Forum meeting to approve the amended agreements, which were shared with us by Newmont, the final drafts adopted by the Standing Committee from December 2013 were approved with only minor corrections to the names and titles of some members. ${ }^{184}$

The renegotiation was regarded as leading to less favourable outcomes for the communities. Specifically the reduction of the required percentage of community citizens within the company's national workforce from 35 to $24 \%{ }^{185}$ was seen as being won by the company without the community gaining anything in exchange. One interviewee noted that this reduction was conceded by the community even though the percentage of net profits payable to the Foundation remained at $1 \%$ of Newmont's net pre-tax profit after consideration of all inter-company transactions; that interviewee suggested that this concession by the community may have been given because of the dominant role of the moderator. Community members were described as being "shocked," "not comfortable" and "hav[ing] all sorts of complaints" about the reduction in percentage, which appeared to be the subject of widespread frustration and grievance. Dissatisfaction with lack of employment for community members more generally was also one of the BAses for subsequent advocacy and protests that took place in August 2017. ${ }^{186}$

One local civil society organization noted that information about the negotiations in 2014 was not made available publicly; instead, the organization used its networks to find out about the proposed diminution from 35\% to $24 \%$ before the 2014 agreement was signed. The organization then wrote to the chief of one of the communities and to district assembly members, among others, to object. Subsequently, according to a member of the organization, a local member of parliament did not attend the meeting and that particular chief refused to sign the agreement. (The version of the 2014 Local Employment Agreement reviewed for this study features one signature by the Chief of Kenyasi No. 1 on behalf of all communities; four chiefs-from Yamfo, Ntotroso, Susuanso, Wamahinsosigned as witnesses.) $)^{\mathrm{i}}$

A representative from a local organization focused on the rights of people with disabilities noted that the Forum lacks anyone charged with representing the rights of people with disabilities, and while the local organization did not exist during the initial negotiations, the organization was operational when the renegotiations took place. To the knowledge of the organization, no one sought to include the perspectives of people with disabilities in the make-up of Forum members.

We reviewed the "Agreement Review Report," shared with us by Newmont, which contains the recommendations from various stakeholders, the recommendations taken by the Standing Committee, and the decisions taken by the Forum. The document shows the Standing Committee balancing stakeholder demands-for example, not agreeing to a proposal to replace youth and farmer representatives with Members of Parliament, nor one to increase the number of NGO or women representatives; it even rejected a Newmont suggestion to have the Standing Committee manage employment and galamsey, indicating some independence from the company. ${ }^{187}$ Regarding

iv A representative from Newmont, responding to the draft factual findings for this report, noted that the community members decided for themselves which individuals would be appropriate to sign the document on behalf of the community. 
the renegotiation of the employment target, the report indicates that many of the stakeholders advocated for a higher employment target, but the Standing Committee recommended, and the Forum agreed, that new criteria would be proposed by the moderator. ${ }^{188}$ There was also advocating for better employment reporting, but the Standing Committee did not agree to the suggestions. ${ }^{189}$ A variety of proposals advocated increasing the payment formula, and the Standing Committee agreed to refer the proposals to the company to come back and decide. ${ }^{190}$

Some requested amendments to the Ahafo BAs seemed to be more about ensuring political support and rent-seeking than the efficiency or equity of the institutions created. One request from Newmont to set aside some payment of the funds for an "Annual Donation to the Overlord (Otumfuo)" was proposed by the Standing Committee at $2 \%$ of funds, and approved by the Forum under the cultural heritage category of expenditure (but noted that it would not appear in the agreement as a clause). ${ }^{191}$ The Otumfuo is the traditional ruler of the Ashanti kingdom. Other suggestions, such as an "end of service package" for SDC and Forum members as proposed by SDC members, relate to the value of the positions set up through the Ahafo BAs. ${ }^{192}$

\subsubsection{Support Available to Communities}

While there was variation in community opinions regarding the availability or not of legal assistance for community members, the balance of opinions, including those of Newmont, was that there was one lawyer (or perhaps two) for the communities who were present during the signing of the agreements in 2008 and 2014. Interviewees from Newmont explained that the company paid for the community lawyer but left the decision of which lawyer to engage to the community. According to interviewees from both Newmont and the community, no other forms of technical experts were made available to the community for the purposes of the negotiation. Members of one community noted that the lawyer for the communities did not consult separately with representatives of each community, because the lawyer was tasked with representing all ten communities collectively.

Community interviewees noted that the lawyer's role focused on reading and explaining in Twi language what the draft agreement said for community representatives, rather than providing advice or seeking to advance the concerns or ideas of community representatives in the negotiations. This was confirmed by Newmont who explained that the lawyers were brought in after agreement had been reached to put the agreements in writing. Such an arrangement would likely leave the chiefs to fend for their own without any professional advice when negotiating the substance of the BAs; this would fall far short of international best practices, which underline the importance of communities being adequately informed and equipped with the necessary expertise to negotiate benefit agreements with private sector actors. ${ }^{193}$

One community representative at the Forum at the time of the negotiations recalled that the lawyers were not introduced to, and did not confer with or advise, community representatives at the Forum other than the chiefs, though a Newmont representative noted that "[t]he lawyer provided the interpretation service at the Forum[,] where all members including community representatives were supposed to benefit from his services." If true, this imbalance in access to legal assistance between the chiefs and all other community representatives at the Forum would have undermined efforts to increase participation and access by non-dominant community groups, such as women and youth. This imbalance is also reflected in the fact that the 2014 EA and RA are signed by one chief presumably on behalf of all ten communities, and witnessed by four more chiefs, but are not signed by any other community representative participating in the Forum. 


\subsection{GENERAL IMPLEMENTATION OF THE AHAFO BAS}

This section describes the implementation experience of the Ahafo BAs that are common across the different agreements or related to the collective project.

\subsubsection{Varying Experiences of Communities}

The Ahafo BAs, and the mine's operations more broadly, affect and involve a range of different communities, who have different characteristics and priorities, and who experience the impacts from the mine and the BAs in different ways.

Interviewees from communities located within the active Ahafo South mine area shared first-hand accounts of adverse environmental and social impacts of the mine, but also of opportunities deriving from the mine (including local employment and NADeF projects). Members of one satellite community, located some distance from the community town with which it is formally attached, described bearing the brunt of the nearby mine's environmental impacts, including potential or actual disruptions to their access to water, food, education, and other essential services, while having less exposure to potential benefits offered under the BAs due to their geographic isolation. In addition, members of one community argued that its members should be entitled to more, or at least an equal share of, jobs at the underground mine, given that it had born the majority of the social and environmental impacts from the existing mining operations, which include impacts on local farming practices and livelihoods. They also considered that northern communities who had not yet experienced significant impacts to be less entitled to the opportunities the BAs offered for the same reason. According to the minutes of the February 2014 Forum meeting, the Ahafo South chiefs "raised the issue about the stopping the Ahafo North Communities from receiving funds from the NADeF." 194

Members of northern communities, on the other hand, tended to discuss their anticipation of the mining activities in the future. One community leader from the North was satisfied with the implementation performance of the BAs, noting that the community's expectations were being met. Many interviewees were impatient for the mine activities to reach them, in part because they perceived mining activities as bringing increased opportunities for employment and economic stimulation, and believed that community members in the South had greater access to these opportunities thus far. Other community members located in the North perceived community members in the South as having greater access to mine-related jobs because there are more people in the South who have already undergone training.

Another set of communities not mentioned in the BAs, and thus less well positioned to seize opportunities afforded under the agreements, are those located just outside the concession area, but who are still affected by the mine. One prominent example is Hwidiem, a community town located near Kenyasi No. 2, which unsuccessfully sought to be included in the BAs at their inception, and whose community members accordingly could not access NADeF projects or preferential employment. One interviewee, BAsed in Hwidiem, lamented that the town experienced some of the negative impacts of mining-including increased population due to an influx of people seeking mine-related employment and proximity to environmental damage_-but without receiving any positive opportunities under the BAs.

\subsubsection{Varying Experiences Within Communities}

Different segments of the communities also expressed different levels of satisfaction with the performance of the Ahafo BAs. Not surprisingly, individuals who personally or professionally benefitted from the BAs tended to be more satisfied. Chiefs and other opinion leaders participating in different decision-making processes set out in the BAs tended to be pleased with them, while also voicing concerns or suggestions for improvement. Contractors of the mine also saw the BAs as 
working well, even if they had concerns about the operation of procurement processes. Members of one community stakeholder interest group felt financially supported to shift the focus of their organization to one that better corresponded to their needs, and generally felt content with the operation of the BAs, despite noting that less than half of their articulated concerns were articulated by that stakeholder group's representatives at the Forum. In addition, those community members who had financially benefitted from the company's CSR interventions also tended to view the BAs (and the presence of the mine more generally) in a more favourable light.

On the other hand, those who felt ignored or marginalized by the processes were less satisfied with the BAs. A representative of people with disabilities felt that their perspective was excluded from the Forum and other deliberative spaces and felt accordingly dissatisfied by the operation of the Ahafo BAs. Community members, especially those who had been resettled, those whose wishes to be resettled were ignored, and those located in less visible satellite communities or outside of the mine area were dissatisfied with the BAs. These community members generally considered it unlikely that such agreements would lead to better outcomes for them. Chiefs in one town felt frustrated by the company's failure to recognize them as the legitimate representatives following a leadership dispute, and failure to grant them access to the Forum. (Newmont noted this dispute is before the courts and they were waiting for the outcome.) One community member also thought that the BAs were "really not working" because benefits like scholarships seemed to be less prevalent now than at the beginning of the mine. Representatives from the District Assembly also had concerns, lamenting the lack of coordination between SDCs and the District Assembly needed to ensure coherence between NADeF-funded development projects with the District Assembly's local development plans.

\subsubsection{Community Awareness of the Ahafo BAs}

The study team observed varying degrees of understanding among community members regarding the BAs. No interviewees-including chiefs, opinion leaders, and other community members participating in processes established by the BAs-said that they had actually read the BAs. (The one segment of the community that had previously paid close attention to the BAs' contents was the chiefs who had been present at the negotiations, who had the BAs explained to them by the lawyer.) Chiefs from several communities acknowledged that they owned copies of the BAs but had not actually read them; some chiefs and opinion leaders explicitly noted that they had a low level of understanding of the BAs.

Interviews with community members not involved in any of the BAs' processes demonstrated a far lower level of familiarity with the BAs. Interviewees from three different communities had not heard of the BAs at all, and some interviewees had not heard of the Forum or the SDCs. One interviewee described the BAs as being between the chiefs and Newmont, and therefore not concerning the majority of community members.

\subsubsection{Information Sharing and Communication}

The BAs establish many committees and processes that are designed to enhance communication between the communities and NGGL. Despite these initiatives, the majority of interviewees who spoke about community-company information sharing and communication expressed dissatisfaction. In describing their reasons for this, community members alleged that information about discussions at the Forum is not consistently made available to community members who do not directly participate, and that community queries to NGGL about issues like local employment numbers are sometimes handled in an unhelpful way. One interviewee noted that Newmont's responses to such queries are not "satisfying" and often involve asking the community for evidence, when such evidence may only be accessible by Newmont, such as for break-downs of local employment data. Another noted that requests for information regarding local employment took a year before NGGL provided the relevant data. (A Newmont representative stated that the process was a Forum-led validation exercise with quarterly updates.) Another interviewee noted that Newmont information 
offices were not a reliable means of communicating with the company. Although located in each community town, they were not always open and did not have the information sought by community members.

Representatives from NGGL also noted that it is difficult to reach the grass roots of each community, though highlighted the Community Consultative Committee's work in connecting Newmont with community perspectives. They also confirmed that NGGL does not monitor whether Forum representatives are meaningfully consulting within their community. Finally, the company representatives noted that NGGL's presence in the communities has reduced over time, with community relations staff being reduced from 140 to 40 over a six-year period.

\subsubsection{Barriers to Articulating Grievances}

Meaningful participation also requires the absence of pressure and intimidation, with community members having the confidence to freely communicate both their priorities and their grievances. Several community members described barriers to community members articulating their grievances in practice. These, whether or not founded on legitimate apprehensions, included that avenues for complaints were closely affiliated with Newmont and with chiefs, such as the Forum, or the Complaints Resolution Committee, whose process requires that any complaints from a community town must be lodged via the chief/Omanhene of that town. ${ }^{195}$ Complaining would therefore earn a person the reputation of being someone "who talk[s] too much." For instance, a Forum member who raised concerns about the Forum's governance and compliance with the Relationship Agreement said he is now seen as a "bad boy." Newmont representatives noted that they have a separate complaints and grievances mechanism with public reporting.

Those who are reliant on the mine for employment are reluctant to draw attention to themselves for fear that they will lose their position. One interviewee asked rhetorically, "Why would they open their mouth? If they did it would be shut up." One employee of a contractor to NGGL was allegedly told by their employer to choose between working for the contractor and speaking out about community grievances with the mine. (Newmont representatives noted that their code of conduct prescribes sanctions against anyone who prevents someone from speaking up.) Similarly, community members who aspire to benefit from Newmont's operations-or have their family members benefit-are also reluctant to raise legitimate grievances; for instance, one community member expressed detailed grievances regarding how he was compensated as part of the resettlement process before noting that he had stopped pursuing the resolution of the grievance because "I don't want to destroy my children's future."

\subsubsection{Barriers to Meaningful Community Participation}

The BAs create various entities and processes to encourage participation by members of the communities in decision-making regarding the allocation of benefits, and to communicate with the company. For example, the Forum, in addition to having two traditional authority representatives from each town also has six representatives of "women groups," ten for youth, two for non-governmental organizations, and two for "farmers representatives."

These participatory entities and processes offer the potential for increased involvement by different segments within the communities, though much comes down to how differing levels of experience, education, language skills, and other sources of inter-personal power and influence are resolved during interactions. What may appear as a process weighted heavily towards ensuring opportunities for community members to contribute to decision-making may turn out to be the opposite if such power relations make it difficult in practice for different actors to advance the interests of the people they are charged with representing.

Many interviewees shared accounts of power imbalances undermining the ability of the BAs to facilitate meaningful community participation. Three examples are highlighted below. 
The first example is Sustainable Development Committees (SDCs), which are the community-BAsed committees that are supposed to decide how to spend NADeF funds after consulting with their constituents. In practice, there was a strong perception that some of the SDCs were often either unable or unwilling to adequately consult with community members, and instead chose projects for NADeF funding themselves-despite the apparent requirement that SDCs submit attendance sheets of community members present at meetings along with projects for approval. Some interviewees noted that youth representatives are often silenced by chiefs at SDC meetings. Other interviewees noted that community members might have more luck holding the attention of their SDC if Newmont representatives were present at meetings between the SDC and the community, suggesting the accountability of the SDC is to NGGL rather than to the community. NADeF has decided that in the future, staff will sit in on community meetings to ensure they are following the provisions in the DFA.

A second example is the Forum. The Forum's structure included representatives from different segments of the community but in practice was perceived as being dominated by the moderator and the Standing Committee, which regularly set the agenda of meetings. In addition, the presence of chiefs could be problematic. On the one hand, chiefs were regarded as too powerful for other participating community members to contradict; on the other, some chiefs lacked the language skills or confidence to organize collectively and resist proposals that were not in the interests of the community. Youth representatives participating at the Forum, among other entities, also often felt silenced or powerless when seeking to advocate for greater information sharing with, or other opportunities for, youth; this further entrenched the perception that such processes did not always create spaces for participation by different groups. Community members not participating at the Forum also felt that Forum members did not regularly update communities regarding what occurred at each meeting; this made it harder for them to have their perspectives represented at Forum meetings.

A third example is the community citizen validation process under the EA. This process was designed to ensure that jobs reserved for community members were not allocated to outsiders. Yet community members interviewed often believed that such jobs were regularly allocated to outsiders, and that chiefs self-interestedly used this process as another leverage point for personal gain, rather than allowing the process to achieve its aim.

In each example, the challenges to ensuring that community members can participate in and influence these entities and processes lie, at least in part, in the dynamics within the communities themselves. Newmont is thus perceived as trying its best to encourage participation but being stymied by local dynamics outside of its control, including powerful, self-interested chiefs. One community member considered the problem to be tied to the fact that chiefs and opinion leaders are too powerful, and often do not represent the broader interests of the community. Another noted that the chiefs derive influence from their formal ownership of stool lands. They were thus described as facing a conflict of interest between their formal role in representing the community (which should include ensuring the equitable disbursement of benefits, such as contracting work, among community members) and their de facto incentive to seek to benefit personally. One community member summed this up by saying, "if you are a chief, [you should] do chief work, not contractor work". Other community members echoed this sentiment, noting that the stream of benefits had shifted from being "for the community" to being "for the individual."

Other challenges stem from community perceptions regarding the neutrality of entities and processes established by the BAs. Various committees were regarded as being "sponsored," by Newmont, and featuring chairs aligned with the company. One group of interviewees also viewed NADeF as a partner of the company rather than the community. One interviewee, musing on these challenges, proposed that such entities be funded by external parties, such as bilateral donors, to avoid a situation where the company, as the one source of funding, has "greater control over who should be the leader of the house." 
These entities and processes have created a formalized buffer between challenges linked to power dynamics within the community, on the one hand, and Newmont, on the other. The unfortunate result is that Newmont appears to be acting responsibly by encouraging participation, but community members themselves are often unable to meaningfully participate in key decisions. Local powerbrokers exploit the gap.

\subsection{IMPLEMENTATION OF THE RELATIONSHIP AGREEMENT}

Here we review findings regarding the implementation of the Relationship Agreement (RA) (and, before 2014, the Social Responsibility Agreement or SRA). The primary facts around the RA have already been mentioned in section 3.2.1, above. A stated aim of the RA is "to provide the Community with the opportunity to participate in the Company's decisions and plans that may affect the Community and its environs." 196 This is bolstered by the agreement's cardinal principles, which refer to consultations, openness and the sharing of information. ${ }^{197}$ These aims resemble an evolving set of international norms concerning the human rights of community members affected by large-scale resource projects to participate in decision-making regarding projects that affect them. These norms include the right to information ${ }^{198}$ and the right to participate in public affairs, ${ }^{199}$ which may also include entitlements for project affected communities to be consulted and to effectively influence public decision-making processes regarding resource projects that affect them. ${ }^{200}$

\subsubsection{The Forum as a Multi-Stakeholder Body}

The Forum's structure provides for the representation of many different stakeholders, and different segments of the community, such as women and youth. Yet as mentioned in section 6.2, above, some community members expressed frustration that, owing to local power structures and the contracting opportunities of the mine, chiefs had too much relative influence on the Forum and were not incentivized to represent the interests of other community members as a whole. One member of the Forum questioned the capacity of some participating chiefs to even follow and understand the substance of discussions at the Forum.

Various community members also expressed concern regarding alleged inadequate consultation practices of Forum members. Community members were concerned that they are generally not consulted regarding specific issues that will be discussed at Forum meetings. Forum members were also perceived as not faithfully conveying what happens at Forum meetings back to community members. Representatives from NGGL also suspected this was the case and expressed concern. One community member suggested that Newmont could apply more pressure on Forum members or community representatives to consult with community members before signing anything on their behalf.

Some community meetings and consultations do occur. Yet one interviewee noted that community members are not motivated to attend community meetings or consultations because they expect that the issues they raise with community leaders will not be conveyed to the Forum. There is a lack of clear information about deliberations at the Forum made available to community members not directly involved, with different Forum members providing information to community members in different ways, and with varying degrees of balance or accuracy. One Forum representative also noted the need for funds for logistical support with community consultations (their requests to Newmont for financial support to facilitate this had not been met).

Certain segments of the communities were especially un- or under-represented. First, the Forum lacks anyone charged with representing the rights of people with disabilities. Requests for the inclusion of the perspectives of people with disabilities, and for support to establish independent offices to enable the group to more effectively advocate on behalf of its members, were either rejected or referred to NADeF. Second, less than one third of Forum members are women. While this may echo the over-representation of men in leadership roles in the communities more generally (and indeed 
in our interview sample), it still undermines the representation of women's perspectives. Third, barriers also existed in the representation of youth perspectives. Some of the youth representatives appeared to be much older than the age bracket they were charged with representing, indicating the potential for a dissonance between the concerns youth have and those noted at the Forum. On the other hand, youth representatives from one community had a different opinion: they considered that the RA was going well, but saw the operation of the EA as having problems.

\subsubsection{Representation versus Delegation}

In any setting, getting substantive progress with a deliberative body of over 50 members is hard work. Some degree of delegation must usually be carried out; this is the case even for parliamentary committees in Canada's legislature. At the Forum, delegation also occurs; looking at the Forum's structure and according to interviews conducted, Forum members seemed to regularly delegate decision-making (whether formally or otherwise) to the Standing Committee and the moderator.

As we described in Section 3, above, the RA establishes a Standing Committee that is charged with acting on the Forum's behalf in emergencies and performing duties assigned to it by the Forum. ${ }^{201}$ The Standing Committee is also charged with receiving and reviewing proposals for review or amendment of the RA, and with making recommendations before such proposals are discussed and voted on. ${ }^{202}$ The Standing Committee comprises 14 people: the Forum's moderator and co-moderator, two representatives from Newmont, four Omanhene chiefs (two from each district), one youth representative, one women's representative, one district chief and presiding member from each district (four total). ${ }^{203}$ While the earlier SRA also included two farmer representatives in the Standing Committee, ${ }^{204}$ this was removed in the subsequent RA.

Several interviewees regarded the Standing Committee as proactively setting the agenda for Forum deliberations and proposals, rather than merely receiving proposals from others and performing tasks on the request of the Forum. The Standing Committee was regarded as being in the practice of meeting in advance of Forum meetings to determine the agenda for such proposals. Interviewees noted that the Standing Committee would often merely inform Forum members as to what it had agreed on. One interviewee said that there had not been a single instance where the Standing Committee had brought something to the Forum that was not subsequently approved by the Forum.

In both the Forum and the Standing Committee, the moderator emerges as an influential actor. The moderatorv was widely regarded by interviewees as highly qualified and playing a commanding role during Forum meetings. While one community interviewee described the moderator as representing the views of the communities well, several interviewees who had experienced interactions with the moderator saw him as overly dominant, and often dismissive of community concerns.

Specifically, a number of allegations were made regarding the moderator's conduct. First, the moderator allegedly created an inaccessible environment, rendering it difficult for community representatives to participate. Forum members were often unable to follow discussions about the "nitty gritty" of the BAs or the law and were not supported to overcome this barrier. The moderator was alleged to "become so superior" and act disrespectfully because of his level of knowledge and experience, such that other Forum members felt intimidated and discouraged from contributing. Second, the moderation was perceived as unfair or biased. Some interviewees said that there had been meetings where the moderator shut down Forum members, or even told them they were not allowed to speak; in one case this was allegedly because the Forum member was affiliated with a civil society organization that was frowned upon by other members of the Forum. Another interviewee recounted another occasion, where youth representatives were told there was not enough time for them to contribute to the discussion and that they should instead communicate their concerns to other committees. Various interviewees regarded the moderator as being too closely affiliated with Newmont and thus not acting impartially. One noted that despite the overwhelming majority of Forum members being community representatives, the Forum was weighted towards the interests of Newmont, who paid for the moderator and co-moderator. Another considered that the moderator was usually in agreement with Newmont regarding issues being discussed. Third,

\footnotetext{
$\checkmark$ We contacted the moderator via email to request a formal interview but did not receive a response.
} 
one interviewee alleged that the moderator had privately changed draft documents after they were prepared by the Forum's Standing Committee.

\subsubsection{Environmental and Social Monitoring}

The RA makes provision for the company and the communities to "identify and develop" a participatory program to monitor the mine's environmental and social impacts. ${ }^{205}$ This is contemplated as an additional measure, separate from "the obligatory environmental/social impact monitoring programmes contained in the Environmental Impact Statement and Environmental Management Plan of the Company"206 that NGGL is required to carry out. According to the agreement, the communities are to select at least three representatives to participate in the participatory monitoring, ${ }^{207}$ and NGGL is to provide training to those who will participate "so that they can understand the processes and be able to draw objective conclusions."

Representatives from NGGL noted that there have been instances when community members have been involved in observing or reporting impacts to Newmont, including regarding noise complaints and galamsey activities. However, NGGL initial attempts to train community members ceased long ago, and a fully participatory process has not yet been implemented. ${ }^{\text {vi }}$ The company noted that it is not currently in the practice of proactively sensitizing community members about the potential for such a process, but does consider community complaints and grievances regarding the impacts of the mine as a form of participatory monitoring. In May 2018, Newmont notified us that a community participatory monitoring framework is "earmarked for development in 2018 and implementation from 2019."

Community interviewees generally noted that they had not heard of any participatory monitoring program at Ahafo but thought it would be a promising opportunity for community members, particularly given memories of the 2009 cyanide spill and the lack of NGGL's clear communication around it at the time. One community member noted the need for sensitization so that people can understand what a monitoring program would involve and why it might be in their interests to participate. Another interviewee also noted the need for more education and sensitization as to the dangers of living close to a mine site more generally. Others highlighted perceptions that community members who monitor and highlight the mine's adverse impacts would be viewed as unfavourable candidates for future jobs with NGGL or its contractors. (One interviewee noted a perception that for a community member who notices a problem, "when you talk about it, it will not end positively.") Further feedback highlighted the need not only for training, but also for access to independent technical experts to help community members, given that monitoring the mine's potential effects is a complex task.

\subsubsection{Dispute Resolution Process}

The establishment of complaints and dispute resolution procedures is important for all stakeholders in the context of a large-scale mining operation. For community members, these processes provide avenues to communicate grievances, seek remedies, and protect their rights and interests. For the company, such processes are an important means of monitoring the performance of the BAs and of company operations more generally, can help to maintain good relations with community members, and, as noted in one study of the mine, can lead to significant financial savings. ${ }^{208}$

The RA establishes a Complaints Resolution Committee for "complaints relating to the implementation" of the agreement that is closely linked to the Forum. ${ }^{209}$ The committee is staffed by the Forum's co-moderator (as Chairman), and four other members of the Forum, whom the Chairman appoints in consultation with at least four members of the Standing Committee (two from Newmont and two representing the community). ${ }^{210}$

vi In May 2018 correspondence with Newmont representatives, we learned that there is a participatory monitoring program on water with representatives from the District Assembly, regional Environmental Protection Agency, Ghana Water Resources Commission, Ghana Water Company, and community representatives. 
The agreement establishes processes for community towns, Newmont, or the District Assembly to lodge complaints with the Committee. It does not provide a process for individual community members to lodge grievances directly. For community towns, complaints are communicated to the committee by the chief/Omanhene of the town. ${ }^{211}$ This would mean that community members aggrieved by the operation of the Forum or other elements of the RA-including when such grievances relate to the influence or behaviour of chiefs-have no choice but to communicate such grievances through their chief. This could be problematic in practice: as discussed above, the influence and power of chiefs within the communities could create a chilling effect and discourage community members to raise complaints.

Representatives from NGGL spoke about dispute resolution with community members more generally as having three stages. First, community members can make complaints or requests for information at Newmont's information offices, located in each town. Second, the Complaints Resolution Committee process can be invoked for relevant complaints (the company representatives envisioned a role for chiefs to "intervene" at this stage and assist with the resolution of complaints). Third, complainants could resort to a "legal process" (presumably this would involve formal litigation and dispute resolution using Ghana's courts).

Despite the various grievances shared by community members interviewed, no interviewees shared experiences about engaging with the Complaints Resolution Committee. Given the challenges that even members of the Forum face in raising concerns, other community members may be reluctant to use this process to raise grievances, if they are even aware that it exists. One recent study also underlined the need for improved grievance and compliance mechanisms (albeit in the context of the administration of the Mineral Development Fund, rather than the operation of the Relationship Agreement) to ensure decision makers remain accountable. ${ }^{212}$

\subsection{IMPLEMENTATION OF THE EMPLOYMENT AGREEMENT}

Here we review findings regarding the implementation of the Employment Agreement (EA). The primary facts around the EA have already been mentioned in section 3.2.2, above. The EA was signed in 2008 with the key benchmark set in section 2.1 (f) of the agreement, which required a minimum of $35 \%$ of the national workforce in the Ahafo Mines, including contractors, to be community citizens. Newmont was expected to raise the threshold to $50 \%$ within ten years of commencing gold production through the adoption of appropriate policy interventions. ${ }^{213}$ Given the density of smallscale farming on the concession area, in essence the agreement was a trade of farm lands (and associated livelihoods) for jobs. The targets under the agreement were not met, in spite of visible attempts to create opportunities for community citizens. Consequently, the minimum requirement for local employment was lowered in the 2014 EA to $24 \%$, with an expectation to reach $35 \%$ within ten years of commencing gold production; the dissatisfaction with that change is described in section 6.1.3, above.

\subsubsection{Meeting the Target}

There is acknowledgement within the community that the mine has created jobs for some people in the community. NGGL makes efforts to comply with the agreement by ensuring that the various communities get a share of the local employment opportunities. In accordance with the agreement, vacancies are published in the communities for qualified people to apply. The company has notice boards and information centers in each community to aid information sharing and to receive feedback and complaints. That said, some community members believed that employers were more interested in hiring their "own people" than employing locals.

Despite the importance of employment to the community, employment figures are generally unavailable online. A local official noted that jobs data are only available when attending quarterly presentations to the community in which PowerPoint slides are used; Newmont did not share those 
presentations when asked. ${ }^{\text {vi }}$ A number of community members believed the numbers were inflated as they included temporary and part-time workers.

We asked for, and received, a copy of the Q1 2017 employment presentation; we report the data below (see Table 6-1). The employment figures presented by Newmont for first quarter 2017 show that the targets set out in the 2014 EA as well as the earlier 2008 EA have been met. According to the data, $41 \%$ of NGGL employees and $43 \%$ of contractors' employees are from the local community. It is not clear whether these figures would hold up if they were scaled by full-time equivalent (which means weighting the positions by whether they are full time, part time, or seasonal).

\section{Table 6-1 NGGL Employment Data ${ }^{214}$}

\begin{tabular}{|l|l|l|l|}
\hline & Sep 2016 & Dec 2016 & Mar 2017 \\
\hline NGGL & 1,029 & 1,041 & 1,049 \\
\hline Non-local & 596 & 620 & 620 \\
\hline Local & 433 & 421 & 429 \\
\hline Local \% & 42 & 40 & 41 \\
\hline Contractors & 2,498 & 2,458 & 2,424 \\
\hline Non-local & 1,488 & 1,307 & 1,389 \\
\hline Local & 1,010 & 1,151 & 1,035 \\
\hline Local \% & 40 & 47 & 43 \\
\hline NGGL + Contractors & 3,572 & 3,499 & 3,473 \\
\hline Total Non-local & 2,084 & 1,927 & 2,009 \\
\hline Total Local & 1,443 & 1,572 & 1,464 \\
\hline Total Local \% & 41 & 45 & 42 \\
\hline
\end{tabular}

\subsubsection{Dissatisfaction with Community Citizen Validation}

As we described in section 3.1.2, the EA establishes a validation process through which a potential Ghanaian employee is deemed a "community citizen." Specifically, the chief, Assembly member, and youth leader are required to validate that a person is, in fact, from the community. ${ }^{215}$

Numerous community members expressed dissatisfaction with the functioning of this vetting process. In some instances, leaders were accused of demanding and accepting bribes to validate as "community citizens" people from outside the communities. Even legitimate community members found themselves burdened by the process, which lent itself to corruption and favouritism. These accusations point to failures within traditional authority structures, arguably something that is outside of NGGL's responsibility to manage. Indeed, NADeF representatives were of the opinion that determining who is local and who is not is ultimately up to the community.

To address such challenges, the revised EA's process of validation has been made more transparent in an attempt to minimize corruption and favouritism. Section 2.5.3(ii) of the revised agreement states that community citizens who are shortlisted must present themselves for initial confirmation of their citizenship by their respective youth leader, assembly member and chief/Omanhene at a joint sitting in the presence of a representative of NGGL's Human Resource Department.

vii Responding to the draft findings for this report in May 2018, Newmont representatives noted that copies are distributed at meetings and, going forward, the employment statistics will be posted on community notice boards. 


\subsubsection{Unskilled Locals and Training for Jobs}

Finding employment for unskilled community members remains a source of contention. Specifically, community members and Newmont disagree on the relationship between the skill level of community members, and the training programs available to them.

Some respondents and other local community citizens have been beneficiaries of the company's training programs. According to statistics provided by NGGL, twenty-five locals were recently trained to become truck operators, loaders service crew, grader operators, etc. for the operation of the new underground mine. ${ }^{216}$ Similar trainings have also happened in the past. A community member acknowledged this, noting that when community members have gone through such trainings, they "come back as different people," now able to earn a livelihood, for example, by driving bulldozers.

Despite these training opportunities, many community members remain dissatisfied. One community member asserted that many locals had gone through training programs but remained unemployed. In addition, two community members lamented that many locals had even benefitted from NADeF scholarships and had university degrees, even in relevant disciplines, but upon completion of their studies found that there were no jobs available.

NGGL representatives themselves noted that they initially had trouble finding community members with the skills needed, which explained why they were initially "unable" to meet their employment targets. A further complication is that the number of jobs becomes fewer later in the mine's life, which may be just at the time when community members start to graduate with relevant skills. As such, there is a mismatch between supply of, and demand for, skilled graduates. The need for unskilled labour also reduces after the initial construction of the mine. One community member noted that the mine has been in operation for 12 years, and many community members had built up relevant skills and expertise, before calling on NGGL to increase the quota. Yet from the company's perspective, those twelve years have been spent training up a skilled national and local workforce, and few vacancies now exist to offer to skilled community members.

Finally, issues were raised by community members with respect to workplace discrimination. Women and people with disabilities found it challenging to get jobs at Newmont, though female community members volunteered that most manual work jobs would go to men. In contrast, NGGL could point to efforts to train women to drive trucks and other technical positions. Community members with disabilities appeared to be especially neglected, according to a representative of people with disabilities.

\subsection{IMPLEMENTATION OF THE DEVELOPMENT FOUNDATION AGREEMENT}

In this subsection we review the performance of implementation of NADeF as experienced by the community stakeholders we spoke with. NADeF has been reviewed by others, as we summarized in section 4. In addition, we have already described project outlays in section 3.1.3 and 3.3, and in section 6.2 we covered the challenges of implementation regarding consultation and meaningful participation in NADeF. Our impression from interviews conducted aligned with the findings of other research. Specifically, NADeF was regarded as well known, professionally run, and successfully spending money on community projects and scholarships. Given these impressions, in this section we focus on project selection, value for money, inter-community projects, and NADeF's funding formula.

\subsubsection{Project Selection}

As detailed in section 3.1.3, above, NADeF spends its funds across a range of project types. In our discussions with community stakeholders, the most popular target for expenditure was in the 
development of human capital through scholarships and apprenticeship training for citizens of the Ahafo mining communities. The process of awarding the scholarships was seen as fair and meritocratic by the majority of people we spoke to; the only complaints were that students risked losing their scholarships if they did not perform academically but would still be responsible for paying their school fees. One community member was also under the impression that fewer scholarships were awarded in recent years than at the beginning of the mine. NADeF also runs an apprenticeship training program. The $2016 \mathrm{NADeF}$ annual report indicated 670 youth have benefited from the apprenticeship training programme. Some of the community members that the research team interviewed were direct beneficiaries of the apprenticeship programme who had established their own businesses. 217

The Foundation funds infrastructure development and many such projects are visible in the communities. Some of those projects are of questionable development value; most communities have an elaborate chief's palace, for example, that did not show evidence of extensive use, whereas community members complained that when NADeF expenditures fell, scholarships were cut. (The funding formula would dictate broad cuts across the board in this situation.) In addition, as described in section 6.2, above, not all SDCs conducted meaningful consultations with the community before submitting their project proposals to NADeF. In one community, members were irate that an old school had been knocked down in order to make room for a sports field that didn't have enough room for spectators. ${ }^{\text {vii }}$ Even local government officials acknowledged that SDC members had political power and thus it would be difficult to go against their wishes even if the project did not appear wisely selected.

\subsubsection{Value for Money}

The process of selecting projects is complicated by the fact that the SDCs responsible for making recommendations to NADeF do not have information on price for the proposals. As a result, communities have been upset when they have chosen to do a project that they assumed would be a small-ticket item, only to find that it ends up costing a lot of money. One community member described the value for money in the following way: "If they build a door, it costs the price of a house." One set of community members thought that the high costs for contracting must be due to corruption between NADeF and contractors; yet our discussions with the District Assembly, NADeF and contractors revealed what seemed to be a professional procurement operation, albeit more formal than the communities would need to be acting on their own.

\subsubsection{Cross-Community Projects}

Some of the communities are close enough to each other to plan some projects together in order to create greater value for the limited NADeF funds. Yet in practice no joint planning occurs, and two communities may end up replicating the same project. The District Assembly, NGGL, and the NADeF board members were all of the view that better projects could be achieved through some coordination between communities. Even some SDCs had ambitious plans that could not be funded from within their envelope, like a university or a hospital, and the Forum has discussed cross-community agribusiness projects. At present, none of this coordination is occurring, perhaps because the SDCs have failed to coordinate, or because the funding formula discourages it. Representatives from NGGL noted that at Newmont's Akyem mine in Ghana, whose benefit sharing provisions were established after those at Ahafo, a common fund exists for development projects spanning more than a single community.

viii Newmont's comments on the draft factual findings noted that NADeF worked hard to suggest an alternative location, and that the classroom block was unsafe and abandoned. 


\subsubsection{The Funding Formula}

The DFA specifies that the $\$ 1 / \mathrm{oz}$ and $1 \%$ of net pre-tax income is paid from NGGL's operations to NADeF. ${ }^{218}$ Many community members were familiar with this formula and had opinions about it. One view was that it was simply too low. For instance, a community member pointed out that if the price of gold was $\$ 1350 / \mathrm{oz}$, the $\$ 1 / \mathrm{oz}$ term would still transfer just one dollar to the communities; that person's conclusion was that his leadership must not be aware of the price of gold. A second view was that the funding formula ought to vary by the impact and scale of the challenge. Since the mine had brought about population growth and the underground mining would have increased environmental impact, for example, the funding formula ought to be adjusted to at least keep per capita funding steady. A third view was that Newmont did not inform the community in sufficient detail on its own revenues and pre-tax income, particularly during the recent fall in contributions. As a result, the community was forced to take a huge decline in NADeF funding-despite a still high gold price-at face value.

\subsection{PERFORMANCE OUTSIDE OF THE AGREEMENTS}

As we described earlier, there are some aspects that are often handled in BAs in a developed-country context that are absent from the Ahafo BAs. We did not research these in depth during the field visit since they were outside of the agreement implementation. However, some issues-both positive and negative-were hard to ignore. In this section, we describe what we learned about supplier development and compensation/resettlement.

\subsubsection{Developing Local Suppliers}

There are two aspects of the mine that have led to opportunities for local suppliers. One is the effort by NGGL to get more local firms involved in supplying the mine and mining-related activities like reclamation; the Ahafo Linkages Program, a two-year programme implemented in cooperation with the IFC, was not a requirement of the BAs yet had documented success developing local businesses. ${ }^{219}$ The second aspect is the contracting opportunities to deliver on the NADeF projects, which are usually small-scale and involve community labour.

We were not able to meet with a beneficiary of the ALP but we did speak with contractors, community members, local officials, and NGGL representatives to discuss local supplier development and contracting. According to NGGL representatives, the company sets targets for local content, and set aside some opportunities that are just for local contractors. On its side, NADeF had a process of inviting qualified local companies to bid on projects, and then going through an organized procurement process. A community representative volunteered that most contracts have gone to local contractors when they had the capacity to do the work, such as building resettlement houses or operating transportation services.

One contractor said that NGGL's bidding process was the most professional, followed by NADeF's, but that both of them were more fair and professional than doing projects for the local government. Community members were concerned that chiefs were disproportionately represented in getting contracting opportunities, as we described in section 6.2.6. One contractor echoed those concerns for NGGL, and another cited an instance in which collusion appeared to be present between the NADeF contracting office and the winning bid. For a different take, one contractor observed that contracts can make a businessperson more wealthy and influential, and they can use that wealth and influence to earn themselves a role as sub-chief. Thus local power and contracting could be correlated, but driven by this alternative mechanism.

According to the contractors, NGGL offers a more stable payment schedule for contracts, in contrast to what happens with government contracts. The risk burden on contractors working for NGGL and $\mathrm{NADeF}$ is therefore lessened on loans procured from banks. The banks are also more comfortable 
and flexible in financing projects funded by NGGL, because of the reliability of payments. One contractor estimated a profit margin of between $15-20 \%$ of projects delivered.

\subsubsection{Compensation and Resettlement}

In section 4.2 we described that much of the independent research on the impact of the Ahafo mine on the communities has focused on issues of resettlement and compensation. While it may have seemed with IFC's involvement that the issue went away, in our experience it remained a source of extreme distress for many affected community members.

The study team met with villagers who were living within view and earshot of the tailings pile and rock crushing. These "satellite towns" belong to one of the ten communities, but represent a smaller hamlet of residents that are sometimes a far drive from the community center; they were truly unpleasant places to be living. The noise from the mine was jarring, and the waste rock had created huge, impassable hills of dry rock that were the highest points around. Villagers in one community said that they were waiting to be resettled like their neighbouring communities already had been, but they had not yet heard from Newmont what plans were in store for them. They noted that they lived between the mine and the nearest water testing station; thus they weren't sure that the water they relied on was safe, or that any impurities would be detected. Their community school had been destroyed to make way for the mine; now students were forced to take a bus into town. Some children had gone without schooling for months owing to a lengthy dispute between the community and the government that arose after the children were re-assigned to a school with no electricity or running water. Villagers in another community that had largely been resettled were holding out for better resettlement rates, mainly, that they wanted to be able to continue in their farming lifestyle and not just be paid for their structures and crops.

We also met with community members who had been resettled. Compensation seemed to be a key driver of satisfaction. One interviewee described how the payments for resettlement were handled differently by different people depending on their financial acumen. Another noted that, despite expectations for a better life, compensation "accounted for around two years of field value," and a third mentioned that after the compensation is spent, "people have nothing left."

Community members described having fallow land (that did not have crops on it at the time) being taken without compensation, and only being compensated for buildings and crops. Different crops have different rates. One savvy farmer was experimenting with one type of crop that would generate a higher value than what he otherwise would have planted, just in case Newmont took his land away. Another noted that subsistence farmers were not experts and thus often just accepted whatever offer was given to them. He described a process by which the company first offered compensation for cocoa field destruction worth less than a year's production; only with negotiation did the compensation rate rise to about 2.5 production years' worth.

NGGL representatives pointed to the existence of committees, not unlike the Forum or SDCs, that exist specifically for compensation and resettlement. These multi-stakeholder committees use IFC processes, include other livelihood programs like vocational training and a vulnerable peoples program that includes support with food BAskets and health. They also noted that all "fenceline communities" in the Subika East mining area have been, or are being, resettled, and that they have begun processes to resettle other fenceline communities.

Government officials ascribed some of the blame in the disputed resettlement programs to "speculative development" in which villagers build simple dwellings in towns slated for destruction to make way for the mine, hoping to get compensated. This acknowledges that mines could be better planned by engaging communities ahead of time, and mapping out properties and settlements, before a decision to mine. However, they noted that their view was that all people in the affected villages should be resettled. 
The experience of the Ahafo communities with respect to the implementation of the Ahafo BAs offers a number of relevant observations for community leaders, policymakers, and leading extractive industry companies. We divide these observations into two groups: those relating to the design and implementation of the Ahafo BAs, and those relating to Newmont's performance around implementation.

\subsection{DESIGN AND IMPLEMENTATION OF THE AHAFO BAS}

It is easy to conclude from the conversations at roundtables on CSR and mining that getting to an agreement with the local community in mining projects is difficult but necessary, and from then on it's all about working together. Yet, as we observed in Ahafo, the negotiation is just one step of a very complex process. What happens after the agreement is signed may require even more attention than the agreement itself. This is consistent with international human rights law and international best practices, as articulated by governments, ${ }^{220}$ international financial institutions, ${ }^{221}$ and extractive companies themselves, 222 which stress the importance of ongoing, iterative consultations and community participation in decision-making. Relatedly, the question of whether the BAs will actually "benefit" the communities needs to be considered in the broader context of the social and environmental impacts that the mine brings. Financial and other transfers to the communities will be of little significance if the social and environmental conditions needed for community livelihoods and survival are put at risk. This is why any "benefit agreement" may also include robust social and environmental protections designed to mitigate and avoid the project's adverse impacts.

The first observation is that true multi-stakeholder agreement and implementation is hard. We observed that in spite of the wide swath of the community represented in the negotiations, they did not all have equal voice. Moreover, once the agreement was up and running, that same inequality of representation continued, with some community members having a louder voice than others. Consultation is another important element of multi-stakeholder participation-in this case, multi-stakeholder participation means that there are representatives for women, youth, farmers, etc.-but we found a distinctly poor degree of consultation between constituencies and their representatives. Thus, what looks on paper like a multi-stakeholder dialogue or institution may in fact be not much more than a diverse set of attendees at a meeting run by, and for, an influential subset of participants. The lesson here is that the multi-stakeholder character of the agreement needs to go beyond ensuring presence, and actually target and facilitate meaningful and representative participation.

The second observation we noted concerns the formalization of community-company relations, and the new institutions generated by the Ahafo BAs. Institutions don't always work as planned, and there is an extensive range of development literature that looks at the political economy of institutions and explores themes like elite capture, suboptimal institutions, and poor links between citizen preference and ultimate policy choices. ${ }^{223}$ In the case of the Ahafo BAs, the representativeness of the new institutions set up-including the Forum, the SDCs, and the tender board-is questionable because these institutions suffered from weak consultation and replicated power imbalances. Sometimes they re-formalized existing power structures, like through giving chiefs a seat on the SDCS (perhaps not coincidentally leading to the construction and renovation of palaces throughout the host communities, funded by NADeF). They also generated new power players, or re-formalized existing ones, through structures such as the Standing Committee or the citizen validation process for local employment. 
The new structures of the Ahafo BAs institutionalized processes that might have otherwise gone through more ad hoc mechanisms. Sometimes that formalization put up barriers that impeded meaningful interactions between different actors, creating a sort of "red tape" that when applied in other contexts like business regulation can prevent desired outcomes (like business registration) from occurring. ${ }^{224}$ In the case of the Ahafo BAs, we were struck by the fact that no one we spoke to had used the dispute mechanism, while many had given reasons for why they might not. On top of all this, no one we spoke to had read the agreements: the formalization of community-company relations created both distance and ignorance. The lesson from this second observation is that BAs need political economy analysis for their design, and not just lawyerly solutions. Political economy, the study of how political interests and institutions interact with economic outcomes, acknowledges a world of "second bests" in which institutions are expected to be gamed for private interest. Politics should not only be considered at the stage of designing institutions under BAs; instead both the firm and host community should commit to ongoing political engagement instead of letting the committees and devices be run strictly by technocrats. If no one is willing to provide that high-level political attention, we would question the potential value of signing BAs in the first place. Any interventions to support community participants to participate should be equally conscious of, and seek to address, these political challenges.

Our third observation is that BA design and implementation may contain unresolvable dilemmas, often relating to conflicts of interest. For example, involving local powerbrokers who are effective at representing the community presents both advantages and disadvantages. In many communities around the world, leaders are not representatives elected through a rigorous election process, and may be in a position of power because of inheritance or business success. In the case of Ahafo, these powerbrokers are tasked with speaking for the community and can bring the community around to work constructively with the company; yet by virtue of their outsized potential to benefit from the specifics of the BAs, these powerbrokers may also prevent the fair implementation of the BAs, or at least create the impression of unfair implementation. Another conundrum is the funding of the staff positions necessary to govern and implement the BAs, such as the moderator or NADeF secretary in the case of the Ahafo BAs. Funding arrangements also have advantages and disadvantages. When a company takes on the financial responsibility to cover an officer's salary, thereby reducing the financial pressure on the community or local government, it also creates an apparent conflict of interest, that the employee may feel incentivized to please the employer.

Related to the third observation is that for BAs to be successful, they need an honest broker who can help to even out power and informational asymmetries. Communities need support for negotiation and ongoing operations and monitoring of the BAs to which they are a party. If they do not have that support, they will likely find themselves stymied by aspects of an agreement that nobody in the community understands. In Ahafo, we found that the local community at all levels was uninformed as to global best practices, and-as we have described-that there was insufficient community participation both during the negotiations and once the BAs were in operation. In other contexts, the company might be expected to pay for the community to get advice and for the general operations of the institutions created by the BAs. Yet as noted above, when the company directly pays for a service, or when there are financial gains to be had, in Ahafo many will likely suspect that the outcome will be unfair. Innovative solutions for financing support to communities are needed. One option is for an international organization or national government to fund technical support and trainings for communities to reduce information and power asymmetries. International organizations like the World Bank should consider stepping up to this role, or otherwise reduce their insistence on using BAs to provide solutions to company-community relations. Another option is for the company (or companies, if the solution is national) to fund an arms-length trust or foundation to take on such a role.

A fifth observation, particularly relevant in those countries that do not legally require resource companies to negotiate agreements with local communities, is that the national government is a de facto party to the agreement whether it likes it or not. For one, royalties and other expenses that go to the community are in all likelihood deducted from taxable income. In Ghana, the corporate 
income tax rate for mining and upstream petroleum companies is 35\%,225 thus the government is in effect contributing more than a third of the allocation to NADeF and other community expenditures. Finally, it is worth noting that even when the government has no policy on BAs, that is in effect a policy. No policy means that there is likely to be a wide variety of approaches taken by different resource companies to manage community relations. It also means that more proactive companies like Newmont are likely to be called on to play roles outside of their core business activities; for instance, at one Forum meeting a chief asked Newmont to remind the national government to pay the communities their overdue royalties. ${ }^{226}$ The lesson from this fifth observation is that governments need to have a deliberate approach to community-company relations and benefit sharing; if they do not have an explicit approach, they should gather the kind of information that might lead to informed policy in the future.

\subsection{TOWARDS BETTER CORPORATE PERFORMANCE}

So, is Newmont doing a good job with the implementation of the Ahafo BAs? Nine years of winning awards from chambers of commerce and Ghanaian philanthropy events might suggest that it is. Yet it is a complicated question. There are many things going well, while others-including very fundamental issues, as raised in the earlier sections-could be improved. Most fundamentally, as we describe below, the impact of the Ahafo BAs on the communities is frankly impossible to measure. In this sub-section we describe several observations that should guide Newmont and other mining companies as they manage the implementation of BAs.

The first observation is that there is a mismatch between different actors' narratives concerning the BAs, which is reflected in the agreement's administration and re-negotiation, and in community-company relations more generally. The community's narrative when signing the BAs was effectively "land for jobs" - not surprising, given the importance of the agricultural and residential land that Newmont would take. Narratives can be a very powerful feature mediating the governance of natural resources, influencing the population's tendency towards conflict. ${ }^{227}$ This narrative of "land for jobs" would seem to be the one non-negotiable of the 2008 agreements, and indeed the cornerstone of NGGL's efforts in community relations. As such, in reaction to the largest single change to the BAs following 2014 renegotiations, the reduction of the headline job target by one third, the community was unsurprisingly upset. Further, as we discuss in the next observation, the company has not made its strongest case that it is upholding its end of the employment bargain. Our lesson here is that when there is a narrative around the signing of BAs, the implementation and follow-through should respect that narrative.

Second, there does not seem to be an active program of BA implementation monitoring and learning. These agreements are complex and, in 2008, in a setting like Ahafo, they were innovative. It would thus make sense to monitor them closely in order to improve performance. Yet, at least BAsed on our research, monitoring does not seem to be a significant part of the BAs' implementation nor the culture around the BAs. This is not a problem specific to Newmont at Ahafo: a related CIRDI project on monitoring and evaluation (M\&E) of BAs has, in preliminary research, found a broad-BAsed weakness in agreement M\&E. NGGL did hire a local consultancy to do an evaluation of NADeF, but to our knowledge there has been no evaluation of the RA nor the EA. (This itself may indicate that the company's focus in the BAs was always more squarely on the financial benefits payable to NADeF, in contrast to the community's focus on jobs.) Even more important than an evaluation (independent or otherwise) is regular monitoring and a culture of learning and improvement. Transparency is one means to achieve this, for example with respect to employment figures, but these are hard to find unless, we are told, you attend a briefing and remember to ask for a copy of the PowerPoint slides. In the absence of monitoring and transparency regarding the key terms of the agreement, the numerous accolades won by Newmont and NGGL risk taking on the characteristics of an echo chamber rather than reflecting actual performance. The lesson here is that ensuring that these agreements operate effectively is hard, and that a commitment to continuous improvement (and the concomitant collection and dissemination of data) is probably the only way to 
come close to getting implementation right. This commitment may need to be at the global level, such as Newmont's commitment to performance monitoring of its social management plans. ${ }^{228}$

Third, and related to the second observation on monitoring and learning, it is nearly impossible to measure the impact of the Ahafo BAs. There are a number of reasons for this. One, as Community Empowerment Associates noted, there are no BAseline data collected against which to measure improvements. ${ }^{229}$ Luckily for future researchers, the Ghanaian census taken in 2010 measures literacy, schooling, employment, migration, and housing conditions, so in a careful study might measure the effects of the mine and BAs once the 2020 census data are available. Two, even if there were local BAseline data collected in 2008, it would be hard to establish the "counterfactual," or what would have happened in the absence of the Ahafo BAs. The reason this is hard is that the largest shock to the community is probably the mine itself, with the BAs reducing the negative impact and increasing the benefits. Moreover, even in the absence of terms included in the agreement, as we note in the next observation, there may still be voluntary corporate activity or domestic law that would go partway to the behaviour codified in the BAs. A separate paper by Adebayo and Werker attempts to measure the potential economic impact of the Ahafo BAs at the time of their signing. ${ }^{230}$ The lesson for here is that companies should establish a rigorous and transparent M\&E system including BAseline data and to consider an enhanced M\&E system including (a) data collection in "control" households not affected by the mine and agreements and (b) joint modeling of benefits with community stakeholders in order to anchor expectations around how their livelihoods might be affected.

Our fourth and final observation for company performance during implementation of the Ahafo BAs is that the agreements only govern a fraction of company-community relations. Some other aspects are determined by voluntary corporate action against the constraints of either domestic law or outside actors like the IFC. In Table 7-1, below, we describe some of the main community benefit or impact mitigation categories, and note what is determining NGGL's behaviour in the case of Ahafo.

\section{Table 7-1 Spheres of Company-Community Interactions in the Ahafo Mine}

\begin{tabular}{|l|l|l|l|}
\hline & $\begin{array}{l}\text { Ad hoc voluntary } \\
\text { corporate action }\end{array}$ & $\begin{array}{l}\text { Codified in benefit } \\
\text { agreements }\end{array}$ & $\begin{array}{l}\text { Domestic law or coun- } \\
\text { terparty constraint }\end{array}$ \\
\hline Local employment & & EA & \\
\hline Local procurement & & & IFC Linkages \\
\hline $\begin{array}{l}\text { Environmental protec- } \\
\text { tion }\end{array}$ & & & $\begin{array}{l}\text { Ghana law and regula- } \\
\text { tions }\end{array}$ \\
\hline Resettlement & & & $\begin{array}{l}\text { Ghana law and IFC } \\
\text { standards }\end{array}$ \\
\hline Compensation & & & Ghana law \\
\hline $\begin{array}{l}\text { Community develop- } \\
\text { ment }\end{array}$ & $\begin{array}{l}\text { Some mitigation } \\
\text { projects }\end{array}$ & DFA & \\
\hline
\end{tabular}

Source: Authors. The columns specify the constraints on corporate action, while the rows describe different responsibilities of the company with respect to the community.

The areas of the most controversy-resettlement and compensation, and environmental protection-fall outside of the relationship articulated in the BAs. The commitments in the voluntary BAs were inconsistent in their approach and application (i.e. falling back on national law rather than fully committing to one set of standards such as the IFC Performance Standards). Had communities been made aware of international best practice and expectations, these BA inadequacies might have been avoided. It is the norm that negotiations with informed communities with free and prior access to information, who have the capacity and opportunity provided by a fair negotiation process, will use international best practice (such as the IFC Standards) as a starting place for negotiating impact management, rather than accept sub-best practice commitments, as appears to have been done in this case. 
Of course, community perception of the BAs is not just governed by the company's performance along the dimensions of benefits and impact mitigation included in the agreements. One lesson here for companies is that a "weak link" in community relations, in which a commitment to best practice is avoided, can be hidden outside of the BAs but nonetheless may come back to bite. An additional lesson is that when the distribution of benefits and impact mitigation measures is institutionalized through the BAs, but those institutions do not evenly serve the population (as we noted earlier, because of local power players or weak capacity), there may be a need for additional company initiatives to target those individuals and groups left out of the new distribution.

\subsection{CONSIDERATIONS FOR THE 2019 REVIEW OF THE AHAFO BAs}

Although the Relationship Agreement allows for amendments to the BAs at any time, NGGL representatives say that a review happens every five years or so, with the next to be in 2019. Because we were asked how "best practice" might be improved, we offer some items for consideration during the next review. Since the study did not compare across mining properties with different arrangements for distributing benefits and mitigation efforts, we are unable to make specific policy recommendations regarding Ghana's overall approach towards BAs. The spirit of these suggestions is to enable the Ahafo model to reach its fullest potential. Almost all of these suggestions are consistent with Newmont's own corporate policies, and various voluntary principles and guidelines (such as those of the International Council on Mining \& Metals, where Newmont is a member). Indeed, a few of these recommendations look remarkably similar to those in Newmont's own commissioned review of its community relations. ${ }^{231}$

\subsection{IMPROVING FUTURE RENEGOTIATION PROCESSES FOR THE AHAFO BAS}

While there are no reliable ways of completely resolving the political challenges and power imbalances discussed above, the process of the 2018/2019 review could be made more fair and representative through consideration of the following suggestions.

1. Provide community representatives with independent, experienced legal counsel during the entire renegotiation process. We appreciate the desire to negotiate an agreement between principals, and then have lawyers formalize it after the key terms have been worked out. That said, BAs around the world are already legalized and much of the experience for what constitutes a fair deal lies with lawyers who have negotiated in different contexts. Mining companies like Newmont have access to a global experience pool whereas a local community in rural Ghana does not. Lawyers ought to be available to the community to do more than just formalize an agreement and translate it to Twi; they should help the community understand trade-offs, consider new ideas, and be on the lookout for loopholes. Moreover, given the multiple communities and interest groups, more than a single lawyer may be required to negotiate for the interests of the different stakeholder groups. The selection of lawyers should take into account their potential to act independently, given the risks of political capture or influence by the company, the government or other potential clients.

2. Provide community representatives with independent technical assistance during the entire renegotiation process. Most of the BAs contain content that falls within the domain of experts, whether in environmental impact, finance, or local development (see, e.g. s. 8.2, par. 6, below). It would be hard for the communities to be considered informed without access to relevant technical expertise; this should be allocated to different groups as for legal counsel, as described above. 
3. Provide training to Forum members in advance of the renegotiations. Whatever expertise is brought in, it will be community members who will have to ultimately make the decisions and live with them. Our experience in the communities is that there would be both appetite for, as well as significant benefits from, a general training in the negotiation and implementation of benefit agreements. There is now a global experience BAse that Ahafo community leaders can tap into that can take some of the uncertainty out of the relationship with Newmont. Such training should not only focus on technical issues, but must also address the inherently political nature of stakeholder interactions and deliberation; to avoid elite community members dominating proceedings, any training interventions must also seek to nurture solidarity and support of different interests within the community. ${ }^{232}$ Such training should be provided to community members in addition to, and not instead of, legal and technical support.

4. Publicize future negotiations and consult widely with the community. In the run-up to the next set of discussions on the Ahafo BAs, all sides should be transparent with their constituents about the timing and content of the negotiations. Community leaders need to sensitize their communities that negotiations are uncertain, and do not necessarily result in better outcomes, and should thus seek input from community members regarding the most important aspects to reconsider as well as what concessions they might be willing to make in order to achieve new wins.

5. Make the BAs available in plain-language, Twi versions. Given the mixed command of English in the Ahafo areas, and the fact that the legal language of the BAs is inaccessible to most people anywhere, all parties could make both the existing and revised agreements more accessible by translating them into Twi and converting any legalese in the BAs into plain language. This has already been done in agreements in other parts of the world.

6. Include more representatives of the communities as signatories to the agreement. As we described in section 6.1.3, the copy of the amended agreement that we reviewed for this report was signed by just one chief. The Forum should discuss how many community leaders, and whether other community representatives-such as representatives of women's groups and of youth-should also be signatories to the agreements. It can also consider other ways, such as roll-call votes, to create greater accountability and broader representation between Forum members and constituents.

\subsection{IMPROVING THE AHAFO BAS}

The parties coming together will have many ideas to improve the Ahafo BAs. It is not our goal here to prescribe changes to the agreements, which is ultimately a choice of the negotiating parties, but rather to suggest ideas for discussion that emerged from our research findings.

1. A more representative Standing Committee and more trusted moderator. Given the power of the Standing Committee and moderator in the decision-making of the Forum, the legitimacy of the Forum could be enhanced if those important positions were seen to be chosen by all parties. One possibility is for the Forum to elect its own Standing Committee with a secret ballot, and to choose its own moderator in a competitive process following presentations of three potential candidates.

2. An independent grievance mechanism. As it currently stands, the grievance mechanism effectively prevents many complaints, given that it runs through existing structures within the communities and that such structures are now intertwined with corporate interests through the Ahafo BAs and other arrangements. If members of the Forum wish to encourage all legitimate grievances to surface, they could consider a new independent structure such as an ombudsman or elected committee consisting of independent Forum members, in which grievances could be lodged privately and without fear of retribution or discrimination. Any 
grievance mechanism in place should meet the effectiveness criteria of the UN Principles on Business and Human Rights (including that the mechanism is legitimate, accessible, predictable, equitable, transparent, rights-compatible, a source of continuous learning, and BAsed on engagement and dialogue with the community). ${ }^{233}$

3. Clear delineation as to what matters are under the jurisdiction of the Forum. The BAs at present assign the Forum the responsibility to oversee the implementation of the agreement and give the Forum power to establish committees and assign functions to them. Yet the actual jurisdiction remains vague. For example, it seems that community still has no influence on how the mine is conducted; this undermines the meaningfulness of consultation and of structures like the Forum, and also introduces the possibility for community discontent that may be expressed in vehicles outside the Forum.

4. More ambitious compensation and resettlement standards. Rather than fall back on the Ghanaian law, the agreement could aspire to Newmont's own standards, or those of the IFC. Though NGGL representatives told us that they continue to follow IFC standards, those could be formally included in the RA or a separate agreement. To offer meaningful protection to community members, such standards would need to be included in an agreement which is legally enforceable.

5. Local procurement development targets. If this agreement were being negotiated in Canada or Australia, it would almost certainly have either language promising programming around developing the capabilities of local suppliers and increasing their chances of winning bids, or targets around local contractor spend. Yet Canada and Australia are different from Ghana, given that the firms being targeted in the former are Indigenous rather than locally owned per se. The Ahafo Linkages program is an example of a program that could have been included in the BAs.

6. More ambitious employment targets. The reduction in the local employment target from $35 \%$ to $24 \%$ could be reversed, with a more ambitious target, expressed as full-time equivalent employment, sought for the revised agreements. Targets on skilled positions could be included too. Modest, agreed-on penalties for failure to meet the target, such as a fine equal to the salary for each position in which a local is not employed below the target, payable to NADeF, could be a substitute for a low target. Such a fine would create a salient signal to both Newmont headquarters and local community members regarding NGGL's failure to meet the employment targets. Redefining the profit term as a royalty. The $1 \%$ of net profit term presently determining the financial flows into NADeF is impossible to monitor at the local level, given that community members are not able to observe Newmont's cash costs let alone "all inter-company transactions." An equivalent transfer to NADeF, as occurred from the 1\% of net profits term over the period 2008-2016, would have resulted from a more transparent formula which is as follows:

\section{(International price of gold - Expected cash cost) $\times$ Volume gold sold $\times 0.7 \%$}

7. Where the expected cash cost is defined as $\$ 708 / 0 z$ in 2013 (the average of the nine years of Newmont-reported data, set for the middle year of data) and is assumed to increase at 3\% per year. Thus we have cash costs for 2008 of $\$ 629,2009$ of $\$ 648$, and so on through $\$ 797$ in 2016. With a formulation like this, the community could see that rising gold prices will lead to higher contributions from the company, and vice versa, without having to second-guess whether some creative accounting is instead driving the fluctuations. By describing this formula, we do not wish to convey any view as to whether $0.7 \%$ is the "right" number, rather it is the number that is broadly comparable to the $1 \%$ in the existing agreement (and we do not mean to endorse, or criticize, the $1 \%$ in the initial agreement). A fair number might very well be different. Indeed, the right number might change BAsed on impact on the communitieswhich might be higher or lower-from the underground mining and the realized impact of the first decade of the project as opposed to just expectations. 
8. Escalating, anticipatory targets. For each of procurement, employment, and royalty numbers, there is some predictability in terms of how the mine's needs, the community's needs, and the community's capabilities will progress over time. For instance, NADeF scholarships and the lure of a massive gold mine in the neighbourhood are likely to lead to local citizens earning the qualification to be competent workers at the mine. Rather than have a company that is reactive (or defensive) in the face of these changes, the BA can simply anticipate them and chart out a fair path of obligations that changes over time.

9. Cross-community projects permitted under NADeF. At present, each community chooses their projects BAsed on the funding allocations, and there is a natural tendency to spend the budget. Yet as the communities grow and the local projects are completed, it may be worth considering more ambitious projects that cross community lines and might be more transformative in preparing the area for life after the mine. Amendments to the funding formula could be considered to allow and encourage these projects to be conceived.

10. Auditing for gender awareness and inclusion of under-represented groups. While there are efforts in the Ahafo BAs to increase the representation of women, there still remains a gender imbalance in formal roles under the BAs. The BAs also still feature needlessly gender-specific language like "chairman" instead of "chairperson" that presupposes male leadership. Auditing to identify how where the agreement could be made inclusive could help bolster the degree to which entities established by the BAs are truly representative. At the same time as this audit, the parties could consider whether there are any groups that have not been represented during the first decade of the BAs that ought to have a formalized role, such as persons with a disability.

11. Making the agreements legally binding. In 2019, it will have been 11 years since the execution of the original Ahafo BAs, with all parties having accumulated trust and experience working together. It might be worth discussing whether to change the language in the RA and EA to make them legally enforceable. This would give all parties experience with a judicial backstop_creating a valuable experiment that could help inform Ghanaian policy regarding BAs going forward.

\subsubsection{Improving the Implementation of the Ahafo BAs}

Regardless of the formal changes to the Ahafo BAs, there a number of changes to their implementation could lead to better outcomes, including more community trust and satisfaction concerning the operations. We suggest a number of operational fixes for consideration by the parties, mainly NGGL and NADeF.

1. Transparent meetings. Given the weak consultation by many representatives, a simple fix is available: make meetings, their minutes, and materials from any presentations given available in Newmont's information offices and on the Internet. Agendas for the meetings should be similarly made available beforehand. This could be for Forum and Standing Committee meetings at a minimum.

2. Disaggregated jobs data. Much of the dissatisfaction with the EA stems from community members' uncertainty about whether the jobs targets are being legitimately met. Although NGGL presents slideshows containing aggregate employment statistics, this does not align with the information the community often demands. It would be useful to see disaggregated jobs data, described by community; gender ratios; whether jobs are casual, part-time, or full time; whether jobs are temporary or ongoing; whether jobs are management, skilled, unskilled, among other potential criteria. In other contexts it is quite simple to count full-time equivalents-in other words, counting two half-time employees as one full-time equivalent employee. The data ought to be made more accessible. 
3. Transparency around NADeF contributions. Given the fluctuating contributions of NADeF and their weak correlation to the gold price, there was understandable confusion among community members about why NADeF funds were declining. Newmont could make the BAsis for the contributions clear at the corporate level, and publish the components (e.g. oz sold, revenue, costs) in order to eliminate speculation regarding the fairness of the contribution.

4. Capacity building on consultation and participation. Members of the Forum and SDCS have responsibilities for which they often do not have extensive training or experience. Capacity building on community consultation and effective participation could be contemplated for members of these important entities.

5. Sufficient time for consultation before decisions. Forum meetings during which decisions are made would ideally allow for members to be able to consult with their constituencies before casting their vote or contributing to a consensus-BAsed decision. Sufficient time should be planned for to allow community members to be advised well in advance as to what is up for discussion, and how that might affect them, so that they have time to communicate their opinions to their representatives.

6. Closely monitoring and adjusting how deliberative processes operate to maximize the extent to which they are participatory. The BAs establish various useful forums for communication between different stakeholders. These should be used to maintain regular contact about how processes are working, and to collaboratively work towards making them more participatory. Where problems arise or improvements are suggested, the parties should build consensus to adjust processes as needed.

7. Participatory environmental and social monitoring. The RA specifies that community members should participate in environmental and social impact monitoring programs, yet these programs had not begun at the timing of our visit. The first step is to begin outreach to, and sensitization of, the community, and to co-design a plan for how community members will be able to participate in such an approach. In order to have effective participation, community members would need to be trained and have access to independent technical assistance; selection would also have to ensure that no potential conflicts of interest-such as fear of lost employment or contracts- might arise, or that such conflicts are adequately managed. To be truly participatory, the scope of what will be monitored should also be co-designed with community members. Best practice would also suggest that impacts on human health be included as one aspect of the mine's social and environmental impacts that should be monitored closely, that plans for mine closure be made, and that the company supports open, disaggregated, updated, and user-friendly data.

8. Costing transparency for NADeF projects. At present, SDCs must choose projects without knowing how much they might cost, and our research showed that community-level estimates often differed substantially from the final bill. We understand that the cost range is communicated to the SDCs but from the community perspective it did not appear that this information arrived in time to affect the decision on which projects to fund. Improving the information to SDCs about the cost of potential projects without delaying their implementation would benefit all parties and likely lead to better project selection. 


\section{ENDNOTES}

1 Jim Cooney, "Reflections on the 20th Anniversary of the Term Social License," Journal of Energy and Natural Resource Law 35, no. 2 (2017): 200.

2 Ciaran O'Faircheallaigh, "Community Development Agreements in the Mining Industry: An Emerging Global Phenomenon," Community Development 44, no. 2 (2013): 222-3, doi: 10.1080/15575330.2012.705872.

3 James Gathii and Ibironke T Odumosu-Ayanu. "The Turn to Contractual Responsibility in the Global Extractive Industry," Business and Human Rights Journal 1, no. 1 (2016): 88-90.

4 James Otto, Mining Community Development Agreements Source Book, (Washington, DC: World Bank, Mar 2012): 5, http://siteresources.worldbank.org/INTOGMC/Resources/mining_community.pdf.

5 Kendra Dupuy, "Community Development Requirements in Mining Laws," The Extractive Industries and Society 1, (2014): 211-3. and Yukon.

6 With the exception of Nunavut and oil and gas development in the Northwest Territories

7 Irene Sosa and Karyn Keenan, Impact Benefit Agreements Between Aboriginal Communities and Mining Companies: Their Use in Canada, (Toronto, ON: Canadian Environmental Law Association, 2001): 8.

8 David Brereton, John Owen and Julie Kim, Good Practice Note: Community Development Agreements, (Brisbane, Australia: Centre for Social Responsibility in Mining, 2011): 5, https://www. csrm.uq.edu.au/Portals/0/docs/CSRM-CDA-report.pdf.

9 Radu Mares, "Corporate Responsibility and Compliance with the Law: A Case Study of Land, Dispossession, and Aftermath at Newmont's Ahafo Project in Ghana," Business and Society Review 117, no. 2 (2012): 236.

10 Ciaran O'Faircheallaigh and Ginger Gibson, "Economic Risk and Mineral Taxation on Indigenous Lands", Resources Policy 37, no. 1 (2012): 10.

11 Tim Martin et al., From Rights to Results, (Washington, DC, USA: RESOLVE, 2015): 49, http://solutions-network.org/site-fpic/files/2015/09/From-Rights-to-Results-Sept-2015-FINAL-ENG. pdf. 10.

12 O'Faircheallaigh and Gibson, “Economic Risk and Mineral Taxation on Indigenous Lands",

13 Lindsay Gailbraith, Ben Bradshaw and Murray Rutherford, "Towards a New Supra-Regulatory Approach to Environmental Assessment in Northern Canada", Impact Assessment and Project Appraisal 25, no. 1 (2007): 37.

14 Murray Browne and Krista Robertson, Benefit Sharing Agreements in British Columbia: A Guide for First Nations, Businesses, and Governments, (Victoria, BC, Canada: Woodward and Company, 2009): vii, http://www.woodwardandcompany.com/wp-content/uploads/pdfs/4487_benefit_sharing_final_report___updated.pdf.

15 O'Faircheallaigh, "Community Development Agreements," 225.

16 Tehtena Mebratu-Tsegaye, Kaitlin Cordes, and Sam Szoke-Burke, Is This Really Benefit Sharing? Understanding Current Practices Around Community-Investor Agreements Tied to Land Investments, (Forthcoming 2018). 
17 John Liu, Recommendations of the Task Force on Public Benefit Agreements, (New York, USA: New York City, 2010), http://landuselaw.wustl.edu/Articles/Community\%20Benefits\%20Agreements\%20Task-Force-Report-Final.pdf. 12-6.

18 O’Faircheallaigh and Gibson, "Economic Risk and Mineral Taxation on Indigenous Lands”,

19 Jennifer Loutit, Jacqueline Mandelbaum and Sam Szoke-Burke, "Emerging Practices in Community Development Agreements," The Journal of Sustainable Development Law and Policy 7, no. 1 (2016): 86; International Council on Mining and Metals (ICMM), Indigenous Peoples and Mining: Good Practices Guide (2nd ed), (London, UK: ICMM, 2015a): 68-70, https://www.icmm.com/website/ publications/pdfs/social-and-economic-development/9520.pdf.

20 ICMM, Indigenous Peoples and Mining, 70.

21 Martin et al., "From Rights to Results," 22; Dupuy, "Community Development Requirements in Mining Laws," 204.

22 Kendra Dupuy, "Corruption and Elite Capture of Mining Company Development Funds in Ghana and Sierra Leone," in Corruption, Natural Resources and Development: From Resource Curse to Political Economy, eds. Aled Williams and Phillipe Le Billon (Cheltenham, UK, Edward Elgar Publishing, 2017): 71.

23 Dupuy, "Community Development Requirements," 211.

24 Act 912, Minerals Development Fund Act, 2016, Ghana.

25 Sharyn McDonald and Suzanne Young, "Cross-sector Collaboration shaping Corporate Social Responsibility Best Practice Within the Mining Industry," Journal of Cleaner Production 37, (2012): 54.

26 McDonald and Young, "Cross-sector Collaboration," 59-61.

27 ICMM, Indigenous Peoples and Mining, (2015a).

28 International Finance Corporation (IFC), IFC Sustainability Framework, (Washington, DC, USA: IFC, 2012). http://www.ifc.org/wps/wcm/connect/b9dacb004a73e7a8a273fff998895a12/ IFC_Sustainabilit y_+Framework.pdf?MOD=AJPERES

29 Martin et al., From Rights to Results, 31-33; O’Faircheallaigh, “Social Equity and Large Mining Projects," 97.

30 O'Faircheallaigh, "Community Development Agreements in the Mining Industry," 222.

31 For examples, see James Otto, “Community Development Agreements: Model Regulations and Example Guidelines," (World Bank Report 61482, 2010); and Brereton, Owen and Kim, "Good Practices Note."

32 Loutit, Mandelbaum and Szoke-Burke, "Emerging Practices in Community Development Agreements," 89-92.

33 Browne and Robertson, Agreements in British Columbia, II-26-7; Sunrita Sarkar et al., Mining Community Development Agreements: Practical Experiences and Field Studies, (Washington, DC, USA: World Bank, 2010): 86.

34 Browne and Robertson, Agreements in British Columbia, II-27; Sarker et al., Mining Community Development Agreements, 88.

35 Sarker et al., Mining Community Development Agreements, 88; Brereton, Owen and Kim, "Good Practices Note," 1.

36 Loutit, Mandelbaum and Szoke-Burke, "Emerging Practices," 91; Sosa and Keenan, "Impact Benefit Agreements," 18. 
37 Martin et al., "From Rights to Results," 62; Jo-Anne Everingham et al., Why Agreements Matter, (London, UK, Rio Tinto Group, 2016): 169, http://www.riotinto.com/documents/Rio_Tinto_ Why_Agreements_Matter.pdf.

38 Ciaran O'Faircheallaigh, "Implementing Agreements Between Indigenous Peoples and Resource Developers in Australia and Canada," (Aboriginal Politics and Public Sector Management Research Paper No. 13, Nathan, Australia: Centre for Australian Public Sector Management, 2003): $12-5$.

39 O'Faircheallaigh, "Implementing Agreements," 19-20.

40 Jason Prno, Ben Bradshaw and Dianne Lapierre, "Impact and Benefit Agreements: Are They Working?", paper presented at the Canadian Institute of Mining, Metallurgy and Petroleum Conference, Vancouver, BC, May 11, 2010, 5.

41 Peter Siebenmorgan and Ben Bradshaw, "Re-Conceiving Impact and Benefit Agreements as Instruments of Aboriginal Community Development in Northern Ontario, Canada," Oil, Gas and Energy Law Intelligence 9, no. 4 (2011): 5-8.

42 Ciaran O'Faircheallaigh, Negotiations in the Indigenous World: Aboriginal Peoples and the Extractive Industry in Australia and Canada (Florence, KY, USA, Taylor \& Francis Group, 2015b): 86-7.

43 Brereton, Owen and Kim, "Good Practices Note," 33-35.

44 Ghana Statistical Service, Ghana Health Service, and ICF International, Ghana Demographic and Health Survey 2014, (Accra Ghana, Accra Ghana, Rockville Maryland: 2015): 2, https:// dhsprogram.com/pubs/pdf/fr307/fr307.pdf.

45 International Council on Mining and Metals (ICMM), Mining in Ghana - What Future Can We Expect?, (London, UK: ICMM, 2015b): 26, http://www.icmm.com/website/publications/pdfs/ mining-parterships-for-development/mining-in-ghana_what-future-can-we-expect.

46 KMPG Global Mining Institute, Ghana Country Mining Guide, (Amsteveen, Netherlands: KMPG International, 2014): 17, https://assets.kpmg.com/content/dam/kpmg/pdf/2014/04/ghanamining-guide.pdf.

47 ICMM, Mining in Ghana, 5.

48 Robin Bloch and George Owusu, "Linkages in Ghana's Gold Mining Industry: Challenging the Enclave Thesis," (Making the Most of Commodities Programme Discussion Paper No. 1, Milton Keynes, UK, The Open University, 2011): 20-21, isbn: 978-1-77011-232-2.

49 ICMM, Mining in Ghana, 38.

50 James McQuilken and Gavin Hilson, Artisnal and Small-Scale Gold Mining in Ghana: Evidence to Inform an 'Action Dialogue,' (London, UK, International Institute for Sustainable Development, 2017): 6, http://pubs.iied.org/pdfs/16618IIED.pdf.

51 Emmanuel Bruce, "Let's Move Galamsey Battle to Next Level - Ken Ashigbey Urges Media," GraphicOnline (Ghana), September 22, 2017, https://www.graphic.com.gh/news/general-news/let-s-move-galamsey-battle-to-next-level-ken-ashigbey-urges-media.html

52 "Ghana Mining Portal > Minerals Commission", on Ghana-Mining.Org, accessed August 16, 2017, http://www.ghana-mining.org/ghanaims/MineralsCommission/tabid/155/Default.aspx (site discontinued).

53 Government of Ghana, "Brong Ahafo," accessed August 16, 2017, http://www.ghana.gov. gh/index.php/about-ghana/regions/brong-ahafo.

54 Newmont Ahafo Development Foundation, Map of Brong Ahafo Region featuring Asutifi and Tano North Districts, digital image, accessed April 12, 2018, from: https://nadef.org/contact-us/ map-of-ahafo-communities/. Asutifi district, as of 2011, is now made up of two districts: Asutifi North 
and South.

55 Newmont, "Newmont Mining / Africa / Ahafo - Ghana / Community," accessed August 17, 2017d, http://www.newmont.com/operations-and-projects/africa/ahafo-ghana/community/default. aspx.

56 Newmont, "Newmont Annouces First Quarter 2018 Results," Press release reported in Business Wire, Apr 26.

57 Cited in: Daniel Owusu-Ansah, Samuel Adu-Gyamfi, Edward Brenya, Yaw Sarpong, and David Damtar, "Corporate Social Responsibility of Mining Companies in Ghana: The Case of Newmont Ghana Gold Limited at Ahafo," Journal of Social and Development Science 6, no. 3 (2015): 54.

58 Ghana Statistical Service, 2010 Population and Housing Census. District Analytical Report: Asutifi North District, (Accra, Ghana, 2014a): 70, http://www.statsghana.gov.gh/docfiles/2010_ District_Report/Brong\%20Ahafo/Asutifi_North.pdf.

59 Ghana Statistical Service, 2010 Population and Housing Census. District Analytical Report: Tano North District, (Accra, Ghana, 2014b): 68, http://www.statsghana.gov.gh/docfiles/2010_District_ Report/Brong\%20Ahafo/Tano\%20North.pdf.

60 Newmont, Creating Long-Term Value: Annual Report and Form 10-K - 2016, (Greenwood, CO, USA, 2017a): 10, http://s1.q4cdn.com/259923520/files/doc_financials/annual/2016/Newmont2016-Annual-Report-Bookmarked-PDF-for-website.pdf.

61 Newmont, "Annual Report (form 10-K," for 2003 and 2006.

62 Newmont, "Newmont Mining / Africa / Ahafo - Ghana / Overview," accessed August 16, 2017e, http://www.newmont.com/operations-and-projects/africa/ahafo-ghana/overview/default. aspx.

63 Joseph Danso, Emmanuel Aubynn, Allison Coppel, Zira John, and Benjamin Teschner, "The Newmont Afaho Development Foundation: Putting Shared Value Into Action," paper presented at Mining and Community Solutions, Vancouver, BC, Canada, June 6-7, 2016, 174.

64 Newmont, Creating Long-Term Value, 38.

65 Newmont, Q2 Operating Statistics, (Greenwood, CO, USA, 2017f): 16, http://s1.q4cdn. com/259923520/files/doc_financials/quarterly/2017/Q2/Q2_2017-Operating-Statistics_final.pdf.

66 Newmont, "Newmont Adds Profitable Gold Production Through Expansion of Ahafo in Ghana," Newmont.com Newsroom, April 20, 2017c, http://www.newmont.com/newsroom/ newsroom-details/2017/Newmont-Adds-Profitable-Gold-Production-through-Expansion-of-Ahafo-inGhana/default.aspx.

67 Newmont, "Newmont Expresses Deep Sorrow Over Fatalities at Ahafo Mill Expansion Project in Ghana," Newmont.com Newsroom, April 7, 2018, https://www.newmont.com/newsroom/ newsroom-details/2018/Newmont-Expresses-Deep-Sorrow-Over-Fatalities-at-Ahafo-Mill-ExpansionProject-in-Ghana/default.aspx.

68 "Newmont Resumes Production at Ghana Operations Following Tragic Fatalities," Mining Review Africa, April 10, 2018, https://www.miningreview.com/newmont-resumes-production-at-ghana-operations-following-tragic-fatalities/.

69 Newmont, "Newmont Announces Full Year and Fourth Quarter 2017 Results," news release, February 22, 2018, https://s1.q4cdn.com/259923520/files/doc_news/2018/02/Newmont-Announces-Full-Year-and-Fourth-Quarter-2017-Results.pdf.

70 Michael Boateng, "Ghana: Irate Youth Demonstrate Against Newmont Ahafo Mine," All Africa, August 3, 2017, http://allafrica.com/stories/201708031016.html. 
71 NGGL, "Newmont Ghana Committed to Local Economic Development and Transparent Stakeholder Engagement," news release, August 1, 2017, http://s1.q4cdn.com/259923520/files/ doc_news/Africa/2017/08/Media-Statement-1st-August-Demonstration-1-August-2017-Final.pdf; Pius Amihere Eduku, "Kenyasi Residents Strike Over 'No Jobs' at Newmont," CitiFMOnline (Accra), August 1, 2017a, http://citifmonline.com/2017/08/01/kenyasi-residents-strike-over-no-jobs-at-newmont/; "Kenyasi No. 1 Youth Stage Demonstration Against Newmont," Ghana News Agency, August 3, 2017, http://ghananewsagency.org/social/kenyasi-no-1-youth-stages-demonstration-against-newmont-47260; Boateng, "Youth Demonstrate Against Newmont."

72 Boateng, "Youth Demonstrate Against Newmont."

73 Newmont, "Newmont Ghana committed to local economic development and transparent stakeholder engagement," press release, Aug 12017.

74 Eduku, "Kenyasi Residents Strike." Dayee, Daniel. "Kenyasi Youth Resist Newmont Underground Mining," DailyGuide Africa, Dec 152016.

75 Boateng, "Youth Demonstrate Against Newmont."

76 "Ahafo Youth Fight Newmont Mining Company for Jobs," GhanaWeb, September 12, 2017, https://www.ghanaweb.com/GhanaHomePage/business/Ahafo-youth-fight-Newmont-Mining-Company-for-jobs-579902.

77 White Paper on Report of Seven-Member Committee Set Up to Investigate Petition of Coalition of Concerned Youth of Five Communities Affected by Mining Against Newmont Ghana Gold Ltd, Brong Ahafo Coordinating Council, (2018).

782008 Social Responsibility Agreement between the Ahafo Mine Local Community and Newmont Ghana Gold Limited, s. 2.

792008 Social Responsibility Agreement, s. 3.

802008 Social Responsibility Agreement, s. 5(2).

812008 Social Responsibility Agreement, s. 3(g).

822008 Social Responsibility Agreement, ss. 10-13.

832008 Social Responsibility Agreement, s. 22.

842008 Social Responsibility Agreement, s. 4.2.

852008 Social Responsibility Agreement, s. 14.

862008 Social Responsibility Agreement, s. 10(2).

872008 Social Responsibility Agreement, s. 18.

882008 Social Responsibility Agreement, s. 24(2).

892008 Social Responsibility Agreement, ss. 25-27.

90 Newmont Ahafo Social Responsibility: 2008 Local Employment Agreement between Newmont Ghana Gold Limited and the Ahafo Mine Local Community, background.

912008 Local Employment Agreement, s. 1.2.

922008 Local Employment Agreement, s. 2.1(f).

932008 Local Employment Agreement, s. 2.4.

942008 Local Employment Agreement, s. 2.6.

952008 Local Employment Agreement, ss. 2.1(g-h).

962008 Local Employment Agreement, ss. 3.1-3.2. 
972008 Development Foundation Agreement between Newmont Ahafo Development Foundation and Newmont Ghana Gold Limited, s. 18.2.

982008 Development Foundation Agreement, s. 21.2.

992008 Development Foundation Agreement, s. 11.1.

1002008 Development Foundation Agreement, s. 14.2.

1012008 Development Foundation Agreement, s. 5.

1022008 Development Foundation Agreement, s. 6.

1032008 Development Foundation Agreement, s. 9.3.

1042008 Development Foundation Agreement, s. 12.

1052008 Development Foundation Agreement, s. 14.5.

1062008 Development Foundation Agreement, s. 9.4.

1072008 Development Foundation Agreement, s. 14.3.

1082008 Development Foundation Agreement, s. 14.4.

1092008 Social Responsibility Agreement, s. 1(2) and Sch. 4.

1102014 Relationship Agreement between the Ahafo Mine Local Community and Newmont Ghana Gold Limited, s. 5.2.

1112014 Relationship Agreement, s. 7.8.

1122008 Social Responsibility Agreement, s. 7(8).

1132014 Relationship Agreement, s. 8.1.

1142014 Relationship Agreement, Annex 2(3).

115 Ahafo Social Responsibility Forum, Review of social responsibility agreements. Agreement review report, Stakeholders recommendations / Forum Standing Committee comments and final Forum recommendations, 3 April 2013.

116 Newmont Ahafo Social Responsibility: 2014 Local Employment Agreement between Newmont Ghana Gold Limited and the Ahafo Mine Local Community, s. 2.1.h.

1172014 Local Employment Agreement, s. 2.1.c.

1182014 Local Employment Agreement, s. 2.8.

1192014 Local Employment Agreement, s. 2.7.2.

1202014 Local Employment Agreement, s. 2.5.3.

1212014 Local Employment Agreement, s. 3.

122 Newmont Ahafo Social Responsibility: 2014 Development Foundation Agreement between Newmont Ahafo Development Foundation and Newmont Ghana Gold Limited, s. 5.2.

1232014 Development Foundation Agreement, s. 7.7.

1242014 Development Foundation Agreement, s. 9.4(a).

1252008 Development Foundation Agreement, s. 12; 2014 Development Foundation Agreement, s. 14.

1262014 Development Foundation Agreement, s. 4.1.3.

1272014 Development Foundation Agreement, s. 14.3. 
128 Danso et al., "Shared Value into Action," 174.

129 Newmont Ahafo Development Foundation (NADeF): 2016 Annual Report, (Ntotroso, Ghana, NADeF, 2017): 5.

130 Danso et al., "Shared Value into Action," 174.

131 NADeF: 2016 Annual Report, 38.

132 London Gold Fixing, Annual Average Gold Price from 1900 to 2017, (January 2018), distributed by Statista, https://www.statista.com/statistics/268027/change-in-gold-price-since-1990/.

133 NADeF: 2016 Annual Report, 40.

134 The Composite Budget of the Asutifi North District Assembly for the 2016 Fiscal Year, (Republic of Ghana, 2016a): 11, http://www.mofep.gov.gh/sites/default/files/composite-budget/2016/ BA/Asutifi-North.pdf; The Composite Budget of the Tano North District Assembly for the 2016 Fiscal Year, (Republic of Ghana, 2016b): 23, http://www.mofep.gov.gh/sites/default/files/composite-budget/2016/BA/Tano-North.pdf.

135 Danso et al., "Shared Value into Action," 177-8.

136 Newmont, "Community."

137 Witold Henisz et al., Calculating the Net Present Value of Sustainability Intiatives at Newmont's Ahafo Mine in Ghana (A), (Philidelphia, PN, Wharton School of the University of Pennsylvania, 2012): 13.

138 Newmont, "Community."

139 Mares, "Corporate Responsibility and Compliance," 257; Ethan Kapstein and René Kim, The Socio-Economic Impact of Newmont Ghana Gold Limited, report prepared for Newmont Ghana Gold Limited, (Harleem, The Netherlands, Steward Redqueen, 2011): 41-2, http://www.stewardredqueen.com/uploads/cases/socio_economic_impact_of_newmont_ghana_gold_july_2011.pdf.

140 Mares, “Corporate Responsibility and Compliance," 258.

141 Elaine Lawson and Gloria Bentil, "Shifting Sands: Changes in Community Perceptions of Mining in Ghana," Environment, Development, and Sustainability 16, no. 1 (2014): 225.

1422014 Relationship Agreement, Annex 3.

1432014 Relationship Agreement, s. 2.6.

144 Foley Hoag, LLP, Community Relationships Review: Global Summary Report, report prepared for Newmont, (Washington, DC, USA, 2009): 1, http://s1.q4cdn.com/259923520/files/ doc_downloads/crr/CRR-Global-Summary-Report-and-Appendices-English.pdf.

145 Foley Hoag, LLP, Community Relationships Review, 45.

146 Foley Hoag, LLP, Community Relationships Review, 46.

147 Foley Hoag, LLP, Community Relationships Review, 45.

148 Sarkar et al., Mining Community Development Agreements, 29-31.

149 Sarkar et al., Mining Community Development Agreements, 23.

150 Danso et al., "Shared Value into Action;" Bright Wireko-Brobby et al., The Evaluation of NADeF Operations in its Ten Host Communities, report prepared for Newmont Ahafo Development Foundation, (Kumasi, Ghana, Community Empowerment Associates, 2014).

151 Wireko-Brobby et al. Evaluation of NADeF Operations, v-vi.

152 Wireko-Brobby et al. Evaluation of NADeF Operations, 12. 
153 Danso et al., "Shared Value into Action," 173.

154 Danso et al., "Shared Value into Action," 179-80.

155 Mares, "Corporate Responsibility and Compliance," 236.

NGGL, 23.

156 Lawson and Bentil, "Shifting Sands," 225-6; Kapstein and Kim, Socio-Economic Impact of

157 Mares, “Corporate Responsibility and Compliance,” 236.

158 Moises Arce and Rebecca Miller, "Mineral Wealth and Protest in Sub-Saharan Africa," African Studies Review 59, no. 3 (2016): 88.

159 Mares, "Corporate Responsibility and Compliance," 239-43.

160 Lawson and Bentil, "Shifting Sands," 226-30.

161 Mares, “Corporate Responsibility and Compliance," 243.

162 Mares, "Corporate Responsibility and Compliance," 237.

163 Mares, "Corporate Responsibility and Compliance," 243-7.

164 Mares, “Corporate Responsibility and Compliance," 249-50.

165 Mares, "Corporate Responsibility and Compliance," 253-55.

166 Mares, “Corporate Responsibility and Compliance," 259.

167 Henisz et al., Sustainability Initiatives at Newmont, 4.

168 Lawson and Bentil, "Shifting Sands," 227.

169 "Ghana: Newmont Accused of Downplaying Impact of Cyanide Spillage," Business and Human Rights Resource Centre, accessed April 11, 2018, https://www.business-humanrights.org/en/ ghana-newmont-accused-of-downplaying-impact-of-cyanide-spillage.

170 Arce and Miller, "Mineral Wealth and Protest," 88.

171 Dupuy, "Corruption and Elite Capture," 72-73.

172 Dupuy, "Corruption and Elite Capture," 73.

173 "Newmont's Ghana Foundation Recognized by EU-Africa Chamber of Commerce," Mining.com, December 5, 2014, http://www.mining.com/web/newmonts-ghana-foundation-recognized-by-eu-africa-chamber-of-commerce/.

174 Pius Amihere Eduku, "Newmont Ahafo Mine is Mining Company of the Year," CitiFMOnline (Accra), November 26, 2017b, http://citifmonline.com/2016/11/26/newmont-ahafo-mine-is-mining-company-of-the-year/.

175 Newmont, "NADeF Named Ghana's Corporate Foundation Philanthropist of the Year," Our Voice Blog, April 19, 2017b, http://ourvoice.newmont.com/2017/04/19/nadef-named-ghanascorporate-foundation-philanthropist-of-the-year/.

176 "Newmont Ranks 16th Among 100 Best Corporate Citizens," Ghanaweb, March 17, 2010, https://www.ghanaweb.com/GhanaHomePage/business/Newmont-ranks-16th-among-100-Best-Corporate-Citizens-178670.

177 "Assessment," RobecoSAM, accessed October 24, 2017, http://www.sustainability-indices.com/sustainability-assessment/corporate-sustainability-assessment.jsp\#tab-2 330.

178 Christine Meyer, "A Case in Case Study Methodology," Field Methods 13, no. 4 (2001):

179 Bent Flyvbjerg, "Five Misunderstandings About Case Study Research," Qualitative Inquiry 
12, no. 2 (2006): 224-226.

180 Wireko-Brobby et al. Evaluation of NADeF Foundation, 12.

1812008 Social Responsibility Agreement, ss. 2-3; 2008 Development Foundation Agreement, background.

1822008 Development Foundation Agreement, background.

1832008 Local Employment Agreement, background - s. 3.

184 Newmont Gold Ghana Limited, "Minutes of the Forum 37th Meeting Held on Thursday, 27th February, 2014 at Eusbett Hotel, Sunyani," pp. 3-4.

1852008 Local Employment Agreement, s. 2.1(f); 2014 Local Employment Agreement, s. 2.1(h).

186 Communities, Petition of the Affected Communities of Newmont Ghana Gold Ltd, Ahafo Mine, Presented to the Management of Newmont, Coalition of Five Affected Communities in the Newmont Ahafo South (July-August 2017).

187 Ahafo Social Responsibility Forum, Review of social responsibility agreements. Agreement review report, Stakeholders recommendations / Forum Standing Committee comments and final Forum recommendations, 3 April 2013. pp. 3, 5.

188 Ahafo Social Responsibility Forum, Review of social responsibility agreements. Agreement review report, Stakeholders recommendations / Forum Standing Committee comments and final Forum recommendations, 3 April 2013. pp. 6-7.

189 Ahafo Social Responsibility Forum, Review of social responsibility agreements. Agreement review report, Stakeholders recommendations / Forum Standing Committee comments and final Forum recommendations, 3 April 2013. p. 13.

190 Ahafo Social Responsibility Forum, Review of social responsibility agreements. Agreement review report, Stakeholders recommendations / Forum Standing Committee comments and final Forum recommendations, 3 April 2013. p. 19.

191 Ahafo Social Responsibility Forum, Review of social responsibility agreements. Agreement review report, Stakeholders recommendations / Forum Standing Committee comments and final Forum recommendations, 3 April 2013. p. 25.

192 Ahafo Social Responsibility Forum, Review of social responsibility agreements. Agreement review report, Stakeholders recommendations / Forum Standing Committee comments and final Forum recommendations, 3 April 2013. p. 26. Also see p. 4.

193 Robert Goodland, "Free, Prior and Informed Consent and the World Bank Group," Sustainable Development Law \& Policy Vol 4 Issue 2 (2004) (noting, in a discussion of meaningful participation of communities affected by World Bank-funded projects, that "Balanced negotiation demands education of stakeholders (governments, proponents, affected communities) on their rights and responsibilities. Such negotiations between asymmetrical parties usually need advocates, facilitators, and technical assistance."); Inter-American Commission on Human Rights, "Indigenous and Tribal Peoples' rights over their ancestral lands and natural resources" (2009), para. 312 (noting, in a discussion on "informed consultation" and Indigenous peoples, that communities may need "technical and independent assistance" in order to make fully informed decisions); Report of the Special Rapporteur on the situation of human rights and fundamental freedoms of indigenous people, James Anaya, U.N. Doc. A/HRC/12/34 (2009), para. 51; (noting that consultation procedures for Indigenous peoples are often "not effective" and that imbalances of power need to be addressed by, among other things, ensuring communities have the "financial, technical and other assistance they need" without such assistance being used "to leverage or influence indigenous positions in the consultations". 
194 Newmont Gold Ghana Limited, "Minutes of the Forum 37th Meeting Held on Thursday, 27th February, 2014 at Eusbett Hotel, Sunyani," p. 4.

1952014 Relationship Agreement, Sch. 3, s. 2.

1962014 Relationship Agreement, s. 3(b).

1972014 Relationship Agreement, s. 2(2)-(3).

198 United Nations General Assembly (UNGA), "International Covenant on Civil and Political Rights," 23 March, 1976, s. 19.2, http://www.ohchr.org/en/professionalinterest/pages/ccpr.aspx.

199 UNGA, "International Covenant on Civil and Political Rights," s. 25.

200 For examples, see UN Committee on Economic, Social, and Cultural Rights, General Comment No. 21: Right of Everyone to Take Part in Cultural Life, (December 21, 2009), UN Doc. E/C.12/GC/21, par. 40; UN General Assembly, Report of the Special Rapporteur on Extreme Poverty and Human Rights, Magdalena Sepúlveda Carmona, (March 11, 2013), UN Doc. A/HRC/23/36, par. 39; and UN General Assembly, Report on the Promotion, Protection, and Implementation of the Right to Participate in Public Affairs in the Context of the Existing Human Rights Laws: Best Practices, Experiences, Challenges, and Ways to Overcome Them, (July 23, 2015), UN Doc. A/HRC/30/26, par. 9.

In addition to these rights, Indigenous peoples have the rights to Free Prior and Informed Consent, which requires that states consult and cooperate in good faith with affected Indigenous peoples about legislation changes (Art. 19) and forthcoming projects (Art. 32) that will affect them: see United Nations General Assembly, UN Declaration on the Rights of Indigenous Peoples, (September 13, 2008), UN Doc. A/RES/61/295.

In practice, companies often extend this right to non-Indigenous communities: see Kristen Hite, Towards Consent: Case Studies and Insights on Company Community Agreements in Forest Landscapes, (North Haven, CT, USA, The Forests Dialogue, 2014): 22-3, https://theforestsdialogue. org/sites/default/files/tfd_fpicreport_towardsconsent_en_hi-rez.pdf.

2012014 Relationship Agreement, s. 11.

2022014 Relationship Agreement, Sch. 4.

2032014 Relationship Agreement, s. 10(2).

2042008 Social Responsibility Agreement, s. 10(2)(g).

2052014 Relationship Agreement, s. 25 and Annex 1.

2062014 Relationship Agreement, Annex s. 1.

2072014 Relationship Agreement, Annex s. 4.

208 Henisz et al., Sustainability Initiatives at Newmont, 18.

2092014 Relationship Agreement, s. 14(1) and Sch. 3 s. 1.

2102014 Relationship Agreement, s. 14(2).

2112014 Relationship Agreement, Sch. 3 Art. 2(a).

212 Dupuy, "Corruption and Elite Capture," 18.

2132008 Local Employment Agreement, s. 2.1(f).

214 Newmont, AUMS Local Employment Highlights, presentation to Kenyasi youth on employment, May 22, 2017.

2152014 Local Employment Agreement, s. 5.1.

216 Newmont, AUMS Local Employment Highlights. 
217 NADeF: 2016 Annual Report, 9.

\section{Development Foundation Agreement, s.11.1}

219 Lawson and Bentil, "Shifting Sands," 225.

220 See ECOWAS Directive on the harmonization of guiding principles and policies in the mining sector (Abuja, Nigeria, 26-27 May, 2009), Economic Community of West African States, Doc. C/DIR.3/05/09, https://goo.gl/AJ4e4V: Art. 16, para. 3 ("[Mining] Companies shall obtain free, prior, and informed consent of local communities before exploration begins and prior to each subsequent phase of mining and post-mining operations)" and para. 4. ("[Mining] Companies shall maintain consultations and negotiations on important decisions affecting local communities throughout the mining cycle.") (emphasis added); and "Consultation," (Perth, Australia, Government of Western Australia, Department of Mines, Industry Regulation, and Safety), accessed April 13, 2018, http:// www.dmp.wa.gov.au/Consultation-16497.aspx: ("Effective and ongoing stakeholder engagement enables better planned and more informed policies, projects and services including a greater understanding and management of issues and potential risks. For stakeholders, the benefits of engagement include the opportunity to have their issues heard and contribute to the decision-making process.")

221 See IFC Performance Standard on Environmental and Social Sustainability, International Finance Corporation, (effective January 1, 2012): Performance Standard 1, para. 31 ("For projects with potentially significant adverse impacts on Affected Communities, the client will conduct an Informed Consultation and Participation (ICP) process that will [...] result in the Affected Communities' informed participation. ICP involves a more in-depth exchange of views and information, and an organized and iterative consultation leading to the client's incorporating into their decision-making process the views of the Affected Communities on matters that affect them directly, such as the proposed mitigation measures, the sharing of development benefits and opportunities, and implementation issues.") (emphasis added).

222 See Cathal Doyle and Jill Cariño, Making Free, Prior \& Informed Consent a Reality: Indigenous Peoples and the Extractive Sector, (London, UK, Indigenous Peoples Links, Middlesex University School of Law, The Ecumenical Council for Corporate Responsibility, 2013): 45, https:// goo.gl/bSRWzN: ("The Xstrata representative noted that they 'prefer broad BAsed support, because consent implies a kind of once off flip the light switch and you have consent, where as we see it as an on-going process that leads to an agreement which is then monitored and reviewed over time'. It was also suggested that 'the word consent can be taken as a one off, [where] you have got consent that's it, but it is very much an iterative process'. Ensuring that their people on the ground and communities understood it as 'an on-going process of consultation and ... gaining the support of the community throughout the operation's life' was described as one of the challenges that they faced.") (emphasis added).

223 Daron Acemoglu, Abhijit Banerjee, Esther Duflo, and Ben Olken, 14.773: Political Economy of Institutions and Development, Spring 2015, MIT course syllabus, accessed November 17, 2017, https://economics.mit.edu/files/10427.

224 Simeon Djankov, Florencio Lopez-de-Silanes, and Andrei Shleifer, "The Regulation of Entry," The Quarterly Journal of Economics 117, no. 1 (2002): 22-28.

225 Ghana: Corporate - Taxes on Income, Worldwide Tax Summaries Series, (Vancouver, BC, Canada, Pricewater Coopers), accessed November 17, 2017, http://taxsummaries.pwc.com/ID/ Ghana-Corporate-Taxes-on-corporate-income.

226 Newmont Gold Ghana Limited, "Minutes of the Forum 37th Meeting Held on Thursday, 27th February, 2014 at Eusbett Hotel, Sunyani," p. 7.

227 Paul Collier, "The Institutional and Psychological Foundations of Natural Resource Politics," The Journal of Development Studies 53, no. 2 (2017): 226-7. 
228 Newmont, "Sustainability and External Relations Standard: Social BAseline \& Impact Assessment Management," Jan 2018. URL: https://s1.q4cdn.com/259923520/files/doc_downloads/ newmont_socialandenvironmentalstandards/2018/Social-BAseline-and-Impact-Standard_January-2018.pdf, accessed May 102018.

229 Wireko-Brobby et al. Evaluation of NADeF Operations, 12.

230 Eric Adebayo and Eric Werker, "Estimating the Value of Benefits in Benefit-Sharing Agreements," (Working Paper, Beedie School of Business, Simon Fraser University, Vancouver, 2018).

231 Foley Hoag, LLP, Community Relationships Review, 72, 80, 87, 95, 106, 116, 122, and 129.

232 Sam Hickey, "Transnational NGDOs and Participatory Forms of Rights-BAsed Development: Converging with the Local Politics of Citizenship in Cameroon," Journal of International Development, 14, 841-857 (2002), 853-854.

233 Guiding Principles on Business and Human Rights: Implementing the United Nations "Protect, Respect, and Remedy" Framework, (New York and Geneva: United Nations, HR/PUB/11/04, 2011): Art. 31. 